\title{
Studies on transbilayer lipid movement in blood cells
}

Citation for published version (APA):

Dekkers, D. W. C. (2001). Studies on transbilayer lipid movement in blood cells. [Doctoral Thesis, Maastricht University]. Universiteit Maastricht. https://doi.org/10.26481/dis.20011221dd

Document status and date:

Published: 01/01/2001

DOI:

10.26481/dis.20011221dd

Document Version:

Publisher's PDF, also known as Version of record

\section{Please check the document version of this publication:}

- A submitted manuscript is the version of the article upon submission and before peer-review. There can be important differences between the submitted version and the official published version of record.

People interested in the research are advised to contact the author for the final version of the publication, or visit the DOI to the publisher's website.

- The final author version and the galley proof are versions of the publication after peer review.

- The final published version features the final layout of the paper including the volume, issue and page numbers.

Link to publication

\footnotetext{
General rights rights.

- You may freely distribute the URL identifying the publication in the public portal. please follow below link for the End User Agreement:

www.umlib.nl/taverne-license

Take down policy

If you believe that this document breaches copyright please contact us at:

repository@maastrichtuniversity.nl

providing details and we will investigate your claim.
}

Copyright and moral rights for the publications made accessible in the public portal are retained by the authors and/or other copyright owners and it is a condition of accessing publications that users recognise and abide by the legal requirements associated with these

- Users may download and print one copy of any publication from the public portal for the purpose of private study or research.

- You may not further distribute the material or use it for any profit-making activity or commercial gain

If the publication is distributed under the terms of Article $25 \mathrm{fa}$ of the Dutch Copyright Act, indicated by the "Taverne" license above, 
Dekkers, David Walterus Cornelis

Studies on transbilayer lipid movement in blood cells Universiteit Maastricht, Capaciteitsgroep Biochemie

ISBN 90-9015300-4

Lay-out: Dave Dekkers

Cover: Antonio Maldenado

Printed by: Datawyse 


\title{
Studies on transbilayer lipid movement in blood cells
}

(met een samenvatting in het Nederlands)

\author{
Proefschrift
}

ter verkrijging van de graad van doctor aan de Universiteit Maastricht op gezag van de Rector Magnificus, Prof. Dr. Nieuwenhuijzen Kruseman, volgens het besluit van het College van Decanen

in het openbaar te verdedigen

op vrijdag 21 december 2001 om 12.00 uur

door

David Walterus Cornelis Dekkers

geboren te Veldhoven op 1 september 1968 


\section{Promotor}

Prof. Dr. R. F. A. Zwaal

\section{Co-promotor}

Dr. E. M. Bevers

\section{Beoordelingscommissie}

Prof. Dr. G. van der Vusse (voorzitter)

Prof. Dr. W. Th. Hermens

Prof. Dr. G. van Meer (universiteit van Amsterdam)

Prof. Dr. J. de Mey

Prof. Dr. F. Paltauf (Technische Universitäet Graz, Austria)

Financial support by the Netherlands Heart Foundation for the publication of this thesis is gratefully acknowledged. 

General introduction.

Chapter 2

Proteins involved in membrane lipid translocation.

\section{Chapter 3}

Comparison between $\mathrm{Ca}^{2+}$-induced scrambling of various

NBD-labeled lipid analogues in red blood cells.

Chapter 4

Impaired $\mathrm{Ca}^{2+}$-induced tyrosine phosphorylation and defective lipid scrambling in erythrocytes from a patient with Scott syndrome: a study using an inhibitor for scramblase that mimics the defect in Scott syndrome.

\section{Chapter 5}

Transbilayer movement of NBD-labeled phospholipids in red blood cell membranes: outward directed transport by the multidrug resistance protein 1 (MRP1).

\section{Chapter 6}

Multidrug resistance protein 1 (MRP1) regulates lipid asymmetry in red blood cell membranes.

Chapter 7

Discussion

Nederlandse samenvatting

Nawoord/Acknowledgements

Publications

Curriculum vitae 

Chapter 1

General Introduction 
Chapter 1

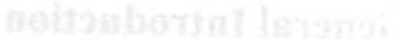




\section{Introduction}

The cell membrane of mammalian cells forms a physical barrier between the intra -and extracellular milieus. It plays a pivotal role in the communication of cells with their environment by mediating transport of nutrients and metabolites and by transferring signals across the membrane. In addition, the plasma membrane surface provides a platform on which intra- and extracellular proteins can interact. The plasma membrane is a dynamic structure composed of lipids and proteins with a high degree of organization. To maintain cellular function, membrane architecture needs to be tightly regulated. Alterations in the arrangement of membrane components have consequences for the interaction of cells with their environment. Mechanisms to regulate the lipid organization of the plasma membrane form the subject of this thesis.

\section{The plasma membrane}

The plasma membrane of cells is primarily composed of lipids and proteins. The lipids are organized in a bimolecular sheet in which the phospholipids are oriented with their lipophylic acyl chains towards the membrane interior and the polar headgroups to the exterior (Fig. 1). The lipid bilayer has a thickness of about 40 to $50 \AA$. Although one single type of lipid would suffice to form the bilayer, in reality the membrane consists of a large variety of lipid classes, which differ in chemical composition of the polar headgroups and length and saturation of their acyl chains. The different lipid classes can be divided in glycerophospholipids, which have a glycerol backbone, sphingolipids with a sphingosine backbone, cholesterol, and glycolipids containing carbohydrate residues. These lipid species are responsible for the structure and properties of the membrane; e.g. length and saturation of the acyl chains influence fluidity and permeability properties of the membrane. Cholesterol, abundantly present in the membrane, is also a key regulator of membrane fluidity. While membrane fluidity is in part brought about by rapid lateral diffusion of lipids in the plane of the membrane, spontaneous transbilayer migration of lipids is rare, unless catalyzed by specific membrane proteins. Membrane proteins also facilitate transport of other molecules across the plasma membrane and mediate transmission of signals from the environment to the cell interior. In addition, membrane proteins provide structural support by coupling the plasma membrane to cytoskeletal components present in the cytoplasmic compartment. Moreover, proteins exposed at the exterior 
surface of the plasma membrane serve as markers in recognition processes between cells. Proteins in the plasma membrane may span the lipid bilayer from one side to the other (transversal or integral membrane proteins) or are embedded in or loosely attached to the exterior or interior lipid leaflet (peripheral membrane proteins).

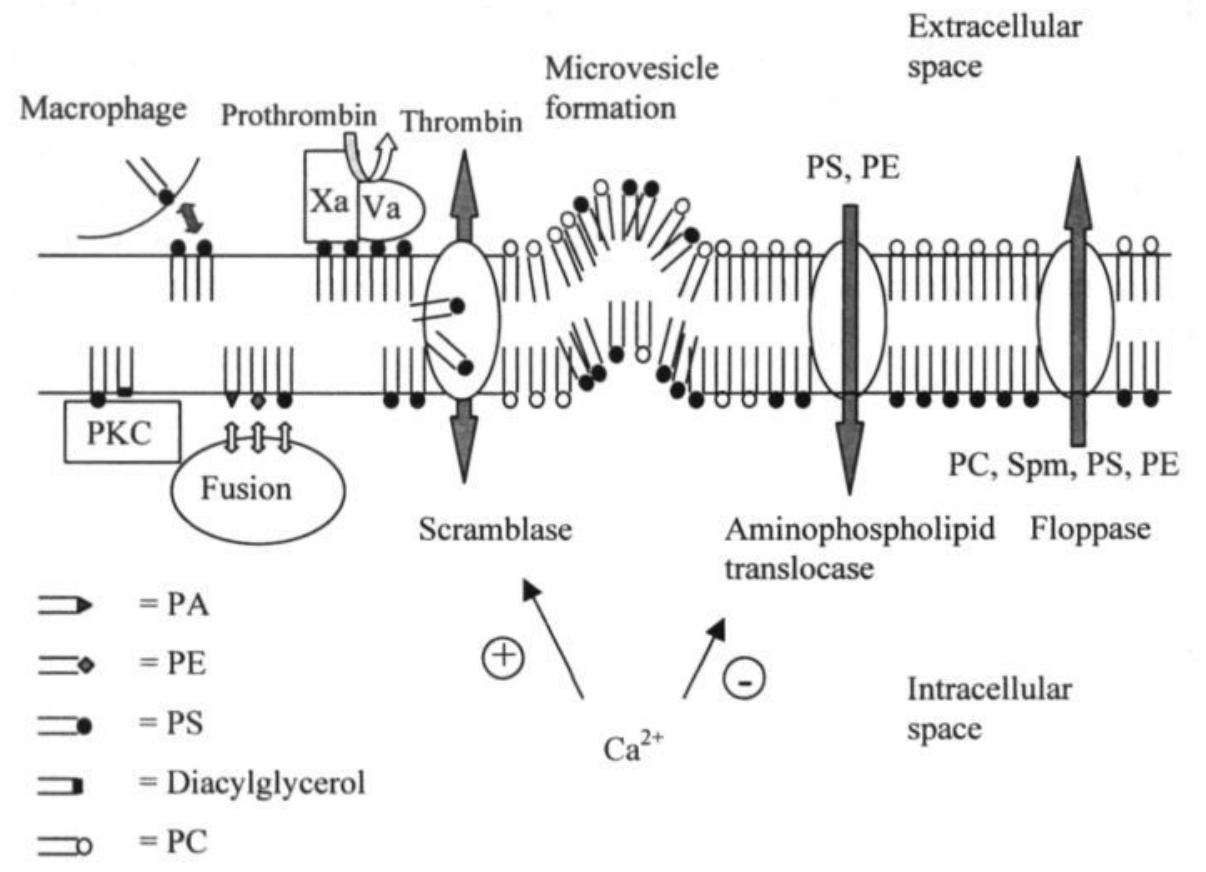

Fig. 1: Regulation and physiology of membrane phospholipid asymmetry. An ATP-dependent aminophospholipid translocase is responsible for the inward movement of PS and PE, whereas the floppase (MRP1) is involved in the outward directed transport of all major lipids. A $\mathrm{Ca}^{2+}$-dependent nonspecific scramblase is responsible for the randomization of all lipids. The figure shows that elevated intracellular $\mathrm{Ca}^{2+}$ induces PS randomization due to activation of the scramblase and inhibition of the translocase. The importance of the presence of PS in the inner or outer leaflet is shown by several processes which are PS-dependent. Anionic lipids, like PS, are necessary for fusion events, furthermore the activity of certain enzymes such as PKC need PS for activity. The presence of PS in the outer leaflet results in a negatively charged lipid surface necessary for promoting blood coagulation, as illustrated for the conversion of prothrombin into thrombin by the prothrombinase complex $(\mathrm{Xa} / \mathrm{Va})$. PS could also be a signal that marks the cell as a target for elimination by macrophages. The three proteins which catalyse transbilayer lipid transport will be discussed in chapter 2 . 


\section{Membrane lipid asymmetry}

The phospholipids of the plasma membrane of mammalian cells are asymmetrically distributed over both leaflets of the bilayer. Cholinecontaining lipids, phosphatidylcholine (PC) and sphingomyelin (Spm) are located predominantly in the outer leaflet, whereas the aminophospholipids, phosphatidylethanolamine (PE) and phosphatidylserine (PS) are found mainly in the inner leaflet (reviewed in Schroit and Zwaal, 1991).One of the most extensively studied membranes is that of the red blood cell (RBC), since these cells are readily available and -in contrast to other cells- are devoid of intracellular membranes which facilitate interpretation of experimental results. The human RBC membrane is composed of $28 \%$ PC, $25 \%$ Spm, $27 \%$ PE, $13 \%$ PS, 3\% phospho-inositols (PI, PIP and $\mathrm{PIP}_{2}$ ) and trace amounts of phosphatidic acid (PA) and lysophosphatidylcholine (lysoPC). The distribution of the major phospholipids over both membrane leaflets has been determined by phospholipase digestion protocols. In the quiescent state, lipid asymmetry is maintained in a dynamic equilibrium required to support the function of several membrane processes. However, particular conditions may lead to a collapse of lipid asymmetry resulting in a change in lipid composition of each of the membrane leaflets. As a result PS becomes exposed on the cell surface, which has important physiological consequences. This is best illustrated by the effects that surface exposed PS may have on the acceleration of blood coagulation and on the process of cell-cell recognition (Fig. 1).

\section{Role of PS in blood coagulation}

Perhaps the most important pathway of blood coagulation is mediated by tissue factor, an integral membrane protein expressed on the surface of activated or disrupted cells (Nemerson, 1992). Tissue factor combined with the activated form of factor VII (VIIa) rapidly converts the zymogens factor IX, factor X, as well as factor VII itself, into their active forms. While anionic phospholipids enhance the activity of the tissue factorfactor VII complex, they are not essential for activity (Ruf et al., 1991). However, the presence of anionic phospholipids, especially PS, is necessary in promoting assembly and catalysis of two subsequent coagulation factor complexes, tenase and prothrombinase. The tenase complex consists of factor IXa and the non-enzymatic cofactor VIIIa and causes the activation of factor X. Subsequently, factor Xa forms a complex with the non-enzymatic cofactor Va to convert prothrombin into thrombin. 
The presence of anionic phospholipids strongly promotes $\mathrm{Ca}^{2+}$-mediated formation of these complexes and accelerates the formation of thrombin dramatically. PS appears to be the most effective anionic phospholipid (Rosing et al., 1988). In the process of hemostasis, the catalytic PScontaining membrane surface is predominantly provided by activated blood platelets, accumulating at the site of an injured vessel wall. Due to their interaction with subendothelial structures such as collagen, platelets become activated and start to form aggregates, which occlude the wound and cause arrest of bleeding (primary hemostatic plug formation). Simultaneously, a mechanism is activated which induces a rapid randomisation of the membrane lipids, resulting in exposure of PS at the platelets' outer surface (Bevers et al., 1983). This reaction, known as the platelet procoagulant response, results in a strong amplification of the rate of thrombin formation. Consequently, the accumulation of procoagulant platelets at the site of injury ensures a rapid and localized formation of fibrin, which consolidates the hemostatic plug.

The importance of the platelet procoagulant response is illustrated by a rare, moderately severe bleeding disorder, referred to as the Scott syndrome, named after the first patient that was discovered with this abnormality (Weiss, 1994). While these patients' platelets exhibit normal adhesion, aggregation and secretion, they show strongly diminished surface exposure of PS when activated. A decreased $\mathrm{Ca}^{2+}$-induced lipid scrambling and a correspondingly decreased amount of surface-exposed PS was found upon activation of the patients' platelets, and was related to an impaired tenase- and prothrombinase activity (Rosing et al., 1985) and a lower number of binding sites for factor Va (Miletich et al., 1979) and factor VIIIa (Ahmad et al., 1989) on the platelet surface. From a study on a family with Scott syndrome in France, it was suggested that this bleeding disorder is transmitted as an autosomal recessive trait (Toti et al., 1996). The defect is not constrained to platelets but also present in red blood cells (Bevers et al., 1992), T-lymphocytes and in Epstein-Barr virus transformed B-lymphocytes of the patient (Kojima et al., 1994; Toti et al., 1996), suggesting a mutation in a stem cell that affects multiple hematologic lineages.

\section{Role of PS in cell recognition and apoptosis}

Existence of a scavenging mechanism, contingent upon surface exposed PS, was first demonstrated by Schroit and colleagues (Schroit et al., 1985). They showed that -in vitro- lipid symmetric RBC ghosts were more rapidly phagocytosed by mouse macrophages than the asymmetric ghosts, 
a process inhibited by PS vesicles but not by PC vesicles (Pradhan et al., 1994). Recognition of PS-exposing cells by macrophages could be operative, in vivo, to remove senescent and pathological RBC, activated platelets, procoagulant cellular microparticles and monocytes from the circulation to avoid a prothrombotic state (Connor et al., 1994; Tait and Gibson, 1994). Removal of apoptotic cells is thought to occur via a similar mechanism. Apoptosis (or programmed cell death) is a physiological process in which cells are deleted from a wide variety of tissues. This process plays an important role in embryogenesis, morphogenesis, normal cell turnover, resolution of hyperplasia and neoplasia and elimination of auto-reactive lymphocytes (Cohen and Gascard, 1992; Savill, 1996; Savill et al., 1993; Wyllie, 1994; Wyllie et al., 1980). Cells triggered to go into apoptosis expose different signals, which ensure rapid and efficient recognition and removal by macrophages. One of these signals is an increased surface exposure of PS (Fadok et al., 1992) which is thought to be recognized by a specific receptor on the phagocyte surface (Fadok et al., 2000). Recently, it became evident that not only the scavenged cells but also the macrophages have to expose PS for recognition to occur (Callahan et al., 2000; Fadok et al., 2000). In this respect, it is of interest to mention an early hypothesis by Papahadjopoulos and coworkers (Papahadjopoulos et al., 1974) that surface exposed PS is required to confer fusion competence to biological membranes. For example, PS localized in the cytoplasmic leaflet of both the plasma membrane and intracellular membranes of storage granules may prime for $\mathrm{Ca}^{2+}$ dependent membrane fusion required for the secretory event (Chap et al., 1977). Also during fusion of myoblasts to form multinucleated myotubes (Sessions et al., 1983) and fusion of cytotrophoblast cells during formation of the syncytiotrophoblast of the placental chorionic villi (Adler et al., 1995), temporarily exposed PS on the external leaflet may be required to facilitate the fusion process.

\section{Other functional aspects of membrane phospholipid asymmetry}

Membrane phospholipids not only form the matrix for embedding membrane proteins, but are also important for modulating enzymatic activities of certain integral and peripheral membrane proteins (BoeszeBattaglia and Schimmel, 1997; Spector and Yorek, 1985). One example is the activity of P-Glycoprotein, a membrane-bound ATPase involved in multidrug resistance (see chapter 2), which becomes inactive when the lipid molecules are removed from the protein and is reactivated when reconstituted in a lipid matrix (Romsicki and Sharom, 1999). Another well 
characterized lipid-dependent enzyme protein kinase C (Nishizuka, 1986), which interacts with the cytoplasmic surface of the membrane requires two lipid cofactors for full activation: diacylglycerol and PS (Fig. 1). Collapse of lipid asymmetry results in a reduced activity of protein kinase C (Newton and Johnson, 1998).

Mediated by the action of different cytoplasmic phospholipases, which become activated upon interaction of an agonist with its receptor, membrane phospholipids also provide precursors for a variety of second messenger molecules such as diacylglycerol, inositol poly-phosphates $\left(\mathrm{IP}_{3}\right)$, and prostaglandins.

From the foregoing it will be clear that the distribution of lipids over the two leaflets of the plasma membrane needs to be tightly regulated for proper cell function. Over the past three decades increasing knowledge on the mechanisms involved in the regulation of transbilayer lipid distribution has emerged. An increasing number of transporter proteins for lipids has been described or postulated. The present state of the art of these proteins and their characteristics is presented in chapter 2.

\section{The objective of the thesis}

The aim of the work presented in this thesis is to contribute to a further understanding of the mechanisms involved in the maintenance of, or alterations in transbilayer lipid asymmetry. The involvement of proteins in transbilayer lipid movement is beyond dispute, but the identity of these proteins has not yet been fully elucidated. Understanding the mechanistic features of transbilayer lipid movements may provide information that may be valuable to identify these proteins.

After reviewing the present state of the art of the membrane lipid transporters in chapter 2 , chapter 3 deals with the $\mathrm{Ca}^{2+}$-induced scrambling properties of different fluorescent-labeled lipid analogues, containing different headgroup sizes, using human red blood cells as a model. We hypothesized that a.o. the headgroup size of a lipid molecule could be important for the scrambling kinetics. Chapter 4 deals with a disorder in lipid scrambling (Scott syndrome) in relation to tyrosine phosphorylation. The observation that a diminished tyrosine phosphorylation pattern was found in Scott cells upon calcium/ionophore treatment, led us to investigate whether or not tyrosine phosphorylation could be related to the inability of scrambling.

In chapter 5, studies are described regarding the identity of active outward-directed transport of phospholipids by the so-called floppase. 
Using knock-out mice for various multidrug resistance proteins, we found the floppase to be identical to MRP1. We hypothesized that the outward orientation of choline-phospholipids in cell membranes was not an indirect effect resulting from active inward transport of aminophospholipids by the aminophospholipid translocase, but that the translocase and the floppase work in concert to maintain lipid asymmetry. This hypothesis was tested in studies described in chapter 6.

In most of our studies we have made extensive use of fluorescent-labeled phospholipid probes. In many aspects, we found that these probes provide valuable information about the various transport mechanisms, which regulate membrane lipid asymmetry and its collapse. Red blood cells have been the cells of choice in most of the studies addressing topology issues of the plasma membrane, since these cells are readily available and do not contain intracellular membranes, which facilitates interpretation of the results. In many aspects the plasma membrane of these cells is a good model for the lipid transport phenomena of the plasma membrane of other cell types.

\section{REFERENCES}

Adler, R. R., Ng, A.K., and Rote, N.S. (1995) Monoclonal antiphosphatidylserine antibody inhibits intercellular fusion of the choriocarcinoma line, JAR. Biol. of Reprod. $53,905-910$.

Ahmad, S. S., Rawala-Sheikh, R., Ashby, B., and Walsh, P. N. (1989) Platelet receptormediated factor X activation by factor IXa. High-affinity factor IXa receptors induced by factor VIII are deficient on platelets in Scott syndrome. J. Clin. Invest. 84, 824-828.

Bevers, E. M., Comfurius, P., and Zwaal, R. F. A. (1983) Changes in membrane phospholipid distribution during platelet activation. Biochim. Biophys. Acta 736, 5766.

Bevers, E. M., Wiedmer, T., Comfurius, P., Shattil, S. J., Weiss, H. J., Zwaal, R. F. A., and Sims, P. J. (1992) Defective $\mathrm{Ca}^{2+}$-induced microvesiculation and deficient expression of procoagulant activity in erythrocytes from a patient with a bleeding disorder: a study of the red blood cells of Scott syndrome. Blood 79, 380-8.

Boesze-Battaglia, K., and Schimmel, R. J. (1997) Cell membrane lipid composition and distribution: Implications for cell function and lessons learned from photoreceptors and platelets. J. Exp. Biol. 200, 2927-2936. 
Callahan, M. K., Williamson, P., and Schlegel, R. A. (2000) Surface expression of phosphatidylserine on macrophages is required for phagocytosis of apoptotic thymocytes. Cell Death Differ. 7, 645-53.

Chap, H., Zwaal, R. F. A., and van Deenen, L. L. M. (1977) Action of highly purified phospholipases on blood platelets. Evidence for an asymmetric distribution of phospholipids in the surface membrane. Biochim. Biophys. Acta 467, 146-164.

Cohen, C. M., and Gascard, P. (1992) Regulation and post-translational modification of erythrocyte membrane and membrane-skeletal proteins. Semin. Hematol. 29, 244-92.

Connor, J., Pak, C. C., and Schroit, A. J. (1994) Exposure of phosphatidylserine in the outer leaflet of human red blood cells. Relationship to cell density, cell age, and clearance by mononuclear cells. J. Biol. Chem. 269, 2399-404.

Fadok, V. A., Bratton, D. L., Rose, D. M., Pearson, A., Ezekewitz, R. A., and Henson, P. M. (2000) A receptor for phosphatidylserine-specific clearance of apoptotic cells. Nature 405, 85-90.

Fadok, V. A., Voelker, D. R., Campbell, P. A., Cohen, J. J., Bratton, D. L., and Henson, P. M. (1992) Exposure of phosphatidylserine on the surface of apoptotic lymphocytes triggers specific recognition and removal by macrophages. J. Immunol. 148, 2207-16.

Kojima, H., Newton-Nash, D., Weiss, H. J., Zhao, J., Sims, P. J., and Wiedmer, T. (1994) Production and characterization of transformed B-lymphocytes expressing the membrane defect of Scott syndrome. J. Clin. Invest. 94, 2237-44.

Miletich, J. P., Kane W. H., Hofmann, S. L. Stanford, N., and Majerus, P.W. (1979) Deficiency of factor Xa-factor Va binding sites on the platelets of a patient with a bleeding disorder. Blood 54, 1015-1022.

Nemerson, Y. (1992) The tissue factor pathway of blood coagulation. Semin. Hematol. 29, 170-6.

Newton, A. C., and Johnson, J. E. (1998) Protein kinase C: a paradigm for regulation of protein function by two membrane-targeting modules. Biochim. Biophys. Acta 1376, $155-72$.

Nishizuka, Y. (1986) Studies and perspectives of protein kinase C. Science 233, 30512.

Papahadjopoulos, D., Poste, G., Schaeffer, B. E., and Vail, W. J. (1974) Membrane fusion and molecular segregation in phospholipid vesicles. Biochim. Biophys. Acta $352,10-28$. 
Pradhan, D., Williamson, P., and Schlegel, R. A. (1994) Phosphatidylserine vesicles inhibit phagocytosis of erythrocytes with a symmetric transbilayer distribution of phospholipids. Mol. Membr. Biol. 11, 181-7.

Romsicki, Y., and Sharom, F. (1999) The membrane lipid environment modulates drug interactions with the P-Glycoprotein multidrug transporter. Biochemistry 38, 68876896.

Rosing, J., van Rijn, J. L., Bevers, E. M., van Dieijen, G., Comfurius, P., and Zwaal, R. F. A. (1985) The role of activated human platelets in prothrombin and factor X activation. Blood 65, 319-332.

Rosing, J., Speijer, H., and Zwaal, R. F. A. (1988) Prothrombin activation on phospholipid membranes with positive electrostatic potential. Biochemistry 27, 8-11.

Ruf, W., Rehemtulla, A., Morrissey, J. H., and Edgington, T. S. (1991) Phospholipidindependent and -dependent interactions required for tissue factor receptor and cofactor function. J. Biol. Chem. 266, 16256.

Savill, J. (1996) Phagocyte recognition of apoptotic cells. Biochem. Soc. Trans. 24, 1065-9.

Savill, J., Fadok, V., Henson, P., and Haslett, C. (1993) Phagocyte recognition of cells undergoing apoptosis. Immunol. Today 14, 131-6.

Schroit, A. J., Madsen, J. W., and Tanaka, Y. (1985) In vivo recognition and clearance of red blood cells containing phosphatidylserine in their plasma membranes. J. Biol. Chem. 260, 5131-8.

Schroit, A. J., and Zwaal, R. F. A. (1991) Transbilayer movement of phospholipids in red cell and platelet membranes. Biochim. Biophys. Acta 1071, 313-29.

Sessions, A., and Horwitz, A. F. (1983) Differentiation-related differences in the plasma membrane phospholipid asymmetry of myogenic and fibrogenic cells. Biochim. Biophys. Acta 728, 103-111.

Spector, A. A., and Yorek, M. A. (1985) Membrane lipid composition and cellular function. J. Lip. Res. 26, 1015-1035.

Tait, J. F., and Gibson, D. (1994) Measurement of membrane phospholipid asymmetry in normal and sickle-cell erythrocytes by means of annexin V binding. J. Lab. Clin. Med. 123, 741-8.

Toti, F., Satta, N., Fressinaud, E., Meyer, D., and Freyssinet, J. M. (1996) Scott syndrome, characterized by impaired transmembrane migration of procoagulant phosphatidylserine and hemorrhagic complications, is an inherited disorder. Blood 87 , 1409-15. 


\section{Chapter 1}

Weiss, H. J. (1994) Scott syndrome: a disorder of platelet coagulant activity. Semin. Hematol. 31, 312-19

Wyllie, A. H. (1994) Death from inside out: an overview. Philos. T. Roy. Soc. Lon. Series B, Biol. Sci. 345, 237-41.

Wyllie, A. H., Kerr, J. F., and Currie, A. R. (1980) Cell death: the significance of apoptosis. Int. Rev. Cytol. 68, 251-306. 


\section{Chapter 2}

Proteins involved in membrane lipid translocation

based on:

Bevers E.M., Comfurius P., Dekkers D.W.C., and Zwaal R.F.A. (1999)

Biochim. Biophys. Acta 1439, 317-330;

Bevers E.M., Comfurius P., Dekkers D.W.C., Harmsma M., and Zwaal

R.F.A. (1998) Biol. Chem. 379, 973-986

Abstract: The phospholipids of the plasma membrane of mammalian cells are asymmetrically distributed over the two leaflets. Membrane lipid asymmetry is controlled by distinct proteins (lipid transporters), catalyzing uni- or bi-directional transbilayer movement of lipids. The aminophospholipid translocase is an ATP-dependent protein which transports aminophospholipids from the outside to the inside, generating an asymmetric phospholipid distribution. The inward movement of aminophospholipids is counter-balanced by the outward movement of all lipids, a process regulated by the floppase. This floppase is also ATP dependent but has no preference for specific lipids. Because floppase activity is much lower than aminophospholipid translocase activity, lipid asymmetry is ensured. Collapse of lipid asymmetry is evoked when the $\mathrm{Ca}^{2+}$-dependent phospholipid scramblase is activated. Concomitant inhibition of the aminophospholipid translocase and floppase prevents lipids from being pumped back, leading to a situation in which the different lipids tend to become randomized over both membrane leaflets. In this chapter these three proteins, involved in transbilayer movement of lipids are reviewed. 
Chapter 2 


\section{Introduction}

Spontaneous transbilayer movement of phospholipids does not occur rapidly; for instance the half-time for PC movement in red blood cells has been estimated to be 3 to 26 hours, depending on the acyl chain composition (Middelkoop et al., 1986). If left uncorrected, however, these rates could result in a significant randomization of lipids over the two membrane leaflets, considering the life span of the red blood cell (120 days). Also, perturbation of the bilayer during membrane fusion events as part of endo- or exocytosis is likely to be accompanied by partial randomization of lipids, changing the normal transbilayer lipid distribution when left uncorrected. Hence, mechanisms are required to maintain or restore membrane lipid asymmetry. In the past, it has been proposed that selective interactions between aminophospholipids and the cytoskeletal network are responsible for the observed steady state distribution of lipids over the bilayer (Haest et al., 1976; Haest et al., 1978). Although support for this model was provided by other laboratories, a number of studies has refuted this model (reviewed in Devaux and Zachowski, 1994; Roelofsen and Op den Kamp, 1994; Schroit and Zwaal, 1991; Williamson and Schlegel, 1994). Over the past two decades at least three different membrane proteins have been postulated to facilitate transmembrane migration of lipids: an inward directed transporter specific for aminophospholipids, a non-selective transporter for outward movement of lipids, and a protein which enhances bidirectional movement of the various membrane phospholipids.

\section{Aminophospholipid translocase: inward movement of lipids}

The first evidence for the involvement of a membrane protein in the maintenance of lipid asymmetry dates from 1984 when Seigneuret and Devaux (Seigneuret and Devaux, 1984) demonstrated a specific inward movement of spin-labeled analogues of phosphatidylserine and phosphatidylethanolamine in human red blood cell membranes. Their findings were corroborated by other investigators using either fluorescentlabeled (Connor and Schroit, 1989), or radio-labeled (Tilley et al., 1986) lipids or non-labeled short acyl chain phospholipids (Daleke and Huestis, 1985). The aminophospholipid translocase has a preference for phosphatidylserine over phosphatidylethanolamine as reflected by a difference in $\mathrm{Km}$-value $\left(\mathrm{Km}_{(\mathrm{PS})} / \mathrm{Km}_{(\mathrm{PE})}=1 / 9.4\right)$ of these two lipids (Zachowski et al., 1986). Choline-containing lipids are not transported by 
this protein. Transport is sensitive to sulfhydryl reagents and bromophenacylbromide suggesting the involvement of one or more cysteine and histidine residues, respectively (Connor et al., 1992). The transport is stereospecific for the naturally occuring L-isomer with respect to the $\mathrm{C} 2$ position in the glycerol backbone of the phospholipid (Martin and Pagano, 1987). There is no selectivity in transport for the stereoisomers of the headgroup of phosphatidylserine; kinetics for inward transport of phosphatidyl-D-serine was found to be indistinguishable from that of the natural occuring L-serine isomer (Hall and Huestis, 1994; Smeets et al., 1994). ATP is required for transport of the aminophospholipids (Seigneuret and Devaux, 1984; Zachowski et al., 1986) with a stoichiometry of one molecule ATP consumed for the inward transport of one lipid molecule (Beleznay et al, 1993). Inhibition of the aminophospholipid translocase by vanadate and $\mathrm{AlF}_{4}{ }^{-}$indicates that this transporter belongs to the family of P-type ATPases. It has been suggested that aminophospholipid translocase is inhibited by increased levels of intracellular $\mathrm{Ca}^{2+}$ in the micromolar range (Bitbol et al., 1987), but since these conditions also induce lipid scrambling (vide infra), this conclusion may have been premature. However, using red blood cells from a patient with Scott syndrome, which are defective in $\mathrm{Ca}^{2+}$-induced lipid scrambling, it could be demonstrated that the aminophospholipid transporter is indeed inhibited by elevated intracellular $\mathrm{Ca}^{2+}$ (Bevers et al., 1992; Bevers et al., 1995). This inhibition may be partly explained by ATP depletion as a result of activation of the $\mathrm{Ca}^{2+}$-ATPases (Bitbol et al., 1987).

Using photo-activatable lipid probes, Schroit and coworkers (Schroit et al., 1987) found labeling of a $30 \mathrm{kDa}$ membrane protein in red blood cells. Labelling was found only with aminophospholipids under conditions conducive to transport. No preferential labelling was found when photoactivatable PC was used. Further characterization of this protein led to the suggestion that it shares features in common with Rhesus protein (Schroit et al., 1990), but this has been refuted since the Rhesus protein lacks an ATP- binding site and Rhesus null cells have normal translocase activity (Smith et al., 1990). Morrot et al. have proposed that the aminophospholipid translocase is a $\mathrm{Mg}^{2+}$-ATPase (Morrot et al., 1990; Zimmerman and Daleke, 1993). This led Auland et al. (Auland et al., 1994) to purify and reconstitute the $\mathrm{Mg}^{2+}$-ATPase in proteoliposomes. They could demonstrate an enhanced transport of spin-labeled phosphatidylserine analogues across the bilayer. However, the active protein fraction appeared to consist of several proteins, ranging in molecular weight from 35 to $120 \mathrm{kDa}$ (Zachowski, 1995). Tang and 
coworkers (Tang et al., 1996) cloned the cDNA encoding the $\mathrm{Mg}^{2+}$ ATPase from bovine chromaffin granules and found that this protein is a member of a new subgroup of P-type ATPases which differ from the Ptype ATPases known to be involved in transport of mono- and divalent cations. A highly homologous gene, DRS2, was found in yeast and a drs2 null mutant was shown to be defective in aminophospholipid transport compared to the wild type of this yeast (Tang et al, 1996). However, Siegmund et al. (Siegmund et al., 1998) observed no changes in uptake or distribution of fluorescently-labeled PS or PE in the mutant strain. Moreover, the absence of Drs2 did not affect the distribution of endogenous PE in the plasma membrane. Also, Marx et al. (Marx et al., 1999 ) found that lipid asymmetry was preserved in S. Cerevisiae endocytosis-deficient yeast- independently of the presence of the Drs2 protein. Another homologous gene, $A L A 1$, which was identified from the Arabidopsis, is involved in aminophospholipid transport. Reconstitution of the ALA1 protein in yeast membrane vesicles from a drs 2 null mutant results in an increased translocation of aminophospholipids (Gomès et al., 2000).

Considering that in most mammalian cells aminophospholipids are predominantly located in the cytoplasmic leaflet of the membrane, it can be argued that the aminophospholipid translocase is an ubiquitous protein. Investigations on different cell types show a similar activity (Connor and Schroit, 1989) but with different rates. Aminophospholipid translocase activity has been measured using a variety of reporter lipids. Because the assessment of endogenous lipid distributions requires chemical modification, enzymatic digestion or recognition by exogenous lipid binding proteins (i.e. annexins (Tait and Gibson, 1994)) or protein kinase C (Daleke et al., 1994), most studies have been performed with lipid analogues with synthetic reporter groups. Since activity of the aminophospholipid translocase is hardly affected by the composition of the acyl chains of the phospholipids, most reporter probes are labeled in the acyl moiety and not in the headgroup. Spin-labeled and NBD-labeled lipid analogues are the most extensively used probes to measure transbilayer lipid distribution.

Alterations of aminophospholipid translocase activity were found under particular pathological conditions. In sickle cells, under deoxygenating conditions, an increased surface exposure of aminophospholipids was shown which was accompanied by a decrease of translocase activity (Blumenfeld et al., 1991). Likewise, red blood cells from a patient with Bthalassemia also exhibited an altered transverse lipid organization, which could be attributed to a -rather small- change in aminophospholipid 
translocase activity (Srinivasan and Basu, 1996). Although the aminophospholipid translocase is important for maintenance of the asymmetric distribution of the aminophospholipids, mere inhibition of this transporter does not readily lead to a loss of lipid asymmetry.

\section{Floppase: outward movement of lipids}

Outward directed movement of phospholipids was first shown by the group of Devaux (Bitbol and Devaux, 1988). They showed that spinlabeled analogues of aminophospholipids and PC are slowly transported to the outer leaflet of red blood cells. This transport phenomenon was confirmed by Connor et al. (Connor et al., 1992), who showed that the half time for outward movement of $\mathrm{C}_{6}$-NBD-lipid analogues is in the order of 1.5 hours. For comparison, inward transport of aminophospholipids by the translocase described above is estimated to have a half time in the order of 5-10 minutes. Because both amino- and cholinephospholipids are transported, it was proposed that the outward movement is less specific with respect to the polar headgroup.

Over the last 10 years evidence has accumulated for a role of $\mathrm{ABC}$ proteins as lipid translocators. ABC-proteins are characterized by the presence of a specific domain, which can bind ATP, the so-called ATPBinding Cassette. The first evidence that $\mathrm{ABC}$-transporters are involved in lipid translocation came from a study by Smit et al. (Smit et al., 1993), who showed that one of the members of a large family of proteins involved in multidrug resistance, MDR3 protein, facilitates ATPdependent transport of phosphatidylcholine over the murine hepatocyte plasma membrane into the bile. ABC-transporters are large transmembrane proteins, which are thought to be responsible for expelling xenobiotics or cell damaging agents out of the cell. MDR1 P-glycoprotein can transport a variety of lipids, including $\mathrm{C}_{6}$-NBD-analogues (Bosch et al., 1997; van Helvoort et al., 1997; van Helvoort et al., 1996). A French group found indications for a role of P-glycoprotein (Pgp) in the transverse distribution of endogenous sphingomyelin (Bezombes et al., 1998). They hypothesized that resistance of human leukemia KGla cells to TNF- $\alpha$ induced apoptosis is related to a limited production of intracellular ceramides due to a decreased inner leaflet sphingomyelin content. Incubation of KGla cells with a specific Pgp blocker restored TNF- $\alpha$ induced ceramide generation and apoptosis, a phenomenon that appeared to be related to a shift in the transverse distribution of sphingomyelin towards the inner leaflet of the plasma membrane. Recent evidence has demonstrated that the floppase in 
red blood cells is identical to MRP1 (Dekkers et al., 1998; Kamp and Haest, 1998) (see also chapters 5 and 6), belonging to a different subfamily of ABC-transporters, formerly called 'multidrug resistant associated protein 1', presently referred to as $\mathrm{ABCCl}$ (Schmitz et al., 2000). In this thesis, we prefer to use the former nomenclature. MRP1 was first cloned by Cole and coworkers (Cole et al., 1992). They showed that MRP1 is a $190 \mathrm{kDa}$ transmembrane protein. It consists of three membrane spanning domains with two nucleotide-binding pockets in the last two domains. The binding and subsequent hydrolysis of ATP is thought to be coupled to substrate transport (Higgins, 1992). Mutations of one of the ATP-binding sites lead to an inactive protein. MRP1 is responsible for transport of a variety of drugs. An important characteristic of this transporter is that elimination of naturally occurring toxins from the cell requires their conversion to gluthation-conjugates (Leier et al., 1994). Findings to indicate that multidrug resistant proteins are involved in transporting drugs over the membrane might have been over-interpreted, since many of the observed transport phenomena could find their origin in changes in plasma membrane electric potential and intracellular $\mathrm{pH}$, as was discussed by Wadkins and Roepe (Wadkins and Roepe, 1997). Recently, additional data have become available to suggest that $\mathrm{ABC}$ transporters are coupled to lipid transport (Hamon et al., 2000; Kaminski et al., 2000). The group of Klucken (Klucken et al., 2000) showed that $\mathrm{ABC} 8$ is involved in transbilayer transport of cholesterol and phospholipids in macrophages. Expression of $\mathrm{ABC} 8$ is regulated by cholesterol uptake or $\mathrm{HDL}_{3}$-mediated lipid release, suggesting a potential role for $\mathrm{ABC} 8$ as transporter in the macrophage lipid homeostasis.

From the foregoing it can be proposed that a concerted action of aminophospholipid translocase and MRP1 is responsible for a dynamic asymmetric steady-state distribution in which aminophospholipids that occupy the inner leaflet are balanced by cholinephospholipids in the outer leaflet. It cannot be excluded that more lipid transporters will be found in the near future, which may require adaptation of the present view.

\section{Scramblase: bi-directional movement of lipids}

While the aminophospholipid translocase and floppase (MRP1) are responsible for maintaining a dynamic equilibrium in which the lipids are non-randomly distributed over both leaflets, inhibition of both processes will not readily lead to a significant loss of lipid asymmetry. However, under particular conditions of cellular activation, a collapse of lipid 
asymmetry can occur in less than a minute. The putative protein thought to be responsible for collapse of lipid asymmetry is called scramblase. Lipid scrambling was first observed in blood platelets (Bevers et al., 1982; Bevers et al., 1983) but has meanwhile been demonstrated in a variety of other cell types such as red blood cells, (Chandra et al., 1987; Comfurius et al., 1990; Williamson et al., 1992), lymphocytes, (Bratton et al., 1997; Fadok et al., 1992; Verhoven et al., 1995) tumorigenic cells, (Utsugi et al., 1991; VanDeWater et al., 1985) endothelial cells (Bombeli et al., 1997; Hamilton et al., 1990) and smooth muscle cells (Bennett et al., 1995). The process of lipid scrambling is most clearly manifested by the exposure of phosphatidylserine at the cell surface, which can be measured in several ways. Earlier studies were based on chemical modification of lipids or on enzymatic degradation by phospholipases under non-lytic conditions. Since the prothrombinase complex readily assembles on PS-exposing membrane surfaces, its activity can be tailored to reflect the amount of PS exposed on the cell surface (Bevers et al., 1982; Bevers et al., 1983; Connor and Schroit, 1989). Due to the high affinity of the prothrombinase complex for PS this method allows to measure trace amounts of PS. Another convenient method to measure exposed PS is binding of annexin $\mathrm{V}$, a $35 \mathrm{kD}$ protein with a high affinity for anionic lipids (Dachary-Prigent et al., 1993; Stuart et al., 1995; Tait and Gibson, 1992). Fluorescentlabeled annexin V is commercially available and can be applied in flow cytometry. The methods mentioned above provide information on the localization of the endogenous lipids, albeit mainly restricted to PS. Most frequently used are trace amounts of phospholipid probes, in which the acyl chain at the $\mathrm{C} 2$ position has been replaced by radio-labeled, spinlabeled or fluorescent-labeled fatty acid. Since most of these analogues are reliable reporters of the behavior of endogenous membrane lipids, valuable information about the dynamics of lipid movement of nearly all lipid classes can be obtained.

The scrambling process was found to be bi-directional and to involve all major lipid classes, although the movement of sphingomyelin in red blood cells appears to be limited in comparison to the glycerophospholipids (Smeets et al., 1994). While most studies have shown that all major lipids seem to undergo an increased rate of bi-directional movement during activation, the group of Bienvenue (Bassé et al., 1993; Gaffet et al., 1995) has claimed that only the aminophospholipids play an important role in lipid scrambling. They postulated that a "reversed" aminophospholipid translocase could be responsible for surface exposure of PS.

The process of lipid scrambling can be induced by an increase of cytoplasmic calcium which may result from cellular activation, 
complement pore formation or induction of apoptosis. Scrambling requires the continuous presence of calcium; removal of intracellular calcium by calcium chelators causes an immediate arrest of the scrambling process (Williamson et al., 1992; Williamson et al., 1995). Although evidence was presented that the increase of calcium leads to the inhibition of the aminophospholipid translocase, this inhibition alone is not sufficient to produce loss of lipid asymmetry (Bevers et al., 1995; Geldwerth et al., 1993; Kuypers et al., 1996). However, provided that the aminophospholipid translocase is not irreversibly inactivated by intracellular calpain, calcium efflux after lipid scrambling can lead to restoration of lipid asymmetry (Bevers et al., 1989). Other mechanisms have been postulated to explain the $\mathrm{Ca}^{2+}$-induced collapse of lipid asymmetry. The strong correlation between lipid scrambling and shedding of microvesicles from the plasma membrane has led others to suggest that membrane fusion events during microvesicle formation are accompanied by a transient perturbation of the normal bilayer structure, which could account for the loss of lipid asymmetry (Chang et al, 1993; Sims et al., 1989; Wiedmer et al., 1990) However, uncoupling of these two events has been demonstrated as they proceed along independent pathways (Bassé et al., 1993; Bucki et al., 1998; Dachary-Prigent et al., 1995; Fox et al., 1991; Williamson et al., 1992).

Two groups have successfully reconstituted the phospholipid scramblase in proteoliposomes with functional calcium inducible activity (Bassé et al., 1996; Comfurius et al., 1996). Zhou et al. (Zhou et al., 1997) cloned a 37 $\mathrm{kD}$ protein, with certain characteristics of the phospholipid scramblase. However, comparison between the rates of transbilayer movement by the scramblase in the original platelet and red blood cell membranes and that of the reconstituted protein reveals that the rate of the latter is more than two orders of magnitude slower than that observed in cells. Also, the transbilayer movement of fluorescent-labeled phosphatidylcholine in the reconstituted proteoliposomes was approximately twice as fast as that of fluorescent- labeled phosphatidylserine (Stout et al., 1997), which is not consistent with the properties of the native scramblase in intact cells, showing identical kinetics for both lipid probes (Williamson et al., 1995). Sims and coworkers (Bassé et al., 1996; Stout et al., 1997; Zhou et al., 1998; Zhou et al., 1998; Zhou et al, 1997) unraveled various properties of this protein. Via an internal peptide sequence of the purified protein they cloned a $1.4 \mathrm{~kb}$ cDNA. The deduced polypeptide consists of 318 amino acid residues, is rich in proline, and was predicted to be a type 2 membrane protein spanning the membrane with a single helix ( $\mathrm{Ala}^{291}$. $\mathrm{Gly}^{309}$ ). In the proximity of the transmembrane domain, a putative $\mathrm{Ca}^{2+}$ 
binding site of 12 amino acid residues $\left(\mathrm{Asp}^{273}-\mathrm{Asp}^{284}\right)$ was found, similar to the well known EF-hand structure (Zhou et al., 1998). A potential $\mathrm{Thr}^{159}$ phosphorylation site was found, which could be reconciled with the observation that prolonged ATP -depletion results in loss of scrambling activity (Martin and Jesty, 1995). They also showed that membrane anchoring via a palmitoylated cysteinyl residue was necessary for folding of the loop $\mathrm{Asp}^{273}-\mathrm{Asp}^{284}$ required for $\mathrm{Ca}^{2+}$ binding (Zhao et al., 1998). Prolonged depletion of ATP shows a slow but gradual loss of lipid scrambling indicating that one or more phosphorylation sites may be required for the scrambling process. The loss of palmitoylation due to prolonged ATP depletion could also reflect the decrease in scrambling activity (Martin and Jesty, 1995). However, lipid scrambling does not require hydrolyzable ATP because the event occurs in resealed white ghosts from erythrocytes when challenged with calcium (Bevers et al., 1992; Connor and Schroit, 1990; Williamson et al., 1985), but it remains possible that the protein is constitutively phosphorylated in situ. Whether or not this $37 \mathrm{kD}$ protein is identical to the scramblase in activated cells remains to be established.

Recently, the molecular cloning of three additional putative scramblases has been reported (Wiedmer et al., 2000). However, experiments with knock-out mice revealed that their blood cells are able to scramble their lipids, suggesting that these proteins are not involved in lipid scrambling or only play a minor role (Sims, P. J., personal communication). In addition, transcriptional levels of this protein are regulated by interferon- $\alpha$ (IFN- $\alpha$ ), but although the protein expression increases as high as 10 -fold above basal levels no increased cell surface exposure of phosphatidylserine was detected (Zhou et al, 2000). Zhao and coworkers (Zhao et al., 1998) found a close correlation between calcium/ionophore triggered PS-exposure and the level of scramblase present in a panel of tumor lines. However, Raji cells, which are diminished in lipid scrambling, are not able to expose PS when these cells are induced to over-express this enzyme, e.g. Fas stimulation (Fadeel et al., 1999). However, it cannot be excluded that there are several scramblases acting in concert or distinctive when cells are triggered in various ways.

\section{REFERENCES}

Auland, M. E., Roufogalis, B. D., Devaux, P. F., and Zachowski, A. (1994) Reconstitution of ATP-dependent aminophospholipid translocation in proteoliposomes. Proc. Natl. Acad. Sci. USA 91, 10938-42. 
Bassé, F., Gaffet, P., Rendu, F., and Bienvenue, A. (1993) Translocation of spin-labeled phospholipids through plasma membrane during thrombin- and ionophore A23187induced platelet activation. Biochemistry 32, 2337-44.

Bassé, F., Stout, J. G., Sims, P. J., and Wiedmer, T. (1996) Isolation of an erythrocyte membrane protein that mediates $\mathrm{Ca}^{2+}$-dependent transbilayer movement of phospholipid. J. Biol. Chem. 271, 17205-10.

Beleznay, Z., Zachowski, A. Devaux, P. F., Navazo, M. P. and Ott, P. (1993) ATPdependent aminophospholipid translocation in erythrocyte vesicles: Stoichiometry of transport. Biochemistry 32 3146-3152.

Bennett, M. R., Gibson, D. F., Schwartz, S. M., and Tait, J. F. (1995) Binding and phagocytosis of apoptotic vascular smooth muscle cells is mediated in part by exposure of phosphatidylserine. Circ. Res. 77, 1136-1142.

Bevers, E. M., Comfurius, P., Hemker, H. C., and Zwaal, R. F. A. (1982) On the clotpromoting activity of human platelets in a one-stage prothrombinase assay. Haemost. 12, $268-74$.

Bevers, E. M., Comfurius, P., and Zwaal, R. F. A. (1983) Changes in membrane phospholipid distribution during platelet activation. Biochim. Biophys. Acta 736, 57-66.

Bevers, E. M., Tilly, R. H., Senden, J. M., Comfurius, P., and Zwaal, R. F. A.(1989) Exposure of endogenous phosphatidylserine at the outer surface of stimulated platelets is reversed by restoration of aminophospholipid translocase activity. Biochemistry 28,2382 7.

Bevers, E. M., Wiedmer, T., Comfurius, P., Shattil, S. J., Weiss, H. J., Zwaal, R. F. A., and Sims, P. J. (1992) Defective $\mathrm{Ca}^{2+}$-induced microvesiculation and deficient expression of procoagulant activity in erythrocytes from a patient with a bleeding disorder: a study of the red blood cells of Scott syndrome. Blood 79, 380-8.

Bevers, E. M., Wiedmer, T., Comfurius, P., Zhao, J., Smeets, E. F., Schlegel, R. A., Schroit, A. J., Weiss, H. J., Williamson, P., and Zwaal, R. F. A., (1995) The complex of phosphatidylinositol 4,5-bisphosphate and calcium ions is not responsible for $\mathrm{Ca}^{2+}$ induced loss of phospholipid asymmetry in the human erythrocyte: a study in Scott syndrome, a disorder of $\mathrm{Ca}^{2+}$-induced phospholipid scrambling. Blood 86, 1983-91.

Bezombes, C., Maestre, N., Laurent, G., Levade, T., Bettaieb, A., and Jaffrezou, J. P. (1998) Restoration of TNF- $\alpha$-induced ceramide generation and apoptosis in resistant human leukemia KGla cells by the P-glycoprotein blocker PSC833. FASEB J. 12, 101-9.

Bitbol, M., and Devaux, P. F. (1988) Measurement of outward translocation of phospholipids across human erythrocyte membrane. Proc. Natl. Acad. Sci. USA 85, 6783-7. 
Bitbol, M., Fellmann, P., Zachowski, A., and Devaux, P. F. (1987) Ion regulation of phosphatidylserine and phosphatidylethanolamine outside-inside translocation in human erythrocytes. Biochim. Biophys. Acta 904, 268-82.

Blumenfeld, N., Zachowski, A., Galacteros, F., Beuzard, Y., and Devaux, P. F. (1991) Transmembrane mobility of phospholipids in sickle erythrocytes: effect of deoxygenation on diffusion and asymmetry. Blood 77, 849-54.

Bombeli, T., Karsan, A., Tait, J. F., and Harlan, J. M. (1997) Apoptotic vascular endothelial cells become procoagulant. Blood 89, 2429-42.

Bosch, I., Dunussi Joannopoulos, K., Wu, R. L., Furlong, S. T., and Croop, J. (1997) Phosphatidylcholine and phosphatidylethanolamine behave as substrates of the human MDR1 P-glycoprotein. Biochemistry 36, 5685-94.

Bratton, D. L., Fadok, V. A., Richter, D. A. Kailey, J. M., Guthrie, L. A., and Henson, P. M. (1997) Appearance of phosphatidylserine on apoptotic cells requires calciummediated nonspecific flip-flop and is enhanced by loss of the aminophospholipid translocase. J. Biol. Chem. 272, 26159-26165.

Bucki, R., Bachelot Loza, C., Zachowski, A., Giraud, F., and Sulpice, J. C. (1998) Calcium induces phospholipid redistribution and microvesicle release in human erythrocyte membranes by independent pathways. Biochemistry 37, 15383-91.

Chandra, R., Joshi, P. C., Bajpai, V. K., and Gupta, C. M. (1987) Membrane phospholipid organization in calcium-loaded human erythrocytes. Biochim. Biophys. Acta 902, 253-262.

Chang, C.-P., Zhao, J., Wiedmer, T., Sims, P. J. (1993) Contribution of platelet microparticle formation and granule secretion to the transmembrane migration of phosphatidylserine. J. Biol. Chem. 268, 7171-7178.

Cole, S. P., Bhardwaj, G., Gerlach, J. H., Mackie, J. E., Grant, C. E., Almquist, K. C., Stewart, A. J., Kurz, E. U., Duncan, A. M., and Deeley, R. G. (1992) Overexpression of a transporter gene in a multidrug-resistant human lung cancer cell line. Science $258,1650-$ 4.

Comfurius, P., Senden, J. M., Tilly, R. H., Schroit, A. J., Bevers, E. M., and Zwaal, R. F. A. (1990) Loss of membrane phospholipid asymmetry in platelets and red cells may be associated with calcium-induced shedding of plasma membrane and inhibition of aminophospholipid translocase. Biochim. Biophys. Acta 1026, 153-60.

Comfurius, P., Williamson, P., Smeets, E. F., Schlegel, R. A., Bevers, E. M., and Zwaal, R. F. A. (1996) Reconstitution of phospholipid scramblase activity from human blood platelets. Biochemistry $35,7631-4$. 
Connor, J., Pak, C. H., Zwaal, R. F. A., and Schroit, A. J. (1992) Bi-directional transbilayer movement of phospholipid analogs in human red blood cells. Evidence for an ATP-dependent and protein-mediated process. J. Biol. Chem. 267, 19412-7.

Connor, J., and Schroit, A. J. (1990) Aminophospholipid translocation in erythrocytes: evidence for the involvement of a specific transporter and an endofacial protein. Biochemistry 29, 37-43.

Connor, J., and Schroit, A. J. (1989) Transbilayer movement of phosphatidylserine in nonhuman erythrocytes: evidence that the aminophospholipid transporter is a ubiquitous membrane protein. Biochemistry 28, 9680-5.

Dachary-Prigent, J., Pasquet, J. -M., Freyssinet, J. -M., and Nurden, A. T. (1995) Calcium involvement in aminophospholipid exposure and microparticle formation during platelet activation: a study using $\mathrm{Ca}^{2+}$-ATPase inhibitors. Biochemistry 34, 11625-34.

Dachary-Prigent, J., Freyssinet, J. -M., Pasquet, J. -M., Carron, J. -C., Nurden, A. T. (1993) Annexin V as probe of aminophospholipid exposure and platelet membrane vesiculation: a flow cytometry study showing a role for free sulfhydryl groups. Blood 81 , 2554-2565.

Daleke, D. L., and Huestis, W. H. (1985) Incorporation and translocation of aminophospholipids in human erythrocytes. Biochemistry 24, 5406-16.

Daleke, D. L., Huestis, W. H., and Newton, A. C. (1994) Protein kinase C as a measure of transbilayer phosphatidylserine asymmetry. Anal. Biochem. 217, 33-40.

Dekkers, D. W. C., Comfurius, P., Schroit, A. J., Bevers, E. M., and Zwaal, R. F. A. (1998) Transbilayer movement of NBD-labeled phospholipids in red blood cell membranes: outward-directed transport by the multidrug resistance protein 1 (MRP1). Biochemistry 37, 14833-7.

Devaux, P. F., and Zachowski, A (1994) Maintenance and consequences of membrane phospholipid asymmetry. Chem. Phys. Lip. 73, 107-120.

Fadeel, B., Gleiss, B., Hogstrand, K., Chandra, J., Wiedmer, T., Sims, P. J., Henter, J.-I., Orrenius, S., and Samali, A. (1999) Phosphatidylserine exposure during apoptosis is a cell-type-specific event and does not correlate with plasma membrane phospholipid scramblase expression. Biochem. Biophys. Res. Comm. 266, 504-511.

Fadok, V. A., Voelker, D. R., Campbell, P. A., Cohen, J. J., Bratton, D. L., and Henson, P. M. (1992) Exposure of phosphatidylserine on the surface of apoptotic lymphocytes triggers specific recognition and removal by macrophages. J. Immunol. 148, 2207-2216.

Fox, J. E., Austin, C. D., Reynolds, C. C., and Steffen, P. K. (1991) Evidence that agonist-induced activation of calpain causes the shedding of procoagulant-containing microvesicles from the membrane of aggregating platelets. J. Biol. Chem. 266, 13289-95. 
Gaffet, P., Bettache, N., and Bienvenue, A. (1995) Transverse redistribution of phospholipids during human platelet activation: evidence for a vectorial outflux specific to aminophospholipids. Biochemistry 34, 6762-9.

Geldwerth, D., Kuypers, F. A., Butikofer, P., Allary, M., Lubin, B. H., and Devaux, P. F. (1993) Transbilayer mobility and distribution of red cell phospholipids during storage. J. Clin. Invest. 92, 308-14.

Gomès, E., Jakobsen, M. K., Axelsen, K. B., Geisler, M., and Palmgren, M. G. (2000) Chilling tolerance in Arabidopsis involves ALA1, a member of a new family of putative aminophospholipid translocases. Plant Cell. 12, 2441-53

Haest, C. W. M., and Deuticke, B. (1976) Possible relationship between membrane proteins and phospholipid asymmetry in the human erythrocyte membrane. Biochim. Biophys. Acta 436, 353-365.

Haest, C. W. M., Plasa, G., Kamp, D., and Deuticke, B. (1978) Spectrin as a stabilizer of the phospholipid asymmetry in the human erythrocyte membrane. Biochim. Biophys. Acta 509, 21-32.

Hall, M. P., and Huestis, W. H. (1994) Phosphatidylserine headgroup diastereomers translocate equivalently across human erythrocyte membrane. Biochim. Biophys. Acta $1190,243-247$.

Hamilton, K. K., Hattori, R., Esmon, C. T., and Sims, P. J. (1990) Complement proteins C5b-9 induce vesiculation of the endothelial plasma membrane and expose catalytic surface for assembly of the prothrombinase enzyme complex. J. Biol. Chem. 265, 380914.

Hamon, Y., Broccardo, C., Chambenoit, O., Luciani, M. F., Toti, F., Chaslin, S., Freyssinet, J. M., Devaux, P. F., McNeish, J., Marguet, D., and Chimini, G. (2000) ABC1 promotes engulfment of apoptotic cells and transbilayer redistribution of phosphatidylserine. Nat. Cell Biol. 2, 399-406.

Higgins, C. F. (1992) ABC transporters: from micro-organisms to man. Annu. Rev. Cell Biol. 8, 67-113.

Kaminski, W. E., Orso, E., Diederich, W., Klucken, J., Drobnik, W., and Schmitz, G. (2000) Identification of a novel human sterol-sensitive ATP-binding cassette transporter (ABCA7). Biochem. Biophys. Res. Comm. 273, 532-8.

Kamp, D., and Haest, C. W. M. (1998) Evidence for a role of the multidrug resistance protein (MRP) in the outward translocation of NBD-phospholipids in the erythrocyte membrane. Biochim. Biophys. Acta 1372, 91-101. 
Klucken, J., Buchler, C., Orso, E., Kaminski, W. E., Porsch Ozcurumez, M., Liebisch, G., Kapinsky, M., Diederich, W., Drobnik, W., Dean, M., Allikmets, R., and Schmitz, G. (2000) ABCG1 (ABC8), the human homolog of the Drosophila white gene, is a regulator of macrophage cholesterol and phospholipid transport. Proc. Natl. Acad. Sci. USA 97, $817-22$.

Kuypers, F. A., Schott, M. A., and Scott, M. D. (1996) Phospholipid composition and organization in model beta-thalassemic erythrocytes. Am. J. Hematol. 51, 45-54.

Leier, I., Jedlitschky, G., Buchholz, U., Cole, S. P., Deeley, R. G., and Keppler, D. (1994) The MRP gene encodes an ATP-dependent export pump for leukotriene C4 and structurally related conjugates. J. Biol. Chem. 269, 27807-10.

Martin, D. W., and Jesty. J (1995) Calcium stimulation of procoagulant activity in human erythrocytes. J. Biol. Chem. 270, 10468-10474.

Martin, O. C., and Pagano, R. E. (1987) Transbilayer movement of fluorescent analogs of phosphatidylserine and phosphatidylethanolamine at the plasma membrane of cultured cells. J. Biol. Chem. 262, 5890-5898.

Marx, U., Polakowski, T., Pomorski, T., Lang, C., Nelson, H., Nelson, N., and Hermann, A. (1999) Rapid bilayer movement of fluorescent phospholipid analogues in the plasma membrane of endocytosis -deficient yeast cells does not require the Drs2 protein. Eur. J. Biochem. 263, 254-263.

Middelkoop, E., Lubin, B. H., Op den Kamp, J. A. F., and Roelofsen, B. (1986) Flip-flop rates of individual molecular spieces of phosphatidylcholine in the human red cel membrane. Biochim. Biophys. Acta 855, 421-424.

Morrot, G., Zachowski, A., and Devaux, P. F. (1990) Partial purification and characterization of the human erythrocyte $\mathrm{Mg}^{2+}$-ATPase. A candidate aminophospholipid translocase. FEBS Lett. 266, 29-32.

Roelofsen, B., and Op den Kamp, J. A. F. (1994) Plasma membrane phospholipid asymmetry and its maintenance: The human erythrocyte as a model. Curr. Top. Membr. 40, 7-46.

Schmitz, G., Kaminski, W.E., and Orso, E. (2000) ABC transporters in cellular lipid trafficking. Curr. Opin. Lipidol. 11, 493-501.

Schroit, A. J., Madsen, J. and Ruoho, A. E. (1987) Radioiodinated, photoactivatable phosphatidylcholine and phosphatidylserine: transfer properties and differential photoreactive interaction with human erythrocyte membrane proteins. Biochemistry 26 , 1812-1819.

Schroit, A. J., Bloy, C., Connor, J., and Cartron, J. P. (1990) Involvement of Rh blood group polypeptides in the maintenance of aminophospholipid asymmetry. Biochemistry 29, 10303-6. 


\section{Chapter 2}

Schroit, A. J., and Zwaal, R. F. A. (1991) Transbilayer movement of phospholipids in red cell and platelet membranes. Biochim. Biophys. Acta 1071, 313-29.

Seigneuret, M., and Devaux, P. F. (1984) ATP-dependent asymmetric distribution of spin-labeled phospholipids in the erythrocyte membrane: relation to shape changes. Proc. Natl. Acad. Sci. USA 81, 3751-5.

Siegmund, A., Grant, A., Angeletti, C., Malone, L., Nichols, J. W., and Rudolph, H. K. (1998) Loss of Drs2p does not abolish transfer of fluorescent-labeled phospholipids across the plasma membrane of Saccaromyces cerevisiae. J. Biol. Chem. 273, 3439934405 .

Sims, P. J., Wiedmer, T., Esmon, C. T., Weiss, H. J., and Shattil, S. J. (1989) Assembly of the platelet prothrombinase complex is linked to vesiculation of the platelet plasma membrane. Studies in Scott syndrome: an isolated defect in platelet procoagulant activity. J. Biol. Chem. 264, 17049-57.

Smeets, E. F., Comfurius, P., Bevers, E. M., and Zwaal, R. F. A. (1994) Calcium-induced transbilayer scrambling of fluorescent phospholipid analogs in platelets and erythrocytes. Biochim. Biophys. Acta 1195, 281-6.

Smit, J. J., Schinkel, A. H., Oude Elferink, R. P., Groen, A. K., Wagenaar, E., van Deemter, L., Mol, C. A., Ottenhoff, R., van der Lugt, N. M., and van Roon, M. A. (1993) Homozygous disruption of the murine mdr2 P-glycoprotein gene leads to a complete absence of phospholipid from bile and to liver disease. Cell 75, 451-62.

Smith, R. E., and Daleke, D. L. (1990) Phosphatidylserine transport in Rh(null) erythrocytes. Blood 76, 1021-1027.

Srinivasan, P. T., and Basu, J. (1996) Altered membrane phospholipid organization and erythrophagocytosis in E beta-thalassemia. Biochim. Biophys. Acta 1285, 65-70.

Stout, J. G., Bassé, F., Luhm, R. A., Weiss, H. J., Wiedmer, T., and Sims, P. J. (1997) Scott syndrome erythrocytes contain a membrane protein capable of mediating $\mathrm{Ca}^{2+}$. dependent transbilayer migration of membrane phospholipids. J. Clin. Invest. 99, 2232-8.

Stuart, M. C., Bevers, E. M., Comfurius, P., Zwaal R. F. A., Reutelingsperger, C. P. M., and Frederik, P. M. (1995) Ultrastructural detection of surface exposed phosphatidylserine on activated blood platelets. Thromb. Haemost. 74, 1145-1151.

Tait, J. F., and Gibson, D. (1994) Measurement of membrane phospholipid asymmetry in normal and sickle-cell erythrocytes by means of annexin V binding. J. Lab. Clin. Med. $123,741-8$.

Tait, J. F., and Gibson, D. (1992) Phospholipid binding of annexin V: effects of calcium and membrane phosphatidylserine content. Arch. Biochem. Biophys. 298, 187- 191. 
Tang, X., Halleck, M. S., Schlegel, R. A., and Williamson, P. (1996) A sub-family of Ptype ATPases with aminophospholipid transporting activity. Science 272, 1495-1497.

Tilley, L., Cribier, S., Roelofsen, B., Op den Kamp, J. A. F., and van Deenen, L. L. M. (1986) ATP-dependent translocation of aminophospholipids across the human erythrocyte membrane. FEBS lett. 194, 21-27.

Utsugi, T., Schroit, A. J., Connor, J., Bucana, C. D., and Fidler, I. J. (1991) Elevated expression of phosphatidylserine in the outer membrane leaflet of human tumor cells and recognition by activated human blood monocytes. Cancer Res. 51, 3062-6.

van Helvoort, A., Giudici, M. L., Thielemans, M., and van Meer, G. (1997) Transport of sphingomyelin to the cell surface is inhibited by brefeldin A and in mitosis, where C6NBD-sphingomyelin is translocated across the plasma membrane by a multidrug transporter activity. J. Cell Sci. 110, 75-83.

van Helvoort, A., Smith, A. J., Sprong, H., Fritzsche, I., Schinkel, A. H., Borst, P., and van Meer, G. (1996) MDR1 P-glycoprotein is a lipid translocase of broad specificity, while MDR3 P-glycoprotein specifically translocates phosphatidylcholine. Cell 87, 50717.

VanDeWater, L., Tracy, P. B., Aronson, D., Mann, K. G., and Dvorak, H. F. (1985) Tumor cell generation of thrombin via functional prothrombinase assembly. Cancer Res. $45,5521-5$.

Verhoven, B., Schlegel, R. A., and Williamson, P. (1995) Mechanisms of phosphatidylserine exposure, a phagocyte recognition signal, on apoptotic t lymphocytes. J. Exp. Med. 182, 1597-1601.

Wadkins, R. M., and Roepe, P. D. (1997) Biophysical aspects of P-glycoprotein-mediated multidrug resistance. Int. Rev. Cytol. 171, 121-65.

Wiedmer, T., Zhou, Q., Kwoh, D. Y., and Sims, P. J. (2000) Identification of three new members of the phospholipid scramblase gene family. Biochim. Biophys. Acta 1467, 244-253.

Wiedmer, T., Shattil, S. J., Cunningham, M., and Sims, P. J. (1990) Role of calcium and calpain in complement-induced vesiculation of the platelet plasma membrane and in the exposure of the platelet factor Va receptor. Biochemistry 29, 623-32.

Williamson, P., Kulick, A., Zachowski, A., Schlegel, R. A., and Devaux, P. F. (1992) $\mathrm{Ca}^{2+}$-induces transbilayer redistribution of all major phospholipids in human erythrocytes. Biochemistry 31, 6355-6360.

Williamson, P., Algarin, L., Bateman, J., Choe, H-R. and Schlegel, R. A. (1985) Phospholipid asymmetry in human erythrocyte ghosts. J. Cell. Phys. 123, 209-214. 
Williamson, P., Bevers, E. M., Smeets, E. F., Comfurius, P., Schlegel, R. A., and Zwaal, R. F. A. (1995) Continuous analysis of the mechanism of activated transbilayer lipid movement in platelets. Biochemistry 34, 10448-55.

Williamson, P., and Schlegel, R. A. (1994) Back and forth: the regulation and function of transbilayer phospholipid movement in eukaryotic cells. Mol. Membr. Biol. 11, 199-216.

Zachowski, A., Dolis, D., Moreau, C., and Devaux, P. F. (1995) Reconstitution of an aminophospholipid translocase activity in proteoliposomes, Conference Jacques Monod (CNRS) 'lipid diversity in membranes and cellular function', La Londe les maures, France. abstract, 80 .

Zachowski, A., Favre, E., Cribier, S., Herve, P., and Devaux, P. F. (1986) Outside-inside translocation of aminophospholipids in the human erythrocyte membrane is mediated by a specific enzyme. Biochemistry 25, 2585-90.

Zhao, J., Zhou, Q. S., Wiedmer, T., and Sims, P. J. (1998) Level of expression of phospholipid scramblase regulates induced movement of phosphatidylserine to the cell surface. J. Biol. Chem. 273, 6603-6606.

Zhao, J., Zhou, Q. S., Wiedmer, T., and Sims, P. J. (1998) Palmitoylation of phospholipid scramblase is required for normal function in promoting $\mathrm{Ca}^{2+}$-activated transbilayer movement of membrane phospholipids. Biochemistry 37, 6361-6366.

Zhou, Q., Sims, P. J., and Wiedmer, T. (1998) Expression of proteins controlling transbilayer movement of plasma membrane phospholipids in the B-lymphocytes from a patient with Scott syndrome. Blood 92, 1707-1712.

Zhou, Q., Zhao, J., Al-Zoghaibi, F., Zhou, A., Wiedmer, T., Silverman, R. H., and Sims, P. J. (2000) Transcriptional control of the human plasma membrane phospholipid scramblase I gene is mediated by interferon- $\alpha$. Blood 95, 2593-2599.

Zhou, Q. S., Sims, P. J., Wiedmer, T. (1998) Identity of a concerved motif in phospholipid scramblase that is required for $\mathrm{Ca}^{2+}$-accelerated transbilayer movement of membrane phospholipids. Biochemistry 37, 2356-2360.

Zhou, Q. S., Zhao, J., Stout, J. G., Luhm, R. A., Wiedmer, T., Sims, P. J. (1997) Molecular cloning of the human plasma membrane phospholipid scramblase - a protein mediating transbilayer movement of the plasma membrane phospholipids. J. Biol. Chem. $272,18240-18244$.

Zimmerman, M. L., and Daleke, D. L. (1993) Regulation of a candidate aminophospholipid-transporting ATPase by lipid. Biochemistry 32, 12257-63. 


\title{
Chapter 3
}

Comparison between $\mathrm{Ca}^{2+}$-induced scrambling of various NBD-labeled lipid analogues in red blood cells

David W.C. Dekkers, Paul Comfurius, Edouard M. Bevers and Robert F.A.Zwaal (2001) Biochem. J. Submitted.

\begin{abstract}
Treatment of red blood cells with calcium and ionomycin causes activation of the lipid scramblase, a putative membrane protein catalyzing flip-flop of (phospho) lipids. Various fluorescent $\left(\mathrm{C}_{6}-\mathrm{NBD}\right)$ analogues were tested for transbilayer movement across the plasma membrane of red blood cells. Among these phospholipid analogues were phosphatidylgalactose $\left(\mathrm{C}_{6}\right.$-NBD-PGal), phosphatidylmaltose $\left(\mathrm{C}_{6}\right.$ NBD-PMal), and phosphatidylmaltotriose ( $\mathrm{C}_{6}$-NBD-PTriose) which were obtained from $\mathrm{C}_{6}$-NBD-phosphatidylcholine by phospholipase Dcatalyzed trans-phosphatidylation. The inward movement after the onset of scrambling was monitored by extraction of the noninternalized probe with bovine serum albumin.

We demonstrate that both the amino-group and the size of the headgroup determine the kinetics of lipid scrambling, and that lipids with a ceramide backbone migrate much slower than glycerophospholipids with the same headgroup.
\end{abstract}


Chapter 3 


\section{Introduction}

The phospholipids of the membrane of human red blood cells (RBC) are asymmetrically distributed over both leaflets. The choline-phospholipids, phosphatidylcholine and sphingomyelin are mainly present in the outer leaflet, whereas the aminophospholipids, phosphatidylethanolamine and phosphatidylserine are located predominantly on the inside (reviewed in Schroit and Zwaal, 1991). Maintenance of this transversal lipid distribution is important for the function of the plasma membrane as a selective barrier between the intra and extracellular environments. However collapse of lipid asymmetry can occur to serve a function in physiological processes such as recognition by phagocytes and blood coagulation. This transverse reorganisation of lipids was first observed in blood platelets (Bevers et al., 1982; Bevers et al., 1983) and later in other cell types (Bennett et al., 1995; Chandra et al., 1987; Comfurius et al., 1990; Fadok et al., 1992; Hamilton et al., 1990; VanDeWater et al., 1985). An increase in intracellular calcium is a requisite for the onset of the scrambling process and concomitant inhibition of the aminophospholipid translocase activity (Bevers et al., 1995; Geldwerth et al., 1993; Kuypers et al., 1996). Using phospholipases, Bevers et al. (Bevers et al, 1983) showed that the major phospholipid classes become randomised when platelets are activated with $\mathrm{Ca}^{2+}$ ionophore. In subsequent studies, we and others showed that NBD-labeled lipid analogues can be used as reporter molecules for measuring transbilayer movement (Chang et al., 1993; Colleau et al., 1991; Connor et al., 1992; Dekkers et al., 1998; Smeets et al., 1994; Williamson et al., 1995). A possible explanation for the non-selectivity of the scrambling process is a model in which a transmembrane proteinaceous pore is formed, facilitating migration of the polar headgroup of the lipids across the hydrophobic core of the bilayer while keeping the acyl chain moieties in the core of the membrane (Zwaal and Schroit, 1997). One way to evaluate this hypothesis is to look for differences in rate of scrambling, as a function of the size of the headgroup. For this purpose, we have synthesised a number of NBD-labeled lipid analogues varying in size of their polar headgroups and subsequently measured their kinetics of transbilayer movement in $\mathrm{Ca}^{2+}$-loaded red blood cells. 
Chapter 3

Fig. 1: Structure of 1-oleoyl-2- [6(7-nitrobenz-2-oxa-1,3-diazol-4-yl) amino] caproyl $\left(\mathrm{C}_{6}-\mathrm{NBD}\right)$-phosphoglyceride molecule

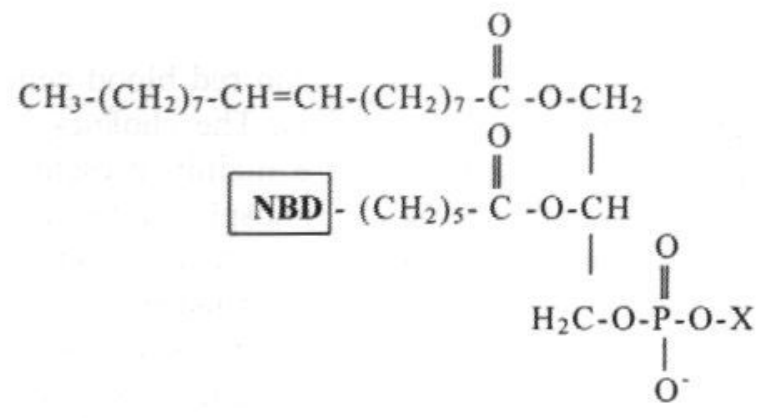

Name

PC

PE

MePE

DiMePE

PS

PGal

PMal

PTriose
Structure X

$-\mathrm{CH}_{2}-\mathrm{CH}_{2}-\mathrm{N}\left(\mathrm{CH}_{3}\right)_{3}$

$-\mathrm{CH}_{2}-\mathrm{CH}_{2}-\mathrm{NH}_{3}$

$-\mathrm{CH}_{2}-\mathrm{CH}_{2}-\mathrm{NH}_{2}\left(\mathrm{CH}_{3}\right)$

$-\mathrm{CH}_{2}-\mathrm{CH}_{2}-\mathrm{N} \mathrm{H}\left(\mathrm{CH}_{3}\right)_{2}$

$-\mathrm{CH}_{2}-\mathrm{CH}-\stackrel{+}{\mathrm{N}} \mathrm{H}_{3}$<smiles>CCCOC(C)=O</smiles><smiles>CC1CC(O)C(O)C(O)C1(O)O</smiles>
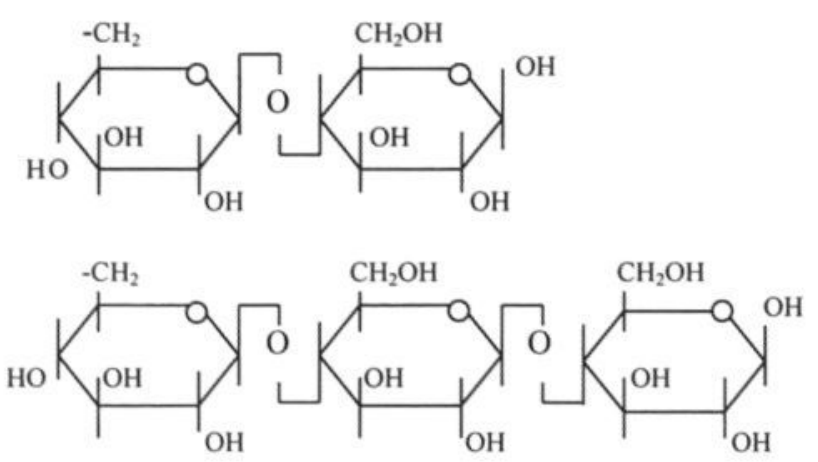
Structure of $\mathrm{C}_{6}$-NBD-sphingomyelin ( $\mathrm{C}_{6}$-NBD-Spm)

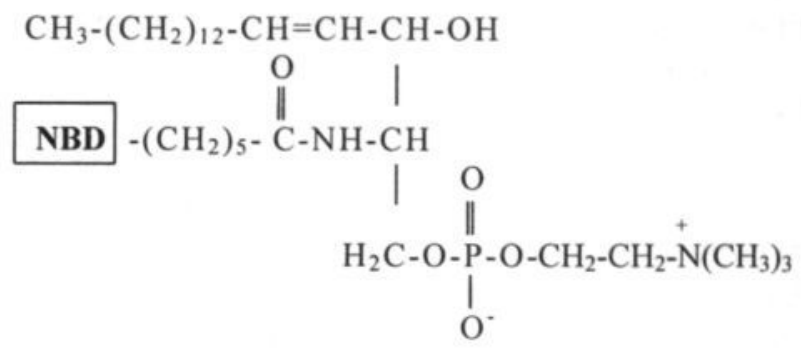

Structure of $\mathrm{C}_{6}$-NBD-ceramide

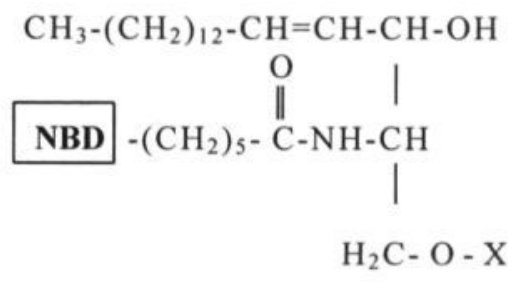

Name

Structure X

GalCer

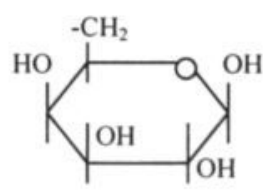

GluCer

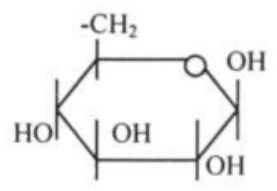

\section{Materials and Methods}

\section{Materials}

1-Oleoyl-2- [6(7-nitrobenz-2-oxa-1,3-diazol-4-yl) amino] caproyl $\left(\mathrm{C}_{6}-\right.$ NBD)-, PC, PS, PE, and 1-oleoyl-2-[6(7-nitrobenz-2-oxa-1,3-diazol-4-yl) amino] caproyl-sn-Sphingomyelin $\left(\mathrm{C}_{6}-\mathrm{NBD}-\mathrm{Spm}\right)$ were obtained from 
Avanti Polar Lipids (Alabaster, AL). $\mathrm{C}_{6}$-NBD-galactosylceramide and C6NBD-glucosylceramide were a gift from D. Hoekstra (University of Groningen). Bovine serum albumin, B-methyl Cyclo-dextrin and phospholipase D (Streptomyces chromofuscus, (EC 3.1.4.4)) were purchased from Sigma (St. Louis, MO). All other reagents were of the highest grade available commercially.

Synthesis of $C_{6}-N B D$-Phospholipids.

Synthesis of 1-oleoyl-2-[6(7-nitrobenz-2-oxa-1,3-diazol-4-yl) amino] caproyl ( $\mathrm{C}_{6}$-NBD)-, MePE, DiMePE, PGal, PMal, and PTriose was carried out using phospholipase D-catalyzed base exchange as described by Comfurius et al. (Comfurius and Zwaal, 1977). Briefly, $1 \mathrm{mg}$ of $\mathrm{C}_{6^{-}}$ NBD-PC was dissolved in $2 \mathrm{~mL}$ diethylether (solution A). A saturated solution of reagent $\mathrm{X}$ (containing a primary $\mathrm{OH}$-group, see chart.1) in a $\mathrm{NaAc} / \mathrm{CaCl}_{2}$ (100 mM f.c, each) buffer adjusted to $\mathrm{pH} 5.6$ with HAc, was used as coupling reagent (solution B). Solutions A and B were mixed and phospholipase D (7.5 IU) was added under stirring. The mixture was incubated for $45 \mathrm{~min}$ at $30^{\circ} \mathrm{C}$ under vigorous stirring in a tightly closed glass tube. The products were extracted, separated by TLC, and quantified by determination of phosphorus as described by Verkleij et al. (Verkleij et al., 1973).

\section{Isolation of red blood cells}

Blood was obtained from healthy volunteers by venipuncture, using acid citrate dextrose (ACD: $0.18 \mathrm{M}$ glucose, $0.08 \mathrm{M}$ trisodium citrate, $0.052 \mathrm{M}$ citric acid) as anticoagulant in a final ratio of $1: 5(\mathrm{v} / \mathrm{v})$. RBC were collected by centrifugation and washed with a Hepes buffer $(136 \mathrm{mM}$ $\mathrm{NaCl}, 2.7 \mathrm{mM} \mathrm{KCl}, 2 \mathrm{mM} \mathrm{MgCl}{ }_{2}, 10 \mathrm{mM}$ Hepes, $0.2 \mathrm{mM}$ EGTA, $5 \mathrm{mM}$ glucose, adjusted at $\mathrm{pH} 7.5$ ). Cells were finally resuspended in the same buffer at a concentration of $5^{*} 10^{8} \mathrm{RBC} / \mathrm{mL}$ and used within one day.

Inward movement of $\mathrm{C}_{6}$-NBD-lipid analogues.

After addition of $\mathrm{C}_{6}$-NBD-probe at a final concentration of $2 \mu \mathrm{M}$, red blood cells were incubated at $37^{\circ} \mathrm{C}$ for $2 \mathrm{~min}$ and the scrambling process was started by adding $\mathrm{Ca}^{2+}$ (1 $1 \mathrm{mM}$ f.c.) and ionomycin $(2.5 \mu \mathrm{M}$ f.c.). At different time intervals, $200 \mu \mathrm{L}$ aliquots were removed and diluted in 850 $\mu \mathrm{L}$ ice-cold Hepes buffer (to stop lipid scrambling) with or without $2 \%$ $(\mathrm{w} / \mathrm{v}) \mathrm{BSA}$. After $20 \mathrm{~min}$ of extraction with BSA at $4{ }^{\circ} \mathrm{C}$, cells were 
sedimented at $12000 \mathrm{xg}$ for $30 \mathrm{sec}$ and the pellets were solubilised in $2 \mathrm{~mL}$ of $1 \%(\mathrm{w} / \mathrm{v})$ Triton $\mathrm{X}-100$. The amount of internalized probe was determined by comparing the fluorescence intensity associated with the cells before and after extraction of the probe from the outer monolayer with BSA. The fluorescence intensities were measured at excitation wavelength of $480 \mathrm{~nm}$, and emission wavelength of $525 \mathrm{~nm}$. Integrity of the lipid probes was verified with TLC. No degradation of the probes occurred during the course of the experiments.

\section{Outward movement of $\mathrm{C}_{6}$-NBD-lipid analogues}

Red blood cells were incubated overnight at $20^{\circ} \mathrm{C}$, in the presence of 0.5 $5.0 \mu \mathrm{M}$ C6-NBD-probe. Only $\mathrm{C}_{6}$-NBD-PC, -PE, -PS, -MePE, and DiMePE could be used for this approach, because insufficient quantities of the other probes reached the inner leaflet to allow accurate measurement of outward movement (see discussion). When, the outer leaflet is depleted of NBD-probe by BSA, the amount of probe remaining on the inside is approximately $1 \%$ of the endogenous lipids. After warming the BSAwashed cells for $2 \mathrm{~min}$ at $37^{\circ} \mathrm{C}$, they were activated with $1 \mathrm{mM} \mathrm{CaCl}$ and $2.5 \mu \mathrm{M}$ ionomycin and the outward movement was measured using the BSA back exchange protocol as described for the inward movement. No degradation of the probe occurred during the course of the experiments.

Cholesterol depletion of RBC by $\beta$-methyl-cyclo-dextrin ( $\beta-C D)$ $5^{*} 10^{8} \mathrm{RBC} / \mathrm{mL}$ were incubated with $3.3 \mathrm{mM}$ B-methyl-cyclo-dextrin at $37^{\circ}$ $\mathrm{C}$ for $90 \mathrm{~min}$ (Irie et al., 1982). Cells were washed three times in Hepes buffer and resuspended at $5^{*} 10^{8} \mathrm{RBC} / \mathrm{mL}$. Samples were taken for cholesterol and phosphate determination. Cholesterol content was determined enzymatically by the cholesterol-oxydase assay, using a commercial kit (Boehringer Mannhein, Mannhein, Germany). Phospholipid concentration was determined by the method of Fiske/Subbarrow (Böttcher et al., 1961).

\section{Results}

Synthesis of $C_{6}$-NBD-lipid analogues

Thin layer chromatography of the different $\mathrm{C}_{6}$-NBD-lipid analogues is shown in Fig. 2. For coupling carbohydrates, the yield of synthesis decreases with increasing size of the substituting molecule: $\mathrm{PGal}>\mathrm{PMal}>$ 
PTriose, accompanied by increased phosphatidic acid formation. The yield of synthesis for PGal, PMal, PTriose, and MePE, was 75, 29, 16 and 90\%, respectively. Although maltose and maltotriose have two, respectively three primary $\mathrm{OH}$-groups available for coupling in the transphosphatidylation reaction, we suspect that due to steric hindrance only one of the primary $\mathrm{OH}$-groups is the target for coupling. TLC analysis showed two major spots in the final reaction mixture, identified as the phosphatidyl-carbohydrate and phosphatidic acid. Which of the primary $\mathrm{OH}$-groups of maltose and maltotriose was used for coupling was not further determined since this will not influence the size of the polar head group.

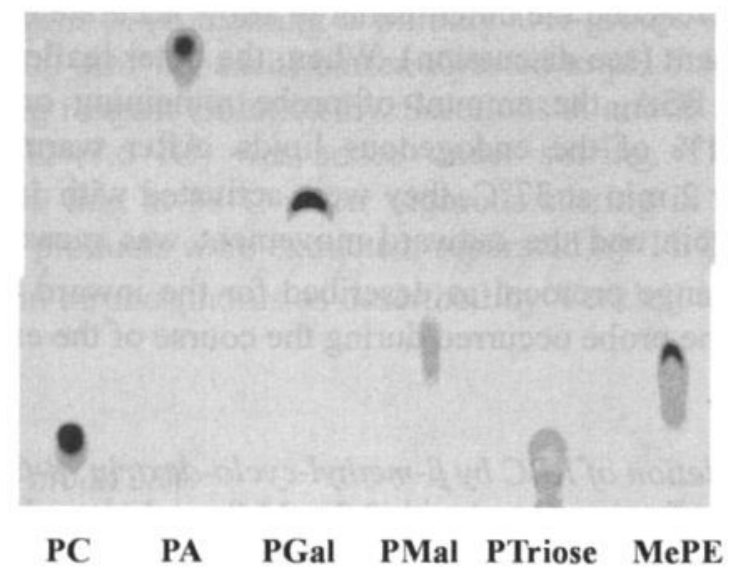

Fig. 2: TLC of the purified $\mathrm{C}_{6}$-NBD-lipid probes on a Silica gel 60 plate eluted with $\mathrm{CHCl}_{3} / \mathrm{MeOH} / \mathrm{HAc} / \mathrm{H}_{2} \mathrm{O}=45 / 20 / 12 / 1$ (v/v/v/v). To discriminate between $\mathrm{C}_{6-}$ NBD-PA, $\mathrm{C}_{6}$-NBD-PC and PGal, PMal, and MePE, the products were first purified by TLC using $\mathrm{CHCl}_{3} / \mathrm{MeOH} / \mathrm{HAc} / \mathrm{H}_{2} \mathrm{O}=45 / 20 / 12 / 1(\mathrm{v} / \mathrm{v} / \mathrm{v} / \mathrm{v})$ as solvent, whereas for PTriose, $\mathrm{CHCl}_{3} / \mathrm{MeOH} / \mathrm{HAc} / \mathrm{H}_{2} \mathrm{O}=45 / 20 / 18 / 1(\mathrm{v} / \mathrm{v} / \mathrm{v} / \mathrm{v})$ was used. The dark areas in the spots are due to self-quenching of the NBD-group.

\section{Inward movement of $C_{6}$-NBD-lipid analogues}

Although the glycophospholipids (PGal, PMal, and PTriose) are rather soluble in water, they were rapidly and virtually completely incorporated in the red blood cell membrane. Once incorporated, these probes are completely extractable by BSA, indicating their presence in the outer 
leaflet of the plasma membrane (data not shown). Fig. 3 shows the inward movement of various NBD-phospholipid analogues upon $\mathrm{Ca}^{2+}$-induced scrambling. Rate and extent of movement are dependent on the size of the headgroup. The inward movement of glycero-phospholipids in calcium/ionophore treated red blood cells decreases from $\mathrm{C}_{6}-\mathrm{NBD}-\mathrm{PE}>$ $\mathrm{C}_{6}$-NBD-PC $>\mathrm{C}_{6}$-NBD-PS $>\mathrm{C}_{6}$-NBD-PGal $>\mathrm{C}_{6}$-NBD-PMal $>\mathrm{C}_{6}$-NBDPTriose. The lipid with the largest headgroup, PTriose hardly reached the inner leaflet whereas the lipid with the smallest headgroup, PE is rapidly migrating over the membrane. In the absence of calcium the inward movement of $\mathrm{C}_{6}$-NBD-lipid probes, with the exception of the aminophospholipids, is negligible within the time course of the experiments. $\mathrm{C}_{6}$-NBD-PA could not be used in this study since it becomes metabolized to diacylglycerol (Pagano et al., 1981; Morrot et al., 1989). It should be mentioned that although the rates and extents of $\mathrm{Ca}^{2+}$-induced lipid scrambling showed some variation between different donors, this did not affect the relative differences between the various NBD-lipid probes.

Although $\mathrm{C}_{6}$-NBD-Spm has the same headgroup as $\mathrm{C}_{6}$-NBD-PC, it hardly undergoes scrambling when the cells are challenged with calcium (Fig. 4). In addition, the inward movement of GalCer was found to be slower than that of PGal, also suggesting that lipids with a ceramide backbone were scrambled much slower than glycero-phospholipids with the same polar headgroup. Binding of Spm to cholesterol may hamper participation in lipid scrambling. To investigate this possibility, red blood cells were preincubated with $\beta$-methyl-cyclo-dextrin, which results in a depletion of approx. $30 \%$ of the total cholesterol content without hemolysis. However, $\mathrm{Ca}^{2+}$-induced lipid scrambling of Spm and PC in these cholesteroldepleted red blood cells was not appreciably different from that in control cells (Data not shown).

\section{Outward movement of $\mathrm{C}_{6}$-NBD-lipid analogues}

In Fig. 5, the kinetics of $\mathrm{Ca}^{2+}$-induced inward and outward movement of $\mathrm{C}_{6}$-NBD-PS, $\mathrm{C}_{6}$-NBD-PC and $\mathrm{C}_{6}$-NBD-PE were compared. While inwardand outward migration of $\mathrm{C}_{6}$-NBD-PC was virtually identical, it appears that the initial inward rate of movement of $\mathrm{C}_{6}$-NBD-PS was significantly slower than its outward movement. The reverse picture is observed for $\mathrm{C}_{6}$ NBD-PE where inward movement considerably exceeds the outward movement. These differences are not due to different amounts of probe present in the inner or outer leaflet at the start of the experiments. Since PC varies from $\mathrm{PE}$ only by its three fold methylated amino group, the effect of progressive methylation on the scrambling behaviour of $\mathrm{C}_{6}$-NBD-PE was determined. 


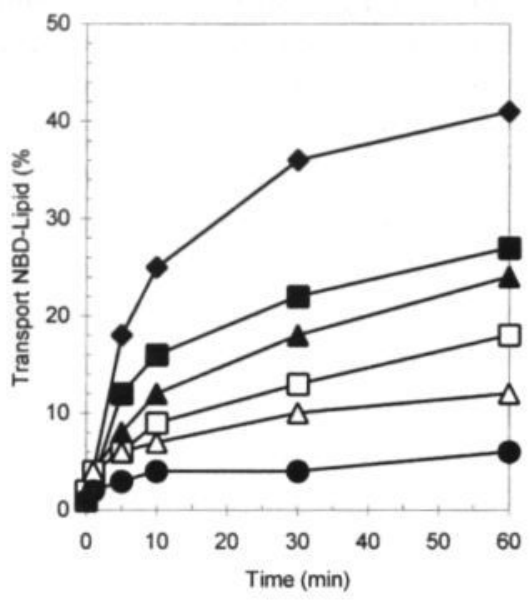

Fig. 3: Inward movement of fluorescent glycero-phospholipid analogues in

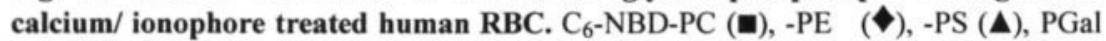
$(\square)$, Pmal $(\Delta)$, PTriose $(\bullet)$. Data shown are from 1 representative experiment out of four so performed; i.e. with red blood cells from one donor at the same day, and repeated three times with cells from other donors.

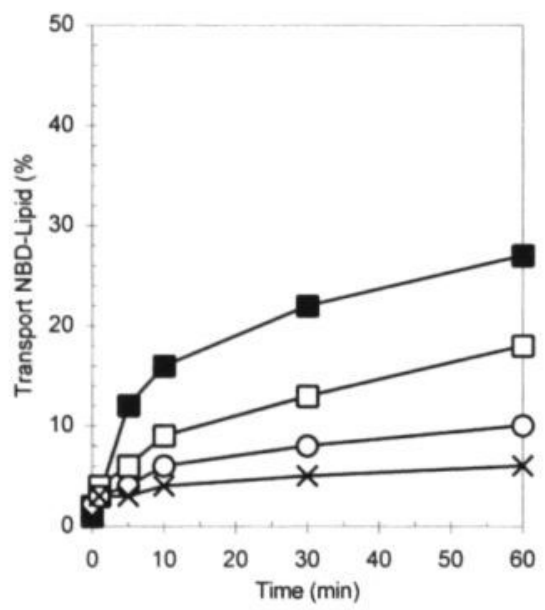

Fig. 4: Comparison of inward movement of fluorescent sphingosine-backbone lipid analogues with glycero-phospholipid analogues in calcium/ionophore treated human RBC. $\mathrm{C}_{6}$-NBD-PC (ש), PGal ( $\square$ ), GalCer (O), Spm (x). Data shown are from 1 representative experiment out of three so performed; i.e. with red blood cells from one donor at the same day, and repeated two times with cells from other donors. 
Fig. 6 shows that mono-methylation of the amino group of PE changes the scrambling behaviour of this lipid probe to become indistinguishable from that of $\mathrm{C}_{6}$-NBD-PC, both with respect to inward and outward movement. The same result was obtained with dimethyl-PE.
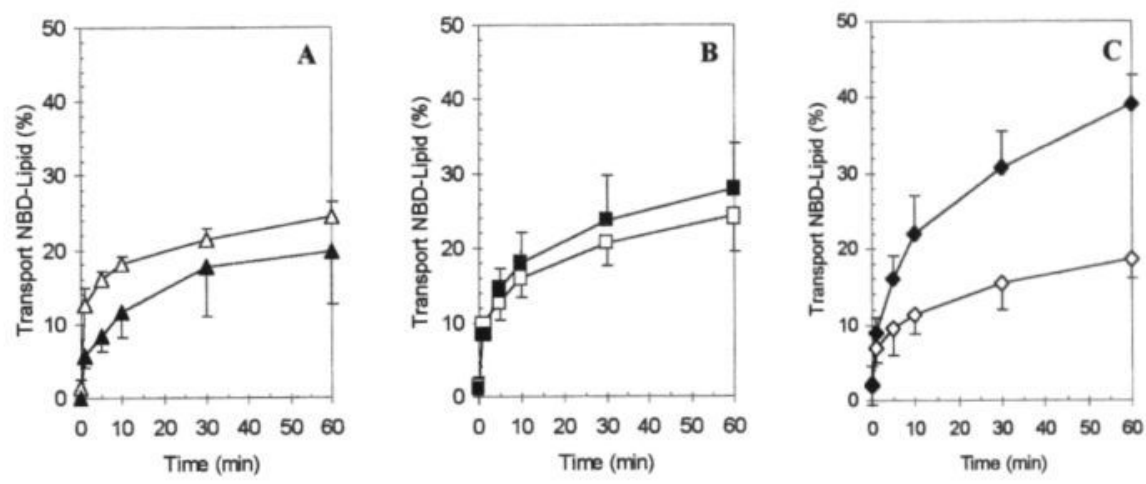

Fig. 5: Comparison between inward (closed symbols) and outward (open symbols) movement of C6-NBD-lipids. C6-NBD-PS $(\boldsymbol{\Lambda}, \Delta)$, C6-NBD-PC $(\boldsymbol{\square}, \square)$ and C6-NBD$\operatorname{PE}(\downarrow, \diamond) A: P S(n=3) ; B: P C(n=3) ; C: P E(n=3)$. Results are shown as the average of 3 experiments $( \pm S D)$ performed with three different donors.

In an effort to measure the outward movement of the glyco-phospholipid analogues, we have used two different protocols aiming to incorporate sufficient fluorescent label on the inside of red blood cell membranes to allow measurement of outward movements. Unfortunately, both protocols were not useful to provide information on the outward movement of these fluorescent lipid probes (see Discussion).

\section{Discussion}

The collapse of lipid asymmetry has been ascribed to the activation of a calcium-dependent lipid scramblase (Comfurius et al., 1996). It is increasingly appreciated that the scramblase is a protein. Reconstitution of protein fractions from both platelet and erythrocyte membranes showed $\mathrm{Ca}^{2+}$-induced lipid scrambling in artificial membranes (Comfurius et al., 1996; Bassé et al., 1996). 


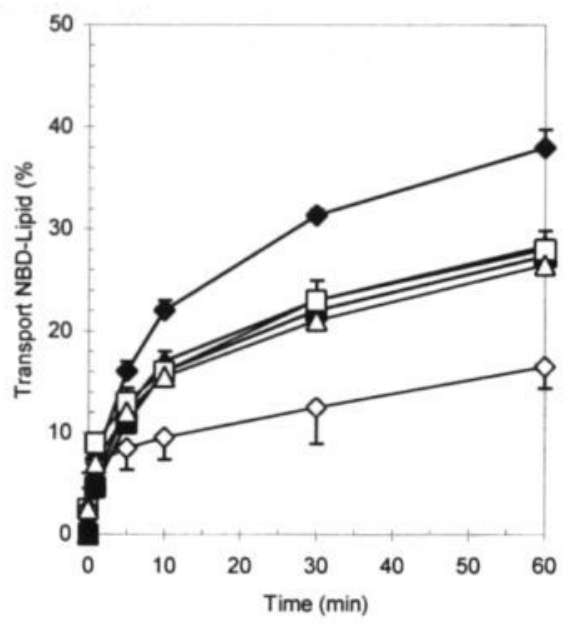

Fig. 6: Effect of methylation of PE on inward (closed symbols) and outward (open symbols) movement. $\mathrm{C}_{6}-\mathrm{NBD}-\mathrm{PC}(\boldsymbol{\square}, \mathbf{\square})(\mathrm{n}=3), \mathrm{C}_{6}$-NBD-PE $(\diamond, \diamond)(\mathrm{n}=3)$ and $\mathrm{C}_{6}$ NBD-MePE $(\boldsymbol{\Lambda}, \Delta)(n=3)$. For reason of clarity, the inward and outward movement of DiMePE are not shown, because they are indistinguishable from those with PC and MePE. Results are shown as the average of 3 experiments $( \pm$ SD) performed with three different donors.

Due to the nonspecificity of the scramblase with respect to the polar headgroup of the lipids, a model has been postulated in which a pore is formed by $\mathrm{Ca}^{2+}$-induced assembly of membrane protein subunits, facilitating bidirectional movement of all lipids (Zwaal and Schroit, 1997). In such a model, scrambling can be envisaged as movement of the lipid polar headgroup through a central aqueous channel, while the acyl chain moieties diffuse along hydrophobic interfaces between the protein subunits.

The relation between the size of the polar headgroup and the rate of inward movement observed in the present study is not inconsistent with the poreforming model described above. Migration of the polar headgroup through an aqueous pore raises the question of whether the permeability for small molecules such as choline or mono-saccharides will also be increased in red blood cells under scrambling conditions. In case of a non-aqueous pore, the observed order in rates of scrambling may reflect differences in 
dehydration energy for the various probes used in this study. In addition to size restriction, migration through a pore may also be dependent on the charge of the headgroup moiety. In the present study, only neutral lipid probes and probes with anionic polar headgroups have been studied. Bevers et al. (Bevers et al., 1990) have shown that the positively charged amphipatic trimethylammonium diphenyl hexatriene (TMH-DPH) is able to cross the plasma membrane of platelets only under scrambling conditions. These observations suggested that the charge of the lipid headgroup is of little importance for $\mathrm{Ca}^{2+}$-induced lipid scrambling.

Differences in the rate of scrambling are not exclusively related to the size of the lipid polar headgroup. Spm, having the same choline headgroup as PC, hardly participates in the scrambling process, at least in red blood cells. Similarly, the rate of scrambling of GalCer was appreciably less than that of PGal, despite its somewhat smaller headgroup (galactose in stead of phospho-galactose). These findings may indicate a diminished recognition by the scramblase of lipids with a ceramide backbone. Alternatively, a decreased rate of scrambling of the ceramide-derived lipids could reflect their preferential localization in rafts (Brown and London, 2000). Associations in rafts with other membrane lipid components such as cholesterol could restrict these lipids to gain access to scrambling sites. This however, is not supported by the present findings showing that a $30 \%$ decrease of the membrane cholesterol content does not increase $\mathrm{Ca}^{2+}$ induced transbilayer movement of Spm, although it can not be excluded that the extent of cholesterol depletion was insufficient to make ceramidederived lipids available for scrambling.

In contrast to red blood cells, a significant rate of inward movement of $\mathrm{C}_{6}$ NBD-Spm was found in platelets activated with calcium/ionophore (Smeets et al., 1994). Moreover, the kinetics of the outward movement of both $\mathrm{C}_{6}$-NBD-Spm and $\mathrm{C}_{6}$-NBD-GalCer in scrambling platelets was found to be indistinguishable from that of $\mathrm{C}_{6}$-NBD-PC (Williamson et al., 1995; Bevers et al., 1999). A possible explanation could be that the platelet plasma membrane contains less Spm and cholesterol and/or is less rich in raft domains. Alternatively, one may speculate that both cells possess different scramblases, although this seems rather unlikely considering that in Scott syndrome the $\mathrm{Ca}^{2+}$-induced scrambling of lipids is impaired in both cell types (Bevers et al., 1992).

Whereas for $\mathrm{C}_{6}$-NBD-PC the rates of outward and inward movement are virtually the same (Fig. 5B), this does not hold for the aminophospholipids: inward scrambling of $\mathrm{C}_{6}$-NBD-PE is much faster and occurs to a larger extent than its outward movement (Fig. 5C). The opposite was found for $\mathrm{C}_{6}$-NBD-PS, were the initial rate of outward movement exceeds that of inward movement, although the difference in 
extent between inward and outward movement was much less pronounced (Fig. 5A). This suggests that the presence of an amino group (and possibly also a carboxy group) has a significant effect on the scrambling behaviour of the phospholipid. This is confirmed by the observation that monomethylation of the free amine of PE makes the kinetics of scrambling of this probe indistinguishable from that of PC (Fig. 6). In an attempt to study the effect of the presence of an amino-group in more detail, we also synthesized $\mathrm{C}_{6}$-NBD-phosphatidyl-galactosamine by phospholipase Dcatalysed transphosphatidylation. However, approximately $15-20 \%$ of the probe was bound irreversibly to the membrane, which hampered interpretation of the results (Data not shown). (Similar irreversible binding was found for $\mathrm{C}_{6}$-NBD-phosphatidylglucose and $\mathrm{C}_{6}$-NBD-GluCer, making these probes unsuitable for these studies (Data not shown)). It should be emphasized also that the $\mathrm{C}_{6}$-NBD-PE probe may not be a very reliable reporter molecule. In contrast to $\mathrm{C}_{12}-\mathrm{NBD}-\mathrm{PE}$ or $\mathrm{C}_{4}$-spin-labelled $\mathrm{PE}$, an anomalous behavior of $\mathrm{C}_{6}$-NBD-PE was observed in studies on the aminophospholipid translocase activity (Colleau et al., 1991; Connor et al., 1992).

Since the spontaneous movement of the glycophospholipid probes was too low to accumulate sufficient fluorescence signal in the inner leaflet to allow reliable measurement of their outward movement, two different protocols were examined: In one protocol, we used resealed ghosts in which probe was trapped in the inner leaflet. In the other protocol, probes were allowed to reach the inner leaflet under scrambling conditions, followed by removal of calcium to stop the scrambling process. However, both approaches were not useful due to strongly enhanced transbilayer movements of all the probes. Apparently, the membranes of resealed ghosts or pre-scrambled red blood cells have different characteristics, which do no longer compare to the membrane of the unperturbed red blood cell.

The group of Hamon et al. (Hamon et al., 2000) showed that $\mathrm{ABC1}$, an ATP-binding-cassette transporter, is involved in $\mathrm{Ca}^{2+}$-induced scrambling of PS and not of PC. Because the process of lipid scrambling in red blood cells is not directly coupled to ATP hydrolysis, whereas transport by $\mathrm{ABC} 1$ is ATP dependent, it is conceivable that both proteins have different functions. Bassé et al. (Bassé et al., 1993) have suggested that the scramblase is specific for aminophospholipids. They showed that in calcium/ionophore activated platelets PS is redistributed rapidly within one minute, whereas movement of PC hardly occurs. Furthermore, Bettache and coworkers (Bettache et al., 1998) showed that $\mathrm{Ca}^{2+}$-induced scrambling of PS is defective in platelets from a patient with Scott 
syndrome whereas the minor redistribution of PC in the patients' cells was found to be similar to that of control cells. However, these observations are not in concordance with those of Smeets et al. (Smeets et al., 1994) and Williamson et al. (Williamson et al., 1995) who showed that PC scrambling in platelets is indistinguishable from PS scrambling, and that scrambling of both lipids is impaired in Scott cells (Bevers et al., 1992). The present findings with red blood cells seem not in line with the apprehension that lipid scrambling is independent on the headgroup moiety, as was previously assumed. It should be emphasized, however, that this notion was based primarily on experiments with platelets, were the high rates of lipid scrambling may have obscured differences in the kinetics of scrambling of the various lipid probes.

\section{REFERENCES}

Bassé, F., Stout, J. G., Sims, P. J., Wiedmer, T. (1996) Isolation of an erythrocyte membrane protein that mediates $\mathrm{Ca}^{2+}$ - dependent transbilayer movement of phospholipid. J. Biol. Chem. 271, 17205-17210.

Bassé, F., Gaffet, P., Rendu, F., and Bienvenue, A. (1993) Translocation of spinlabeled phospholipids through plasma membrane during thrombin- and ionophore A23187-induced platelet activation. Biochemistry 32, 2337-44.

Bennett, M. R., Gibson, D. F., Schwartz, S. M., and Tait, J. F. (1995) Binding and phagocytosis of apoptotic vascular smooth muscle cells is mediated in part by exposure of phosphatidylserine. Circ. Res. 77, 1136-1142.

Bettache, N., Gaffet, P., Allegre, N., Maurin, L., Toti, F., Freyssinet, J. M., and Bienvenue, A. (1998) Impaired redistribution of aminophospholipids with distinctive cell shape change during $\mathrm{Ca}^{2+}$-induced activation of platelets from a patient with Scott syndrome. Brit. J. Haematol. 101, 50-58.

Bevers, E. M., Verhallen, P. F., Visser, A. J., Comfurius, P., Zwaal, R. F. A. (1990) Bidirectional transbilayer lipid movement in human platelets as vizualized by the fluorescent membrane probe 1-[4-(trimethylammonio)phenyl]-6-phenyl-1,3,5hexatriene. Biochemistry 29,5132-5137.

Bevers, E. M., Comfurius, P., Dekkers, D. W. C., and Zwaal, R. F. A. (1999) Lipid translocation across the plasma membrane of mammalian cells. Biochim. Biophys. Acta $1439,317-330$.

Bevers, E. M., Comfurius, P., Van Rijn, J. L. M. L., Hemker, H. C. and Zwaal, R. F. A. (1982) Generation of prothrombin-converting activity and the exposure of phosphatidylserine at the outer surface of platelets. Eur. J. Biochem. 122, 429-436. 
Bevers, E. M., Comfurius, P., and Zwaal, R. F. A. (1983) Changes in membrane phospholipid distribution during platelet activation. Biochim. Biophys. Acta 736, 5766.

Bevers, E. M., Wiedmer, T., Comfurius, P., Shattil, S. J., Weiss, H. J., Zwaal, R. F. A., and Sims, P. J. (1992) Defective $\mathrm{Ca}^{2+}$-induced microvesiculation and deficient expression of procoagulant activity in erythrocytes from a patient with a bleeding disorder: a study of the red blood cells of Scott syndrome. Blood 79, 380-8.

Bevers, E. M., Wiedmer, T., Comfurius, P., Zhao, J., Smeets, E. F., Schlegel, R. A., Schroit, A. J., Weiss, H. J., Williamson, P., and Zwaal, R. F. A. (1995) The complex of phosphatidylinositol 4,5-bisphosphate and calcium ions is not responsible for $\mathrm{Ca}^{2+}$ induced loss of phospholipid asymmetry in the human erythrocyte: a study in Scott syndrome, a disorder of $\mathrm{Ca}^{2+}$-induced phospholipid scrambling. Blood 86, 1983-91.

Böttcher, C. J. F., van Gent, C. M., and Pries, C. (1961) A rapid and sensitive submicro phosphorus determination. Anal. Chim. Acta 24, 203-204.

Brown, D. A., and London, E. (2000) Structure and function of sphingolipid- and cholesterol-rich membrane rafts. J. Biol. Chem. 275, 17221-17224.

Chandra, R., Joshi, P. C., Bajpai, V. K., and Gupta, C. M. (1987) Membrane phospholipid organization in calcium-loaded human erythrocytes. Biochim. Biophys. Acta 902, 253-262.

Chang, C.-P., Zhao, J., Wiedmer, T., and Sims, P. J. (1993) Contribution of platelet microparticle formation and granule secretion to the transmembrane migration of phosphatidylserine. J. Biol. Chem. 268, 7171-7178.

Colleau, M., Herve, P., Fellmann, P. and Devaux, P. F. (1991) Transmembrane diffusion of fluorescent phospholipids in human erythrocytes. Chem. Phys. Lipids 57, 29-37.

Comfurius, P., and Zwaal, R. F. A. (1977) The enzymatic synthesis of phosphatidylserine and purification by CM-cellulose column chromatography. Biochim. Biophys. Acta 488, 36-42.

Comfurius, P., Senden J. M. G., Tilly R. H. J., Schroit A. J., Bevers E. M., and Zwaal R. F. A. (1990) Loss of membrane phospholipid asymmetry in platelets and red cells may be associated with calcium-induced shedding of plasma membrane and inhibition of aminophospholipid translocase. Biochim. Biophys. Acta 1026, 153-160.

Comfurius, P., Williamson, P., Smeets, E. F., Schlegel, R. A., Bevers, E. M., and Zwaal, R. F. A. (1996) Reconstitution of phospholipid scramblase activity from human blood platelets. Biochemistry $35,7631-4$. 
Connor, J., Pak, C. H., Zwaal, R. F. A., and Schroit, A. J. (1992) Bidirectional transbilayer movement of phospholipid analogs in human red blood cells. Evidence for an ATP-dependent and protein-mediated process. J. Biol. Chem. 267, 19412-7.

Dekkers, D. W. C., Comfurius, P., van Gool, R. G. J., Bevers, E. M., and Zwaal, R. F. A. (2000) Multidrug resistance protein 1 regulates lipid asymmetry in erythrocyte membranes. Biochem. J. 350, 531-535.

Dekkers, D. W. C., Comfurius, P., Schroit, A. J., Bevers, E. M., and Zwaal, R. F. A. (1998) Transbilayer movement of NBD-labeled phospholipids in red blood cell membranes: outward-directed transport by the multidrug resistance protein 1 (MRP1). Biochemistry 37, 14833-7.

Fadok, V. A., Voelker, D. R., Campbell, P. A., Cohen, J. J., Bratton, D. L., and Henson, P. M. (1992) Exposure of phosphatidylserine on the surface of apoptotic lymphocytes triggers specific recognition and removal by macrophages. J. Immunol. 148, 22072216.

Geldwerth, D., Kuypers, F. A., Butikofer, P., Allary, M., Lubin, B. H., and Devaux, P. F. (1993) Transbilayer mobility and distribution of red cell phospholipids during storage. J. Clin. Invest. 92, 308-14.

Hamilton, K. K., Hattori, R., Esmon, C. T., and Sims, P. J. (1990) Complement proteins C5b-9 induce vesiculation of the endothelial plasma membrane and expose catalytic surface for assembly of the prothrombinase enzyme complex. J. Biol. Chem. $265,3809-14$.

Hamon, Y., Broccardo, C., Chambenoit, O., Luciani, M. F., Toti, F., Chaslin, S., Freyssinet, J. M., Devaux, P. F., McNeish, J., Marguet, D., and Chimini, G. (2000) $\mathrm{ABCl}$ promotes engulfment of apoptotic cells and transbilayer redistribution of phosphatidylserine. Nature Cell Biol. 2, 399-406.

Irie, T., Otagiri, M., Sunada, M., Uekama, K., Ohtani, Y., Yamada, Y., and Sugiyama, Y. (1982) Cyclodextrin-induced hemolysis and shape changes of human erythrocytes in vitro. J. Pharm. Dyn. 5, 741-744.

Killian, J. A. (1998) Hydrophobic mismatch between proteins and lipids in membranes. Biochim. Biophys. Acta 1376, 401-416.

Kuypers, F. A., Schott, M. A., and Scott, M. D. (1996) Phospholipid composition and organization in model beta-thalassemic erythrocytes. Am. J. Hematol. 51, 45-54.

Middelkoop, E., Lubin, B. H., Op den Kamp, J. A. F., and Roelofsen, B. (1986) Flipflop rates of individual molecular species of phosphatidylcholine in the human red cell membrane. Biochim. Biophys. Acta 855, 421-424.

Morrot, G., Herve P., Zachowski A., Fellmann P., and Devaux P. F. (1989) Aminophospholipid translocase of human erythrocytes: Phospholipid substrate specificity and effect of cholesterol. Biochemistry 28, 3456-3462. 


\section{Chapter 3}

Pagano, R. E., Longmuir, K. J., Martin O. C., and Struck, D. K. (1981) Metabolism and intracellular localization of a fluorescently labeled intermediate in lipid biosynthesis within cultered fibroblasts. J. Cell Biol. 91, 872-877.

Schroit, A. J., and Zwaal, R. F. A. (1991) Transbilayer movement of phospholipids in red cell and platelet membranes. Biochim. Biophys. Acta 1071, 313-29.

Smeets, E. F., Comfurius, P., Bevers, E. M., and Zwaal, R. F. A. (1994) Calciuminduced transbilayer scrambling of fluorescent phospholipid analogs in platelets and erythrocytes. Biochim. Biophys. Acta 1195, 281-6.

VanDeWater, L., Tracy, P. B., Aronson, D., Mann, K. G., and Dvorak, H. F. (1985) Tumor cell generation of thrombin via functional prothrombinase assembly. Cancer Res. 45, 5521-5.

Verkleij, A. J., Zwaal, R. F. A., Roelofsen, B., Comfurius, P., Kastelijn, D., and Deenen van, L. L. M. (1973) The asymmetric distribution of phospholipids in the human red cell membrane. A combined study using phospholipases and freeze-etch electron microscopy. Biochim. Biophys. Acta 323, 178-193.

Williamson, P., Algarin, L., Bateman, J., Choe, H-R. and Schlegel, R. A. (1985) Phospholipid asymmetry in human erythrocyt ghosts. J. Cell. physiol. 123, 209-214.

Williamson, P., Bevers, E. M., Smeets, E. F., Comfurius, P., Schlegel, R. A., and Zwaal, R. F. A. (1995) Continuous analysis of the mechanism of activated transbilayer lipid movement in platelets. Biochemistry $34,10448-55$

Zwaal, R. F. A., and Schroit, A. J. (1997) Pathophysiologic implications of membrane phospholipid asymmetry in blood cells. Blood 89, 1121-32. 


\section{Chapter 4}

Impaired $\mathrm{Ca}^{2+}$-induced tyrosine phosphorylation and defective lipid scrambling in erythrocytes from a patient with Scott syndrome.

A study using an inhibitor for scramblase that mimics the defect in Scott syndrome.

David W. C. Dekkers, Paul Comfurius, Wim M. J. Vuist, Jeffrey T. Billheimer, Ira Dicker, Harvey J. Weiss, Robert F. A. Zwaal and Edouard M. Bevers (1998) Blood 91, 1-7

The authors wish to dedicate this paper to the memory of Mrs. Mary Ann Scott.

Abstract: Scott syndrome is a hereditary bleeding disorder characterized by a deficiency in platelet procoagulant activity. Unlike normal blood cells, Scott platelets, as well as erythrocytes and lymphocytes, are strongly impaired in their ability to scramble their membrane phospholipids when challenged with $\mathrm{Ca}^{2+}$. In normal cells this collapse of membrane asymmetry leads to surface exposure of phosphatidylserine. Here we report that Scott erythrocytes show an apparent defect in tyrosine phosphorylation on treatment with $\mathrm{Ca}^{2+}$ ionophore. Diminished tyrosine phosphorylation was also apparent in activated Scott platelets, but much less pronounced than observed in red blood cells. On the other hand, tyrosine phosphorylation profiles observed in Scott red blood cell ghosts, after sealing in the presence of adenosine triphosphate (ATP) were indistinguishable from those obtained from normal ghosts. Several observations argue in favor of a 
mechanism in which tyrosine phosphorylation in red blood cells is facilitated by, rather than required for scrambling of membrane lipids. Staurosporin blocks tyrosine phosphorylation in normal red blood cells, but does not inhibit the lipid scrambling process. White ghosts from normal erythrocytes, resealed in the absence of ATP, exhibit $\mathrm{Ca}^{2+}$-induced lipid scrambling without tyrosine phosphorylation. A selective inhibitor of $\mathrm{Ca}^{2+}$-induced lipid scrambling also showed an apparent inhibition of tyrosine phosphorylation in ionophore-treated normal red blood cells, similar as observed in Scott erythrocytes. While this inhibitor also suppressed $\mathrm{Ca}^{2+}$-induced lipid scrambling in ghosts that were sealed in the presence of ATP, it did not inhibit tyrosine kinase activity. We conclude that the apparent deficiency in tyrosine phosphorylation in Scott cells is an epiphenomenon, possibly associated with a defect in phospholipid scrambling, but not causal to this defect. 


\section{Introduction}

Membrane phospholipid asymmetry is a seemingly ubiquitous phenomenon that is generated by an adenosine triphosphate (ATP)dependent lipid pump, which specifically shuttles aminophospholipids to the cytoplasmic membrane leaflet. Influx of calcium, however, inhibits this aminophospholipid translocase activity, and activates a lipid scramblase, that produces a progressive loss of lipid asymmetry. This process exposes phosphatidylserine at the outer surface, which can promote assembly on the membrane of the tenase- and prothrombinase complex of the blood coagulation cascade. This assembly dramatically enhances the rate of thrombin formation, responsible for the procoagulant activity of activated platelets (Devaux and Zachowski, 1994; Williamson and Schlegel, 1994; Zwaal and Schroit, 1997).

A deficiency in platelet procoagulant activity associated with a bleeding disorder was first described by Weiss et al., (Weiss, 1994; Weiss et al., 1979 ) and is presently referred to as Scott syndrome. On activation, Scott platelets show a strongly decreased lipid scrambling with little surface exposure of phosphatidylserine (Rosing et al., 1985). Moreover, these platelets express a considerably decreased number of factor Va (Miletich et al., 1979) and factor VIIIa (Ahmad et al., 1989) binding sites and are markedly deficient in their ability to promote both tenase and prothrombinase activity in response to agonists (Rosing et al., 1985). They also exhibit an impaired capacity to shed membrane-derived lipidsymmetric microvesicles, a process often associated with lipid scrambling (Sims et al., 1989). Recent studies on a newly discovered family suggest that Scott syndrome is an inherited bleeding disorder transmitted as an autosomal recessive trait (Toti et al., 1996), and this may also be the case in the family of the originally described patient with this disorder (Weiss and Lages, 1997). The defect is not restricted to platelets, but can also be demonstrated in the patients' erythrocytes and lymphocytes (Bevers et al., 1992; Kojima et al., 1994). The observation that, unlike normal red blood cell ghosts, resealed ghosts from Scott erythrocytes do not show $\mathrm{Ca}^{2+}$ induced scrambling of membrane phospholipids implies that the lesion resides in the plasma membrane or in the tightly associated cytoskeleton (Bevers et al., 1992). Indeed, proteins fractionated from platelet or red blood cell membranes have been reconstituted in artificial lipid vesicles, which exhibited $\mathrm{Ca}^{2+}$-induced lipid scrambling activity (Bassé, 1996; Comfurius et al., 1996). Recently, it was shown that proteoliposomes reconstituted from red blood cells from Scott syndrome resulted in similar $\mathrm{Ca}^{2+}$-inducible lipid scrambling as observed for reconstitutes from normal 
red blood cells (Stout et al., 1997). Moreover, acidification caused $\mathrm{Ca}^{2+}$ independent lipid scrambling in both proteoliposomes and inside-out vesicles derived from normal and Scott erythrocytes, suggesting that the defect in Scott syndrome is caused by an impaired regulatory mechanism rather than the absence of a membrane protein responsible for lipid scrambling.

While hydrolyzable ATP does not seem to be required for lipid scrambling, it has been reported that prolonged ATP depletion of erythrocytes results in markedly diminished $\mathrm{Ca}^{2+}$-induced randomization of lipids (Martin and Jesty, 1995; Sulpice et al., 1994). Because this may suggest a possible involvement of phosphorylated protein(s), it was intriguing to observe a severely impaired tyrosine phosphorylation in Scott erythrocytes after treatment with $\mathrm{Ca}^{2+}$-ionophore. The present study shows that the aberrant tyrosine phosphorylation is a consequence rather than a cause of a defective lipid scrambling process.

\section{Materials and Methods}

\section{Materials}

Ionomycin and bovine serum albumin (BSA; Globulin and fatty acid free) were obtained from Sigma Chemicals \& Co (St Louis, MO). Coagulation factors thrombin, prothrombin, factor $\mathrm{Xa}$, and factor Va were purified from bovine blood as described elsewhere (Rosing et al., 1980). Thrombin-specific chromogenic substrate, S2238, was obtained from AB Kabi Diagnostica (Stockholm, Sweden). Sodium orthovanadate was from Janssen Chimica (Geel, Belgium). NBD-PS: 2-(12-(7-nitrobenz-2-oxa-1,3diazol-4-yl)amino)dodecanoyl-1-oleoyl-sn-glycero-3-phosphoserine was obtained from Avanti Polar Lipids (Alabaster, AL). R5421, ethanimidothioic acid $\mathrm{N}$-([N-butylthio-N-methylamino)-carbonyloxy]methyl ester (see insert Fig. 3 for formula) was from Dupont-Merck (Wilmington, DE). Monoclonal anti-phosphotyrosine antibody (4G10) was obtained from UBI (Lake Placid, NY). Enhanced chemiluminescence (ECL) materials were from Amersham PLC (Aylesbury, UK). All other reagents were of the highest grade commercially available.

\section{Isolation of erythrocytes and preparation of resealed ghosts}

Washed human red blood cells were obtained by differential centrifugation of whole blood collected on citrate $(3.8 \%)$ from healthy volunteers. Blood from patient MS and appropriate control samples were shipped at $4^{\circ} \mathrm{C}$ by air express to Maastricht and processed immediately on 
arrival. After washing in TEMS8 buffer (50 mM TRIS, $120 \mathrm{mM} \mathrm{NaCl}, 2$ $\mathrm{mM} \mathrm{MgCl}, 0.2 \mathrm{mM}$ EGTA, adjusted at $\mathrm{pH} 8.0$ ), erythrocytes were finally resuspended at $10 \%$ hematocrit and stored on ice. Cells were used within one day. Ghosts were prepared by hypotonic shock in ice-cold lysis buffer (5 mM TRIS, $12 \mathrm{mM} \mathrm{NaCl}, 2 \mathrm{mM} \mathrm{MgCl} 2,0.2 \mathrm{mM}$ EGTA). After $15 \mathrm{~min}$ on ice, tonicity was restored by adding one tenth volume $9 \% \mathrm{NaCl}$, followed by incubation at $37^{\circ} \mathrm{C}$ for $15 \mathrm{~min}$. In some experiments ATP $(0.05-2.0 \mathrm{mM})$ and/or R5421 $(0.1 \mathrm{mM})$ was added before resealing. Resealed ghosts were collected by centrifugation at $2250 \mathrm{xg}$ for $20 \mathrm{~min}$ and washed three times in TEMS8 buffer. Ghost concentration was adjusted at $1 \times 10^{9} \mathrm{ml}^{-1}$.

Erythrocytes and resealed ghosts were incubated at a concentration of $1 \times 10^{9} \mathrm{ml}^{-1}$ with ionomycin (final concentration $5 \mu \mathrm{M}$ ) in the presence of 1 $\mathrm{mM} \mathrm{CaCl}{ }_{2}$ at $37^{\circ} \mathrm{C}$.

\section{Preparation of washed platelets}

Platelets were isolated from patient MS and an appropriate control by differential centrifugation of whole blood, according to Bevers et al. (Bevers et al., 1983). Because shipment of the blood samples took approx. $48 \mathrm{hrs}$, the blood was collected in citrate to avoid a prolonged period of acidity. Before centrifugation, acid citrate dextrose (ACD: $0.18 \mathrm{M}$ glucose, $0.08 \mathrm{M}$ trisodium citrate, $0.052 \mathrm{M}$ citric acid) was added to the blood in a ratio 1:5 (v/v). Washed platelets were finally resuspended in a Hepes buffer $(136 \mathrm{mM} \mathrm{NaCl}, 2.7 \mathrm{mM} \mathrm{KCl}, 2 \mathrm{mM} \mathrm{MgCl}, 10 \mathrm{mM}$ Hepes, $0.1 \mathrm{mM}$ EGTA, $5 \mathrm{mM}$ glucose and $0.05 \%(\mathrm{w} / \mathrm{v})$ human serum albumin, $\mathrm{pH} 7.5)$, and diluted to a final concentration of $5 \times 10^{8}$ platelets $/ \mathrm{ml}$

\section{Measurement of prothrombinase activity}

The rate of conversion of prothrombin to thrombin by the enzyme complex factor Xa-factor Va has been shown to be a convenient, rapid, and sensitive method to monitor in a semiquantitative way the extent of exposure of phosphatidylserine at the outer cell surface (Bevers et al., 1983). Briefly, $1 \times 10^{7} \mathrm{~mL}^{-1}$ erythrocytes (or resealed ghosts) were incubated at $37^{\circ} \mathrm{C}$ with factor $\mathrm{Xa}$ and factor $\mathrm{Va}$ at a final concentration of 3 and $6 \mathrm{nM}$, respectively, for $1 \mathrm{~min}$ in the presence of $3 \mathrm{mM} \mathrm{CaCl}_{2}$. The reaction was started by addition of prothrombin (final concentration 4 $\mu \mathrm{M}) ; 1$ min after addition of prothrombin, a sample from the incubation mixture was transferred to a cuvette containing $1 \mathrm{~mL}$ buffer composed of $50 \mathrm{mM}$ TRIS, $120 \mathrm{mM} \mathrm{NaCl}$ and $2 \mathrm{mM}$ EDTA (pH 8.0). The amount of thrombin formed was determined by measuring the change in absorbance 
at $405 \mathrm{~nm}$ caused by the conversion of a thrombin-specific substrate, $\mathrm{S} 2238(0.2 \mathrm{mM})$.

\section{Measurement of scramblase activity in platelets}

A continuous assay for scrambling of platelet lipids was based on reduction of a fluorescent lipid probe (NBD-PS) by dithionite as previously described by Williamson et al. (Williamson et al., 1995). Washed platelets resuspended in Hepes buffer in absence of albumin were preincubated with $0.5 \mathrm{mM}$ phenylmethylsulfonyl fluoride (PMSF) prior to labeling with $1 \mu \mathrm{M}$ NBD-PS. Addition of PMSF was required to prevent degradation of probe once it has been internalized by the action of the aminophospholipid translocase. Platelets $\left(2 \times 10^{8} \mathrm{~mL}^{-1}\right)$ were loaded with NBD-PS for $45 \mathrm{~min}$ at $37^{\circ} \mathrm{C}$, followed by an additional incubation period of $45 \mathrm{~min}$ in the presence or absence of R5421. A total of $50-100 \mu \mathrm{L}$ of NBD-PS-labeled platelets were diluted in $2 \mathrm{~mL}$ of Hepes buffer and placed in the fluorimeter at $37^{\circ} \mathrm{C}$ under continuous stirring and fluorescence was monitored at $534 \mathrm{~nm}\left(\lambda_{\mathrm{ex}} 472 \mathrm{~nm}\right)$. At $60 \mathrm{sec}$, dithionite was added to a final concentration of $5 \mathrm{mM}$ to quench NBD-PS present in the membrane outer leaflet. At $\mathrm{t}=90 \mathrm{sec}$, ionomycin was added $(1 \mu \mathrm{M}$ final concentration) and the scrambling process was started by addition of 1 $\mathrm{mM} \mathrm{CaCl}_{2}$ at $\mathrm{t}=120 \mathrm{sec}$. Fluorescence intensity was monitored for $7.5 \mathrm{~min}$ after which Triton X100 was added to a final concentration of $1 \%$ to make all of the NBD-PS available to dithionite. To determine $\mathrm{IC}_{50}$ and half-time of R5421 inhibition, rate of scrambling activity was analyzed as the initial slope of the fluorescence decay after addition of $\mathrm{Ca}^{2+}$.

\section{Tyrosine Phosphorylation}

Protein-tyrosine phosphorylation was detected after sodium dodecyl sulfate-polyacrylamide gel electrophoresis (SDS-PAGE) and Western blotting. Briefly, after the ionomycin treatment of intact erythrocytes, 0.2 mM PMFS was added and cells were lysed by addition of $20 \mathrm{vol}$ ice-cold lysis buffer. Ghosts were collected and washed once by centrifugation (30000xg for $15 \mathrm{~min})$. After resuspension, one fifth volume of electrophoresis sample buffer (312.5 mM TRIS, 50\% (v/v) glycerol, $15 \%$ $(\mathrm{w} / \mathrm{v})$ sodium dodecyl sulfate, $0.17 \mathrm{mg} / \mathrm{mL}$ Bromphenol blue, $50 \mathrm{mM}$ dithiothreitol, $\mathrm{pH}$ 6.8) was added. Samples for electrophoresis from incubations with resealed ghosts $\left(1 \times 10^{9} \mathrm{~mL}^{-1}\right)$ or platelets $\left(5 \times 10^{8} \mathrm{~mL}^{-1}\right)$ were prepared by addition of one fifth volume of electrophoresis buffer to the incubation mixture. Proteins were separated by SDS-PAGE on $7.5 \%$ gels and transferred to nitrocellulose. After blocking with $3 \%$ bovine serum albumin for $1 \mathrm{~h}$, blots were incubated with the anti-phosphotyrosine 
antibody, 4G10 $(0.04 \mu \mathrm{g} / \mathrm{mL})$ and after extensive washing incubated with a biotinylated goat-anti-mouse antibody. Immunoreactive proteins were detected by streptavidine horseradish peroxidase, visualized by ECL (Amersham) according to the manufacturer's procedure.

\section{Results and discussion}

Incubation of human erythrocytes with $\mathrm{Ca}^{2+}$-ionophore results in a rapid phosphorylation of tyrosine residues in certain membrane proteins of which band 3 appears to be the most prominent (Dekowski et al., 1983; Mohamed and Steck, 1986). We have compared the phosphorylation patterns of erythrocytes from healthy individuals with those from a patient with Scott syndrome by Western blots using a monoclonal antibody specific for phosphotyrosine residues. Fig. 1, left panel, shows that tyrosine phosphorylation is severely impaired in the patients' red blood cells after treatment with $\mathrm{Ca}^{2+}$-ionophore (lanes 1-4). This raises the question whether this impaired phosphorylation is related to the lack of $\mathrm{Ca}^{2+}$-induced lipid scrambling in the patients' blood cells, as shown by the lack of phosphatidylserine exposure monitored by prothrombinase (Fig. 1, right panel).

To investigate if the impaired tyrosine phosphorylation observed in Scott erythrocytes is caused by a deficiency in one or more of the tyrosine kinases, we tested tyrosine phosphorylation in hemoglobin-free ('white') erythrocyte ghosts. The major tyrosine kinase activity in erythrocytes appears membrane associated, and direct phosphorylation can be observed in non-sealed ghost preparations following addition of Mg-ATP (Zipser and Kosower, 1996). For this purpose we used $\mathrm{Ca}^{2+}$-free ghosts as a substrate, because tyrosine phosphorylation in $\mathrm{Ca}^{2+}$-loaded ghosts is too low to detect a possible deficiency of tyrosine kinase activity in Scott syndrome. As shown in Fig. 2, similar phosphorylation patterns were found for both Scott - and control ghosts when incubated with increasing amounts of ATP. Because red blood cell ghosts still contain protein tyrosine phosphatase activity associated to band 3 (Zipser and Kosower, 1996), the level of protein phosphotyrosine is determined by the activity of protein tyrosine kinases and the opposing activity of protein tyrosine phosphatases. 

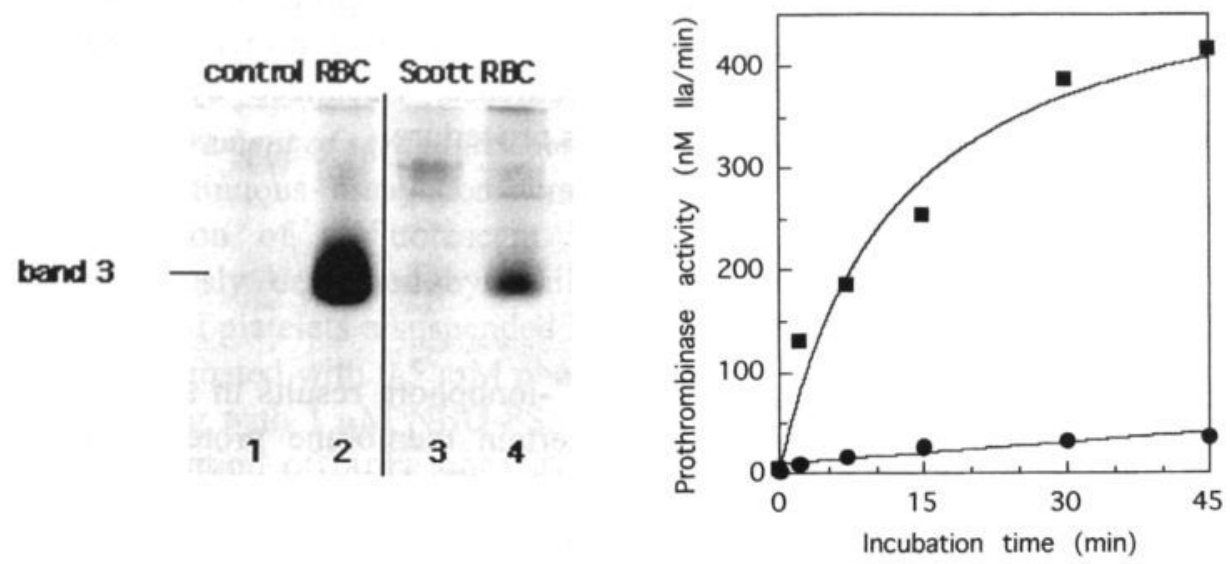

Fig. 1: Tyrosine phosphorylation of membrane proteins and development of prothrombinase activity in normal erythrocytes and erythrocytes from Scott syndrome incubated with $\mathrm{Ca}^{2+}$ - ionomycin. Washed cells were incubated with ionomycin in the presence of $\mathrm{Ca}^{2+}$ as described in materials and methods, and samples were taken at $15 \mathrm{~min}$ for analysis of tyrosine phosphorylation and at various time intervals for measuring prothrombinase activity as a measure for surface exposed phosphatidylserine. Phosphorylation patterns in red blood cells did not appreciably change on varying the incubation time from 5 to $30 \mathrm{~min}$. Left panel: normal erythrocytes in the absence (lane 1) and presence of $\mathrm{Ca}^{2+}$-ionomycin (lane 2) and Scott erythrocytes in the absence (lane 3 ) and presence of $\mathrm{Ca}^{2+}$-ionomycin (lane 4). Right panel: time course of appearance of prothrombinase activity in normal (घ) and Scott erythrocytes $(\bullet)$.

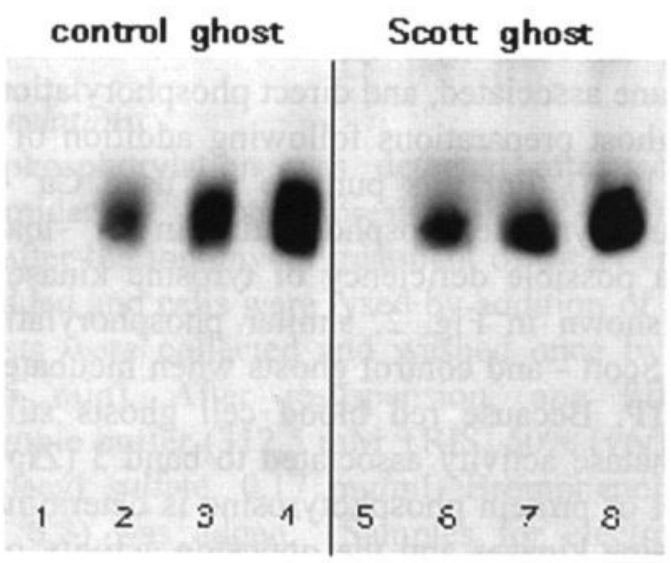

Fig. 2: Western blots showing tyrosine phosphorylation in control (lanes 1-4) and Scott erythrocyte ghosts (lanes 5-8) after a $15 \mathrm{~min}$ incubation period with increasing concentrations of ATP: $0.05 \mathrm{mM}$ (lanes 1 and 5); $0.5 \mathrm{mM}$ (lanes 2 and 6); $1,0 \mathrm{mM}$ (lanes 3 and 7) and 2,0 $\mathrm{mM}$ (lanes 4 and 8). 
As expected, addition of $\mathrm{Mn}^{2+}$ and $\mathrm{VO}_{4}{ }^{3-}$, known inhibitors of tyrosine phosphatase (Mohamed and Steck, 1986; Zipser and Kosower, 1996), causes higher levels of phosphorylation, but again no difference was found between control and Scott ghosts. While these data suggest that neither enzyme is defective in the patients' red blood cell ghosts, it can at present not be excluded that diminished phosphorylation in Scott erythrocytes reflects a difference in either a cytosolic kinase or phosphatase (or regulatory component) that is washed away from intact erythrocytes on preparing ghosts. However, the data from both intact cells and ghosts strongly suggest that tyrosine phosphorylation is not required for lipid scrambling. This is supported by two additional observations. First, incubation of normal erythrocytes with staurosporin at a concentration of $5 \mu \mathrm{M}$, which completely blocks tyrosine kinase activity, does not prevent the generation of prothrombinase activity induced by $\mathrm{Ca}^{2+}$-ionophore. Second, white ghosts from normal erythrocytes resealed in the absence of ATP retain the ability to scramble their phospholipids upon $\mathrm{Ca}^{2+}$-influx (Bevers et al., 1992), while no tyrosine phosphorylation can occur under these conditions.

It should be realized, however, that the identity of the (membrane) protein(s) involved in the collapse of membrane lipid asymmetry is still obscure, and these proteins may escape detection by the phosphotyrosine Western blots. Although our observations rule out that lipid scrambling requires stimulus-response coupled tyrosine phosphorylation, it cannot be excluded that the putative protein(s) involved in scramblase activity are already phosphorylated prior to cell activation. Such involvement of constitutively phosphorylated proteins may explain why red blood cells gradually lose their ability to undergo $\mathrm{Ca}^{2+}$-induced lipid scrambling on prolonged ATP deprivation (Martin and Jesty, 1995; Sulpice et al., 1994). While impaired tyrosine phosphorylation does not underlie defective $\mathrm{Ca}^{2+}$ induced lipid scrambling in erythrocytes from Scott syndrome, it cannot be ruled out that the impaired tyrosine phosphorylation results from defective scrambling. To address this question, experiments were performed using $\mathrm{R} 5421$, which was found to inhibit $\mathrm{Ca}^{2+}$-induced lipid scrambling in erythrocytes and platelets. R5421 was found after screening a variety of organic compounds using, both prothrombinase assay and the assay for scramblase activity described in materials and methods. Its pharmacology and mechanism of action is as yet unknown. 

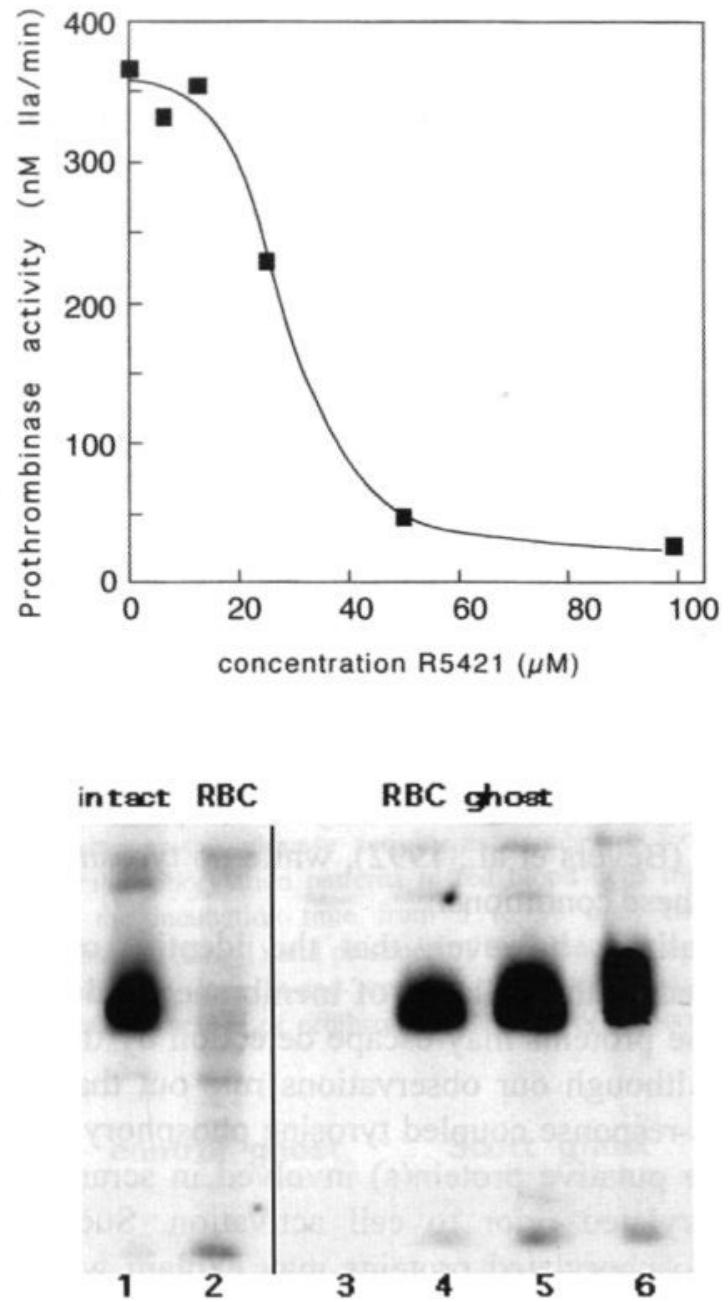

Fig. 3: Upper panel: Inhibition of $\mathrm{Ca}^{2+}$-ionomycin-induced prothrombinase activity in control erythrocytes by compound R5421. Cells were incubated with increasing concentrations of R5421 for $10 \mathrm{~min}$, followed by ionomycin $(5 \mu \mathrm{M})$ in the presence of $\mathrm{Ca}^{2+}(1 \mathrm{mM})$ for $60 \mathrm{~min}$. Subsequently, samples were analyzed for prothrombinase activity as described in materials and methods. Insert: structural formula of compound R5421.

Lower panel: Tyrosine phosphorylation in control erythrocytes incubated for $\mathbf{1 5}$ min with $\mathrm{Ca}^{2+}$-ionomycin in the absence (lane 1) and presence (lane 2) of $\mathbf{R 5 4 2 1}$ $(0.1 \mathrm{mM})$. Lanes 3-6 represent phosphorylation patterns of white ghosts incubated with four different concentrations of ATP (0.05 mM ATP, lane 3; $0.5 \mathrm{mM} \mathrm{ATP,} \mathrm{lane} \mathrm{4;} 1.0$ $\mathrm{mM} \mathrm{ATP}$, lane 5 and $2.0 \mathrm{mM} \mathrm{ATP}$, lane 6$)$, all in the presence of R5421 (0.1 mM). Contrary to the incubations with intact cells, the experiments with ghosts were performed in the absence of $\mathrm{Ca}^{2+}$ to ensure sufficient levels of phosphorylation (see text). 
Fig. 3 (upper panel) shows the effect of increasing concentrations of $\mathrm{R} 5421$ on the $\mathrm{Ca}^{2+}$-ionophore-induced prothrombinase activity in intact normal erythrocytes. An $\mathrm{IC}_{50}$ of $35 \mu \mathrm{M}$ was found while complete inhibition was observed at a concentration of $100 \mu \mathrm{M}$. Similar results were obtained when intact erythrocytes were replaced by resealed ghosts. R5421 at concentrations up to $200 \mu \mathrm{M}$ did not inhibit the prothrombinase assay in the presence of artificial lipid vesicles. As shown in Fig. 3 (lower panel), R5421 causes a dramatic decrease in tyrosine phosphorylation upon $\mathrm{Ca}^{2+}$-influx into normal erythrocytes (lanes 1 and 2). To investigate whether R5421 is a direct inhibitor of the major tyrosine kinase in erythrocytes (or activator of tyrosine phosphatase), we measured the effect of R5421 on tyrosine phosphorylation in 'white' ghosts incubated with ATP. As shown in Fig. 3 (right panel, lanes 3-6), no appreciable difference relative to ghosts without R5421 (Fig. 2) was found. Again, these findings do not rule out a possible effect of R5421 on cytosolic kinase or phosphatase activities.

The present data may indicate that $\mathrm{Ca}^{2+}$-induced scrambling of lipids facilitates protein tyrosine phosphorylation in intact erythrocytes. Because lipid scrambling is associated with membrane unpacking (Williamson et al., 1985), it can be speculated that this increases susceptibility of tyrosine residues for kinases. However, it can at present not be excluded that erythrocytes from Scott syndrome (or normal cells treated with R5421) are affected at an early step that leads to both the collapse of lipid asymmetry and tyrosine phosphorylation.

Originally, impaired lipid scrambling in Scott syndrome was discovered in the patients' platelets (Weiss et al., 1979). These platelets do not develop appreciable procoagulant activity upon activation with $\mathrm{Ca}^{2+}$-ionophore and have a strongly diminished procoagulant activity in response to the combined action of collagen and thrombin (Rosing et al., 1985). As shown in Fig. 4, Scott platelets in response to various agonists consistently show a lower degree of phosphorylation in comparison to healthy controls. This effect is much less pronounced than observed for the patients' erythrocytes, but this may be due to the presence of a wide variety of different tyrosine kinases in platelets (Clark et al., 1994; Jackson et al., 1996), which may obscure a decreased activity of a single kinase. Also, platelets show a significant extent of constitutive tyrosine phosphorylation. Consistent with the observations in intact erythrocytes, R5421 also inhibits prothrombinase activity in platelets stimulated with several agonists including thrombin and $\mathrm{Ca}^{2+}$-ionophore $\left(\mathrm{IC}_{50} 23 \mu \mathrm{M}\right)$. 


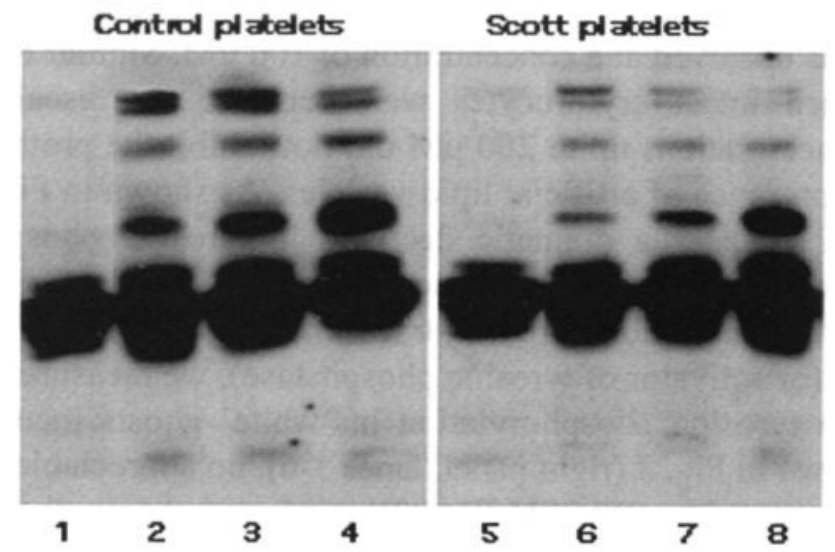

Fig. 4: Tyrosine phosphorylation in normal (lanes 1-4) and Scott syndrome platelets (lanes 5-8). Lanes 1 and 5 represent unstimulated platelets; lanes 2 and 6: platelets stimulated with $4 \mathrm{nM}$ thrombin; lanes 3 and 7: platelets treated with $70 \mathrm{nM}$ thapsigargin and subsequently activated with $4 \mathrm{nM}$ thrombin; lanes 4 and 8: platelets activated with $10 \mu \mathrm{g} / \mathrm{ml}$ collagen.

To further assess the effect of R5421 on scramblase activity in platelets, we used a continuous assay recently described by Williamson et al. (Williamson et al., 1995), which allows monitoring real time movement of a fluorescent lipid analogue, NBD-PS, from the inner to the outer leaflet of the plasma membrane. As shown in Fig. 5, preincubation of NBD-PSloaded platelets with $50 \mu \mathrm{M}$ R5421 inhibited $\mathrm{Ca}^{2+}$-ionophore induced transbilayer movement of PS by more than $90 \%$ (curves a and b). For comparison, no scrambling of NBD-PS was found when Scott platelets were stimulated with $\mathrm{Ca}^{2+}$-ionophore (Fig. 5, curve c). Subsequent experiments showed that the extent of inhibition by R5421 was timedependent with $50 \%$ inhibition obtained at $20 \mu \mathrm{M}$ for $60 \mathrm{~min}$ (Fig. 5, insert). The inhibitory effect of R5421 could not be reversed by washing the platelets, suggesting that R5421 is an irreversible inhibitor of the scramblase.

Unlike the slightly diminished phosphorylation patterns observed with Scott platelets, incubation of normal platelets with R5421 $(100 \mu \mathrm{M})$ does not cause appreciable changes in tyrosine phosphorylation patterns 
obtained on activation with a variety of agonists. However, inhibition of scramblase activity by these high levels of R5421 is not complete (compare curves $\mathrm{b}$ and $\mathrm{c}$ in Fig. 5). If this would be accompanied by a lower extent of inhibition of (a single?) kinase, the effect of this compound may no longer be visible on Western blots.

Of note, as in erythrocytes, aminophospholipid translocase activity in platelets was not affected by R5421 up to a concentration of $100 \mu \mathrm{M}$.

In summary, we found that the impaired $\mathrm{Ca}^{2+}$-induced lipid scrambling in Scott syndrome is accompanied by a diminished tyrosine phosphorylation, an effect that was most pronounced in the patients' erythrocytes. We conclude that the apparent deficiency in tyrosine phosphorylation in Scott syndrome cells is an epiphenomenon, possibly associated with defective lipid scrambling, but is not causal to this defect. The data do not exclude the possibility that deficient lipid scrambling in Scott syndrome directly affects tyrosine phosphorylation, or that a step required for collapse of lipid asymmetry and tyrosine phosphorylation is aberrant.

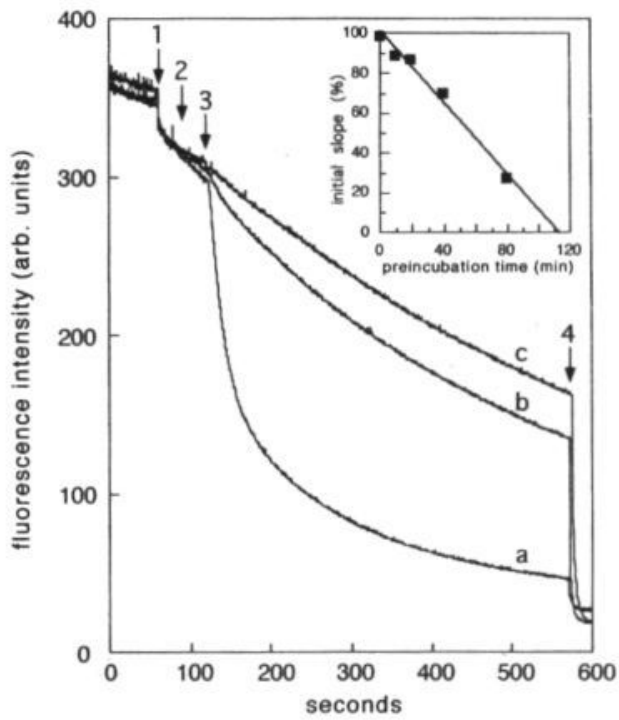

Fig. 5: Effect of R5421 on $\mathrm{Ca}^{2+}$-dependent scrambling of NBD-PS in human platelets stimulated with $\mathrm{Ca}^{2+}$-ionomycin. Platelets were preincubated with $50 \mu \mathrm{M}$ $\mathrm{R} 5421$ for $60 \mathrm{~min}$. At arrow 1, dithionite $(5 \mathrm{mM})$ was added; at arrow 2, ionomycin (1 $\mu \mathrm{M})$; at arrow $3, \mathrm{CaCl}_{2}(1 \mathrm{mM})$ and at arrow 4 , Triton X100 $(1 \%)$. Curve a, control platelets in the absence of R5421, curve b in the presence of R5421. Curve c represents Scott platelets stimulated with $\mathrm{Ca}^{2+}$-ionophore. Insert: effect of preincubation time with $\mathrm{R} 5421(20 \mu \mathrm{M})$ on rate of scrambling. 


\section{REFERENCES}

Ahmad, S. S., Rawala Sheikh, R., Ashby, B., and Walsh, P. N. (1989) Platelet receptormediated factor $\mathrm{X}$ activation by factor IXa. High-affinity factor IXa receptors induced by factor VIII are deficient on platelets in Scott syndrome. J. Clin. Invest. 84, 824-8.

Bassé, F., Stout, J. G., Sims, P. J., and Wiedmer, T. (1996) Isolation of an erythrocyte membrane protein that mediates $\mathrm{Ca}^{2+}$-dependent transbilayer movement of phospholipid. J. Biol. Chem. 271, 17205-17210.

Bevers, E. M., Comfurius, P., and Zwaal, R. F. A. (1983) Changes in membrane phospholipid distribution during platelet activation. Biochim. Biophys. Acta 736, 5766.

Bevers, E. M., Wiedmer, T., Comfurius, P., Shattil, S. J., Weiss, H. J., Zwaal, R. F. A., and Sims, P. J. (1992) Defective $\mathrm{Ca}^{2+}$-induced microvesiculation and deficient expression of procoagulant activity in erythrocytes from a patient with a bleeding disorder: a study of the red blood cells of Scott syndrome. Blood 79, 380-8.

Clark, E. A., Shattil, S. J., and Brugge, J. S. (1994) Regulation of protein tyrosine kinases in platelets. Trends Biochem. Sci. 19, 464-9.

Comfurius, P., Williamson, P., Smeets, E. F., Schlegel, R. A., Bevers, E. M., and Zwaal, R. F. A. (1996) Reconstitution of phospholipid scramblase activity from human blood platelets. Biochemistry 35, 7631-4.

Dekowski, S. A., Rybicki, A., and Drickhamer, K. (1983) A tyrosine kinase associated with the red cell membrane phosphorylates band 3. J. Biol. Chem. 258, 2750-3.

Devaux, P. F., and Zachowski, A. (1994) Maintenance and consequences of membrane phospholipid asymmetry. Chem. Phys. Lipids 73, 107.

Jackson, S. P., Schoenwaelder, S. M., Yuan, Y., Salem, H. H., and Cooray, P. (1996) Non-receptor protein tyrosine kinases and phosphatases in human platelets. Thromb. Haemost. 76, 640-50.

Kojima, H., Newton-Nash, D., Weiss, H. J., Zhao, J., Sims, P. J., and Wiedmer, T. (1994) Production and characterization of transformed B-lymphocytes expressing the membrane defect of Scott syndrome. J. Clin. Invest. 94, 2237-44.

Martin, D. W., and Jesty, J. (1995) Calcium stimulation of procoagulant activity in human erythrocytes. J. Biol.Chem. 270, 10468-10474.

Miletich, J. P., Kane, W. H., Hofmann, S. L., Stanford, N., and Majerus, P. W. (1979) Deficiency of factor Xa-factor Va binding sites on the platelets of a patient with a bleeding disorder. Blood 54, 1015-22. 
Mohamed, A. H., and Steck, T. (1986) Band 3 tyrosine kinase. J. Biol. Chem. 261, 2804-2809.

Rosing, J., Bevers, E. M., Comfurius, P., Hemker, H. C., van Dieijen, G., Weiss, H. J., and Zwaal, R. F. A. (1985) Impaired factor X and prothrombin activation associated with decreased phospholipid exposure in platelets from a patient with a bleeding disorder. Blood 65, 1557-61.

Rosing, J., Tans, G., Govers-Riemslag, J. W., Zwaal, R. F. A., and Hemker, H. C. (1980) The role of phospholipids and factor Va in the prothrombinase complex. J. Biol. Chem. 255, 274-83.

Sims, P. J., Wiedmer, T., Esmon, C. T., Weiss, H. J., and Shattil, S. J. (1989) Assembly of the platelet prothrombinase complex is linked to vesiculation of the platelet plasma membrane. Studies in Scott syndrome: an isolated defect in platelet procoagulant activity. J. Biol. Chem. 264, 17049-57.

Stout, J. G., Bassé, F., Luhm, R. A., Weiss, H. J., Wiedmer, T., and Sims, P. J. (1997) Scott syndrome erythrocytes contain a membrane protein capable of mediating $\mathrm{Ca}^{2+}$. dependent transbilayer migration of membrane phospholipids. J. Clin. Invest. 99, 2232 8.

Sulpice, J. C., Zachowski, A., Devaux, P. F., and Giraud, F. (1994) Requirement for phosphatidylinositol 4,5-bisphosphate in the $\mathrm{Ca}^{2+}$-induced phospholipid redistribution in the human erythrocyte membrane. J. Biol. Chem. 269, 6347-54.

Toti, F., Satta, N., Fressinaud, E., Meyer, D., and Freyssinet, J-M. (1996) Scott syndrome, characterized by impaired transmembrane migration of procoagulant phosphatidylserine and hemorrhagic complications, is an inherited disorder. Blood 87 , 1409-15.

Weiss, H. J. (1994) Scott syndrome: a disorder of platelet coagulant activity. Semin. Hematol. 31, 312-9.

Weiss, H. J., and Lages, B. (1997) Family studies in Scott syndrome. Blood 90, 475-6.

Weiss, H. J., Vicic, W. J., Lages, B. A., and Rogers, J. (1979) Isolated deficiency of platelet procoagulant activity. Am. J. Med. 67, 206-13.

Williamson, P., and Schlegel, R. A. (1994) Back and forth: the regulation and function of transbilayer phospholipid movement in eukaryotic cells (Review). Mol. Membr. Biol. 11, 199-216.

Williamson, P., Algarin, L., Bateman, J., Choe, H-R. and Schlegel, R. A. (1985) Phospholipid asymmetry in human erythrocyt ghosts. J. Cell. Phys. 123, 209-214. 


\section{Chapter 4}

Williamson, P., Bevers, E. M., Smeets, E. F., Comfurius, P., Schlegel, R. A., and Zwaal, R. F. A. (1995) Continuous analysis of the mechanism of activated transbilayer lipid movement in platelets. Biochemistry 34, 10448-55

Zipser, Y., and Kosower, N. S. (1996) Phosphotyrosine phosphatase associated with band 3 protein in the human erythrocyte membrane. Biochem. J. 314, 881-887.

Zwaal, R. F. A., and Schroit, A. J. (1997) Pathophysiologic implications of membrane phospholipid asymmetry in blood cells. Blood 89, 1121-32. 


\section{Chapter 5}

\section{Transbilayer movement of NBD-labeled phospholipids in red blood cell membranes: Outward directed transport by the Multidrug Resistance Protein 1 (MRP1)}

David W. C. Dekkers, Paul Comfurius, Alan. J. Schroit, Edouard M. Bevers and Robert F. A. Zwaal (1998) Biochemistry 37, 14833-14837

Abstract: The outward movement (flop) of fluorescently-labeled analogues of phosphatidylserine (PS), and phosphatidylcholine (PC) in human and murine red blood cells (RBC) was examined. 1-Oleoyl2-[6(7-nitrobenzo-2-oxa-1,3-diazole-4-yl)-amino]caproyl analogues of $\mathrm{PS}$ and $\mathrm{PC}$ were incorporated in the inner leaflet of the plasma membrane through the action of aminophospholipid translocase or through equilibration upon prolonged incubation, respectively. After removal of non-internalized probe, externalization of $\mathrm{C}_{6}$-NBD-PS or $\mathrm{C}_{6}$-NBD-PC from the inner to outer leaflet was monitored by continuous incubation of the cells in the presence of bovine serum albumin. Flop rates for both probes in intact human $R B C$ were virtually identical $\left(t_{1 / 2} \sim 1.5 \mathrm{~h}\right)$, confirming earlier findings by Bitbol et al. [Bitbol, M., et al. (1988) Proc. Natl. Acad. Sci. U.S.A. 85, 6783-6787] and Connor et al. [Connor, J., et al. (1992) J. Biol. Chem. 267, 19412-19417]. Flop activity in resealed RBC ghosts could only be found upon coinclusion of both ATP and oxidized glutathione (GSSG). Furthermore, flop in intact cells was sensitive to verapamil $\left(\mathrm{IC}_{50}=5-7 \mu \mathrm{M}\right)$, vincristine $\left(\mathrm{IC}_{50}=17-22 \mu \mathrm{M}\right)$ and indomethacin $\left(\mathrm{IC}_{50}=\right.$ 44-55 $\mu \mathrm{M})$, suggesting the involvement of proteins conferring multidrug resistance (MDR). Experiments with RBC from knock-out 


\section{Chapter 5}

mice for multidrug resistance P-glycoproteins (Mdr1a/1b-/- and Mdr2-/-) and multidrug resistance protein 1 (Mrp1-/-) revealed that Mrp1 is responsible for the observed flop of the fluorescent lipid analogues. We found no indications for outward transport of endogenous PS by any of these drug-transporting proteins as measured by a sensitive prothrombinase assay. Neither aminophospholipid translocase nor $\mathrm{Ca}^{2+}$-induced lipid scramblase activities were affected in RBC of these knock-out mice. We conclude that lipid floppase activity as detected with lipid probes, reflects the activity of MRP1 recognizing the modified lipid analogues as xenobiotics to be expelled from the cell. 


\section{Introduction}

The two leaflets of the plasma membrane of human red blood cells have a distinct phospholipid composition: cholinephospholipids, phosphatidylcholine (PC) and sphingomyelin, primarily dominate the outer leaflet, whereas the inner leaflet consists mainly of phosphatidylinositol (PI) and the aminophospholipids, phosphatidylserine (PS) and phosphatidylethanolamine (PE) (reviewed in Schroit and Zwaal, 1991). Phospholipid distributions across the membrane bilayer are presently thought to be regulated by at least four different proteins: (i) an ATP-dependent aminophospholipid translocase (Connor and Schroit, 1987; Seigneuret and Devaux, 1984), responsible for the inward transport of aminophospholipids which contributes to the generation of membrane lipid asymmetry, (ii) a phospholipid scramblase (Bevers et al., 1982; Bevers et al., 1983; Zwaal et al., 1993), that can be activated to catalyze bidirectional movement of all phospholipid classes, resulting in a collapse of lipid asymmetry, (iii) a protein encoded by the multidrug resistance gene Mdr2 (Smit et al., 1993), that facilitates ATP-dependent outward movement of PC and is known to be responsible for export of PC into the bile, and (iv) a protein which counteracts the aminophospholipid translocase by transporting lipids from the inner to outer leaflet albeit at a much slower rate than the translocase (Bitbol and Devaux, 1988; Connor et al., 1990). This protein, also referred to as "floppase", was demonstrated to transport short-chain fluorescent analogues of PS, PC and PE with similar kinetics from the inner to the outer leaflet of the erythrocyte membrane (Connor et al., 1992; Zwaal and Schroit, 1997). It has been proposed that this protein-mediated outward translocation of lipids, in conjunction with aminophospholipid-specific transport, leads to an equilibrium status in which lipid asymmetry of the cell is maintained. In a previous study, we have shown that the outward movement of PS, PC and PE was ATP-dependent and was blocked by oxidation of membrane sulfhydryls and by the histidine reagent bromophenacyl bromide (Connor et al., 1992). The aim of the present study was to further investigate the nature of this floppase activity. Evidence is presented that the multidrug resistance protein, MRP1, is responsible for the continuous outward migration of $\mathrm{C}_{6}$-NBD-labeled lipids from inner to outer leaflet of the $\mathrm{RBC}$ membrane. 


\section{Materials and Methods}

\section{Materials}

$\mathrm{C}_{6}$-NBD-PS, 1-oleoyl-2-[6(7-nitrobenz-2- oxa-1,3-diazol-4-yl)amino] caproyl -sn- glycero-3-phospho-serine and NBD-PC, 1-oleoyl-2- [6(7nitrobenz-2-oxa-1,3-diazol-4-yl)amino]-caproyl-sn-glycero-3-phosphocholine, were obtained from Avanti Polar Lipids (Alabaster, AL). Verapamil, indomethacin, vincristine, oxidized glutathione (GSSG) and BSA were purchased from Sigma (St. Louis, MO). Coagulation factors factor $\mathrm{Xa}$, factor $\mathrm{Va}$ and prothrombin were purified from bovine blood as described before (Rosing et al., 1980). Chromogenic substrate for thrombin, S2238, was from AB Kabi Diagnostica (Stockholm, Sweden). All other reagents were of the highest grade commercially available.

\section{Isolation of RBC and preparation of resealed ghosts}

Whole blood was obtained from healthy volunteers by venipuncture, using acid citrate dextrose (ACD: $0.18 \mathrm{M}$ glucose, $0.08 \mathrm{M}$ trisodium citrate, $0.052 \mathrm{M}$ citric acid) as anticoagulant in a final ratio of 1:5 (v/v). RBC were collected and washed with a Hepes buffer $(136 \mathrm{mM} \mathrm{NaCl}, 2.7 \mathrm{mM}$ $\mathrm{KCl}, 2 \mathrm{mM} \mathrm{MgCl}$, $10 \mathrm{mM}$ Hepes, $0.2 \mathrm{mM}$ EGTA, $10 \mathrm{mM}$ glucose, adjusted at $\mathrm{pH}$ 7.5). Cells were finally resuspended in the same buffer and were used within 1 day.

Red blood cell ghosts were prepared by hypotonic shock in ice-cold lysis buffer (13.6 mM NaCl, $0.27 \mathrm{mM} \mathrm{KCl,} 2 \mathrm{mM} \mathrm{MgCl}_{2}, 1 \mathrm{mM}$ Hepes, 0.2 mM EGTA, pH 7.5). After $25 \mathrm{~min}$ on ice and addition of Mg-ATP (10 $\mathrm{mM}$ ) or other compounds, tonicity was restored by addition of 0.1 volume of $9 \% \mathrm{NaCl}$, followed by incubation at $37^{\circ} \mathrm{C}$ for $5 \mathrm{~min}$. Resealed ghosts were collected by centrifugation at $2250 \mathrm{xg}$ for $20 \mathrm{~min}$ and subsequently washed three times in Hepes buffer containing $10 \mathrm{mM} \mathrm{MgCl}_{2}$ and $2 \mathrm{mM}$ glucose, $\mathrm{pH} 7.5$, at $4^{\circ} \mathrm{C}$.

\section{Labeling of $R B C$ and resealed ghosts with $C_{6}$-NBD-phospholipids}

Washed human or murine RBC were resuspended in Hepes buffer to a cell concentration of $10^{8}$ cells $/ \mathrm{mL}$ and loaded with $0.4 \mu \mathrm{M} \mathrm{C}_{6}$-NBD-PS, which corresponds to approximately $1 \%$ of the endogenous phospholipids. Translocation of the probe proceeded for $1 \mathrm{~h}$ at $37^{\circ} \mathrm{C}$, resulting in $75-95 \%$ internalization. For labeling with $\mathrm{C}_{6}$-NBD-PC, human red cells were incubated overnight with $0.8 \mu \mathrm{M} \mathrm{C}_{6}$-NBD-PC resulting in about $20 \%$ internalization of the probe. To measure outward movement, residual $\mathrm{C}_{6}$ NBD-lipid remaining in the cells' outer monolayer was removed by washing for $5 \mathrm{~min}$ with ice-cold $0.5 \%$ BSA prior to the experiment. 
For measuring flop in resealed ghosts, ghosts were prepared from RBC that were pre-labeled with $\mathrm{C}_{6}-\mathrm{NBD}-\mathrm{PS}$ or $\mathrm{C}_{6}$-NBD-PC. Alternatively, in the case of $\mathrm{C}_{6}$-NBD-PS experiments, ghosts with included ATP were labeled by $1 \mathrm{~h}$ incubation in which the aminophospholipid translocase activity ensured sufficient accumulation of probe in the inner leaflet.

\section{Translocation of lipids from the outer-to-inner and inner-to-outer leaflet} Inward movement of $\mathrm{C}_{6}$-NBD-PS was measured using the BSA backexchange procedure as described by Conner et al. (Connor et al., 1992). Briefly, $200 \mu \mathrm{L}$ aliquots from the cell suspension were removed at the indicated time intervals and placed on ice for $5 \mathrm{~min}$ in the presence and absence of $1 \%$ BSA. Pellets obtained after $3 \mathrm{~min}$ of centrifugation at $12000 \mathrm{xg}$, were solubilized in $2 \mathrm{~mL}$ of $1 \%(\mathrm{w} / \mathrm{v})$ Triton $\mathrm{X}-100$, and the amount of internalized probe was determined by comparing the fluorescence intensity associated with the cells before and after backexchange.

Outward movement of $\mathrm{C}_{6}$-NBD-PS and $\mathrm{C}_{6}$-NBD-PC was measured by incubating the cells at $10^{8} / \mathrm{mL}$ at $37^{\circ} \mathrm{C}$ in the absence or presence of $1 \%$ BSA (continuous extraction). Aliquots of cells were taken at the indicated time intervals, and the fraction of lipid remaining associated with the cells was determined as described above. Similar procedures were followed to measure transbilayer migration of $\mathrm{C}_{6}$-NBD-lipids in resealed ghosts. The fluorescence intensities were measured ( $\left.\lambda_{\mathrm{ex}} 472 \mathrm{~nm}, \lambda_{\mathrm{em}} 534 \mathrm{~nm}\right)$ on a Shimadzu RF-5001PC spectrofluorometer (Shimadzu Europe, Duisburg, Germany).

\section{Prothrombinase measurements}

Surface exposure of phosphatidylserine was determined by measuring the ability of RBC to enhance the rate of conversion of prothrombin to thrombin by the enzyme complex consisting of factors $\mathrm{Xa}$ and $\mathrm{Va}$, as described previously for platelets (Rosing et al., 1985). Since the basal prothrombinase activity of RBC is extremely low (Bevers et al., 1992), high cell counts were used in the assay. The conditions were as follows (final concentrations): $10^{8} \mathrm{RBC} / \mathrm{mL}$ were incubated in Hepes buffer containing $0.5 \mathrm{mg} / \mathrm{ml}$ human serum albumin and $3 \mathrm{mM} \mathrm{CaCl}_{2}$ with $3 \mathrm{nM}$ factor $\mathrm{Xa}$ and $6 \mathrm{nM}$ factor $\mathrm{Va}$ for $2 \mathrm{~min}$ at $37{ }^{\circ} \mathrm{C}$. Subsequently, prothrombin was added at a concentration of $4 \mu \mathrm{M}$ and thrombin was formed for $2 \mathrm{~min}$. Aliquots from this incubation mixture were analyzed for the amount of thrombin present using a thrombin-specific substrate S2238. This prothombinase assay was also used to measure $\mathrm{Ca}^{2+}$-induced lipid scramblase activity, as described previously (Bevers et al., 1992). 


\section{Knockout mice}

A double knock-out for P-glycoprotein Mdrla/1b-/- and a knock-out for Mdr2 and their corresponding controls were in FVB background and were generously provided A. Schinkel and J. Smit, respectively. The Mrp1 knock-out and its corresponding control was in a 50\% Ola 129 and $50 \%$ FVB background and were kindly donated by J. Wijnholds. All three knockouts have been previously described (Schinkel et al., 1997; Smit et al., 1993; Wijnholds et al., 1997, respectively).

\section{Results}

Outward movement of $C_{6}-N B D$-phospholipids in human $R B C$ and resealed ghosts

To measure outward movement of lipids, $\mathrm{RBC}$ were first incubated with $\mathrm{C}_{6}$-NBD-PS or $\mathrm{C}_{6}$-NBD-PC. While the $\mathrm{C}_{6}$-NBD-PS is rapidly internalized by the aminophospholipid translocase, an overnight incubation was required to allow sufficient accumulation of $\mathrm{C}_{6}-\mathrm{NBD}-\mathrm{PC}$ in the cells' inner leaflet. To ensure that at the start of the floppase measurement all probe was localized in the inner leaflet, cells were back-exchanged with BSA. Flop of NBD-lipid was then measured by continuous BSA extraction as described in Materials and Methods.

Fig. 1A (closed symbols) confirms earlier findings showing that $\mathrm{C}_{6}-\mathrm{NBD}-$ PS and $\mathrm{C}_{6}$-NBD-PC were externalized with similar kinetics (Connor et al., 1992). When outward movement of $\mathrm{C}_{6}$-NBD-PS was examined in resealed ghosts, it was found that upon further dilution during the lysis step the amount of probe that became accessible to extraction by BSA gradually diminished (Fig. 1A, open symbols). Resealed ghosts, obtained from cells that were lysed in a 10 -fold volume of hypotonic buffer, almost completely lost floppase activity. To investigate whether floppase was abrogated because of shortage of ATP, the ghosts were resealed in the presence of $10 \mathrm{mM} \mathrm{Mg-ATP}$. Although we could confirm that this amount of ATP was sufficient to sustain aminophospholipid translocase activity (Seigneuret and Devaux, 1984) (data not shown), floppase activity was not recovered (Fig. 1B, triangles). Floppase activity in ghosts was found to be present, however, when Mg-ATP $(10 \mathrm{mM})$ and oxidized glutathione (GSSG, $5 \mathrm{mM}$ ) were both included during the resealing step (Fig. 1B, circles). Inclusion of GSSG without ATP, and conversely of ATP without GSSG, did not reveal floppase activity.The outward movement of $\mathrm{C}_{6^{-}}$ NBD-PC was also dependent on the simultaneous presence of ATP and GSSG (data not shown). 

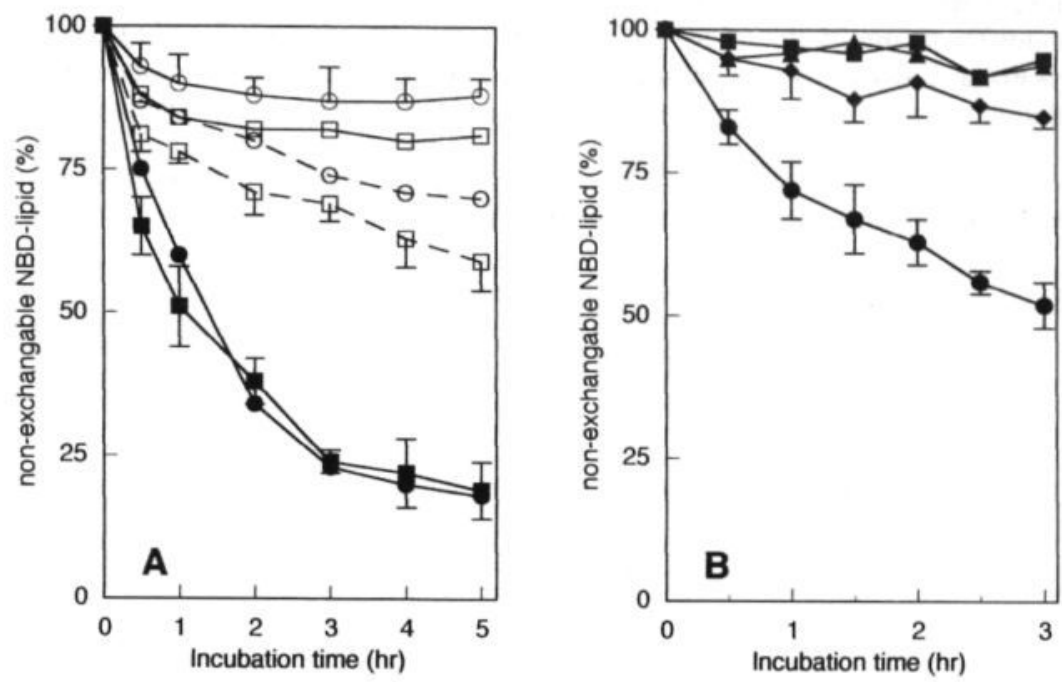

Fig. 1: Outward movement of fluorescent lipid analogues in human RBC.

A. Outward transport of $\mathrm{C}_{6}$-NBD-PS (circles) and $\mathrm{C}_{6}$-NBD-PC (squares) in intact cells (closed symbols) and resealed ghosts obtained from cells lysed in a 3 -fold (open symbols, dashed lines) and in a 10-fold volume (open symbols, solid lines) of lysis buffer.

B. Outward transport of $\mathrm{C}_{6}$-NBD-PS in ghosts obtained from $\mathrm{C}_{6}$-NBD-PS labeled cells, lysed in a 10-fold volume of lysis buffer, and subsequently resealed in the absence ( $\mathbf{\square})$ or presence of $10 \mathrm{mM} \mathrm{Mg-ATP}(\downarrow), 5 \mathrm{mM}$ GSSG $(\boldsymbol{\Delta})$ or $10 \mathrm{mM} \mathrm{Mg}-\mathrm{ATP}+5 \mathrm{mM}$ GSSG (•). Shown are the mean values of three experiments. All standard deviations are less than $12 \%$. Error bars are only shown when they do not interfere with the clarity of the figure.

The finding that GSSG plus ATP stimulated NBD-lipid flop suggested that this activity might be related to that of the multidrug resistence protein 1 (MRP1), also known as the glutathione-conjugate transporter (GS-X transporter) (Ishikawa, 1992; Jedlitschky et al., 1996; Zaman et al., 1995). Therefore, a number of known inhibitors of MRP1 were tested for their effect on outward movement of $\mathrm{C}_{6}$-NBD-PS. As shown in Tab. 1, verapamil, vincristine and indomethacine indeed inhibited the flop of $\mathrm{C}_{6}$ NBD-PS in $\mathrm{RBC}$ with $\mathrm{IC}_{50}$-values ranging from 5-55 $\mu \mathrm{M}$. Similar values were obtained for the effects of these inhibitors on $\mathrm{C}_{6}$-NBD-PC outward transport (Data not shown). Under the same conditions, no appreciable inhibition of aminophospholipid translocase activities was observed. 
Table. 1: Inhibition of inside-to-outside movement (flop) of $\mathrm{C}_{6}$-NBD-PS in human RBC. Washed RBC were incubated with different concentrations of inhibitor for $60 \mathrm{~min}$, followed by incubation with $\mathrm{C}_{6}$-NBD-PS for $45 \mathrm{~min}$. Flop of internalized $\mathrm{C}_{6}$-NBD-PS was measured as described in Materials and Methods. Inhibition was calculated as a percentage of the amount of NBD-PS flop in absence of inhibitors and plotted as a function of the inhibitor concentration. From these titrations, $\mathrm{IC}_{50}$-values were determined. Titrations were per formed in triplicate; data are the range of values found in these experiments.

\begin{tabular}{ll}
\hline Inhibitor & $\mathrm{IC}_{50}(\mu \mathrm{M})$ \\
\hline verapamil & $5-7$ \\
vincristine & $17-22$ \\
indomethacine & $44-55$ \\
& \\
\hline
\end{tabular}

NBD-lipid movement in murine RBC deficient in Mdrla and Mdrlb, Mdr2, or Mrp1

Since the above-mentioned inhibitors are not specific for extrusion of drugs mediated by the MDR P-glycoproteins or by MRP, we used RBC from different knockout mice in an attempt to identify the transporter for the outward movement of fluorescent lipid analogues: (i) Mdr1a/1b -/- is a double knock-out mouse for Mdrla (also called Mdr3) and Mdrlb (also called Mdrl) (nomenclature according to Smit el al., 1994). These two genes encode for the P-glycoproteins that are involved in multidrug resistance in mice and are known to translocate a wide variety of shortchain lipid analogues (Smit et al., 1994). These two proteins together fulfill the same functions as the single human MDR1 P-glycoprotein (Schinkel et al., 1997); (ii) Mrp1-/-, a knockout of a gene different from $M d r$, but also encoding for a protein belonging to the ABC (ATP Binding Cassette) protein family involved in expelling of drugs, and (iii) a knockout of Mdr2 (MDR3 in human), known as the phosphatidylcholine transporter in the bile canalicular system (Smit et al., 1993). All three mice strains have been previously described (Schinkel et al., 1997; Smit et al., 1993; Wijnholds et al., 1997). Fig. 2 shows the inward and outward transport of $\mathrm{C}_{6}$-NBD-PS in RBC obtained from these knockout mice and from their corresponding wild types. While inward transport of $\mathrm{C}_{6}-\mathrm{NBD}$ PS seems unaffected in all three knockout mice, outward movement of this PS analogue was virtually absence only in the Mrp-/- RBC. The other two 
knockouts exhibited outward transport kinetics indistinguishable from those of corresponding controls. Flop of $\mathrm{C}_{6}$-NBD-PC in RBC from knockout mice could not be measured, because murine RBC do not accumulate sufficient amounts of $\mathrm{C}_{6}$-NBD-PC in the inner leaflet to allow reliable measurement of outward movement. This was found for RBC from wild type as well as Mdr2-/- and Mrp1-/- mice. Presumably, the rate of efflux of $\mathrm{C}_{6}$-NBD-PC by Mdr2 in the Mrp-/- mice and conversely by Mrp in the Mdr2-/- mice may be too high in comparison to the spontaneous inward movement, precluding sufficient incorporation in the inner leaflet.
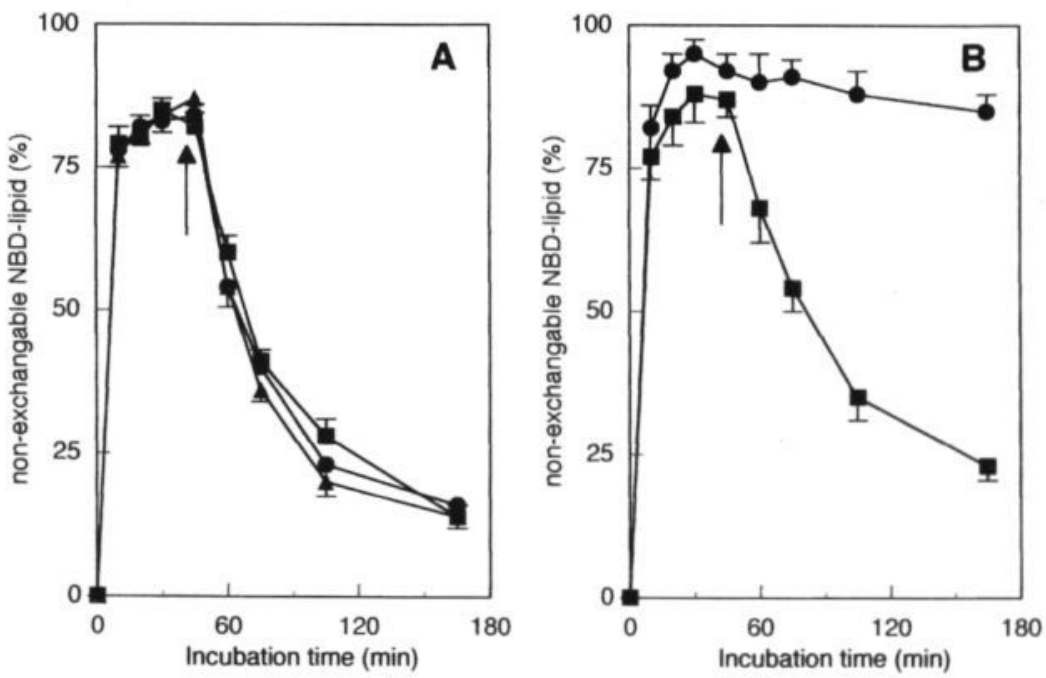

Fig. 2: Transbilayer movement of $\mathrm{C}_{6}$-NBD-PS in intact $\mathrm{RBC}$ from knockout mice. Washed RBC were incubated for 45 min with $\mathrm{C}_{6}$-NBD-PS and samples were analyzed for probe internalization by BSA back-exchange. After $45 \mathrm{~min}$ (arrow), BSA was added to the cell suspensions to start the continuous extraction to prevent $\mathrm{C}_{6}$-NBD-PS which is transported to outer leaflet from being pumped back to the inner leaflet. Aliquots are taken at different time intervals, and residual fluorescence intensity remaining in the cells was analyzed as described under Materials and Methods. Panel A: RBC from Mdrla/lb-/- double knockout $(\bullet)$, Mdr2-/- (ム) knockouts, and corresponding wildtype (匹) mice. Panel B: RBC from Mrpl-/- (•) knockout and corresponding wild-type (घ) mice. Shown are the mean values \pm SD obtained from four experiments. 
Measurement of prothrombinase activity of RBC from MDR and MRPI knockout mice

Fig. 2B shows that the uptake of $\mathrm{C}_{6}$-NBD-PS in the Mrp1-/- RBC seems to exceed that of the control, supporting the notion that net uptake is a result of the balance between aminophospholipid translocase and floppase activities. This phenomenon was repeatedly observed in the Mrpl-/knockout $\mathrm{RBC}$, and raised the question whether such an altered distribution of the $\mathrm{C}_{6}$-NBD-PS is representative for the distribution of endogenous PS. To address this question, we have used the prothrombinase assay. The conversion of prothrombin to thrombin by the enzyme complex consisting of factors $\mathrm{Xa}$ and $\mathrm{Va}$ is strongly catalyzed by the presence of an anionic phospholipid surface. Hence the prothrombinase assay is a very sensitive method to detect traces of PS in a membrane surface. We have investigated whether the knockout mice had an altered PS distribution of their RBC membranes. However, as shown in Tab. 2, no significant differences in the prothrombinase activities of these RBC could be discerned. In addition, murine RBC challenged with $\mathrm{Ca}^{2+}$ ionophore exhibit rapid scrambling of phospholipids while no difference in rate (data not shown) and extent (Tab. 2) of PS exposure could be observed in erythrocytes from the three knockout mice and their corresponding controls, suggesting that scramblase activity is unrelated to the Mdr P-glycoproteins or Mrpl.

Table. 2: Prothrombinase activities of murine erythrocytes. Washed murine RBC were incubated with coagulation factors as described under Materials and Methods. Nonstimulated RBC were measured at a cell count of $10^{8} / \mathrm{mL}$. Incubations with inomycin $(5 \mu \mathrm{M})$ was carried out for $30 \mathrm{~min}$ in the presence of $1 \mathrm{mM} \mathrm{Ca}^{2+}$. Prothrombinase activities of these ionophore-treated cells were measured at a cell count of $107 / \mathrm{mL}$. Prothrombinase assays were preformed in triplicate on three different blood samples of all mice strains. Results are presented as the mean value \pm SD of all measurements and expressed as nanomolar thrombin formed per minute.

\begin{tabular}{ccc}
\hline Mouse strain & $\begin{array}{c}\text { nonstimulated RBC } \\
10^{8} / \mathrm{mL}\end{array}$ & $\begin{array}{c}\text { ionophore-treated RBC } \\
10^{7} / \mathrm{mL}\end{array}$ \\
\hline Mdr+/+ & $43 \pm 4$ & $508 \pm 32$ \\
Mdrla/lb-/- & $40 \pm 10$ & $375 \pm 55$ \\
Mdr2-/- & $34 \pm 13$ & $445 \pm 38$ \\
Mdrl+/+ & $53 \pm 19$ & $514 \pm 43$ \\
Mrpl-/- & $50 \pm 14$ & $422 \pm 37$ \\
\hline
\end{tabular}




\section{Discussion}

Mammalian cells possess an energy-dependent aminophospholipid translocase which ensures sequestration of PS and PE in the inner leaflet of the plasma membrane. A few studies have suggested the existence of an ATP-dependent floppase that facilitates outward movement of lipids (Bitbol and Devaux, 1988; Connor et al., 1992). It has been proposed that the synchronous and cooperative action of the aminophospholipid translocase and floppase activities contribute to the generation and maintenance of membrane phospholipid asymmetry (Connor et al., 1992). While aminophospholipid translocase has been suggested to involve a 110 kDa Mg-ATPase (Auland et al., 1994; Tang et al., 1996) the identity of the transporter responsible for outward lipid movement is less clear. It was conceivable, in fact, that floppase activity was an intrinsic property of the aminophospholipid translocase (Zwaal and Schroit, 1997). In this study we demonstrate that inward and outward movement of short-chain fluorescent lipid analogues is mediated by distinct proteins, because (i) flop of NBD-lipids requires the simultaneous presence of ATP and GSSG, whereas translocase only requires ATP (Seigneuret and Devaux, 1984), (ii) flop of NBD-lipids is inhibited by drugs interfering with multidrug resistance proteins, without inhibiting translocase, (iii) virtually complete absence of flop of $\mathrm{C}_{6}$-NBD-PS was found in RBC from Mrpl knockout mice, while translocase activity in these cells was fully active. This finding proves that outward transport of NBD-lipids in RBC is catalyzed by the multidrug resitance protein MRP1, which is in line with recent observations showing outward transport of NBD-sphingomyelin and NBD-glucosylceramide in LLC-PK1 cells transfected with human MRP1 (R. Raggers, A. van Helvoort, R. Evers and G. van Meer, personal communication)

Several studies have implicated that MRP1 is a so-called GS-X pump, that transports drugs as glutathione conjugates (Ishikawa, 1992; Jedlitschky et al., 1996; Zaman et al., 1995) and is present in many, if not all, mammalian cells, including erythrocytes (Pulaski et al., 1996). Indeed, export of drugs from cells by MRP1 was demonstrated to specifically require glutathione, in contrast to expelling of drugs by the P-glycoprotein MDR1, although it has been suggested that MRP1 can also transport compounds such as daunorubicin in unmodified form (Zaman et al., 1995). We have found no evidence suggesting that the NBD-lipid probes might be transported as glutathione conjugates; all cell-associated fluorescence, as well as the fluorescence of the supernatants after $6 \mathrm{hrs}$ incubation of 
human RBC in BSA, was from unmodified NBD-lipids as judged by TLC analysis (Connor et al., 1992). Moreover, flop of NBD-lipids in resealed ghosts required the presence of oxidized glutathione and not its reduced form, thus making conjugation of the lipid probe unlikely. Like Pglycoproteins, MRP is a tandemly duplicated $\mathrm{ABC}$ transporter, that may contain two or more drug binding sites with different specificities: one for conjugated drugs and another for unconjugated drugs (Shapiro and Ling, 1997). Our present findings are in line with this model: GSSG, being a glutathione-S-conjugate of glutathione and a known substrate for MRP1 (Deeley and Cole, 1997), stimulates export of the unconjugated NBDlipid.

MDR1 P-glycoprotein can transport a variety of lipids, including the $\mathrm{C}_{6}$ NBD-analogues (van Helvoort et al., 1996; van Helvoort et al., 1997; Bosch et al., 1997). As the Mrp1-/- RBC show no appreciable $\mathrm{C}_{6}$-NBD-PS flop, this would imply either a low number or low activity of Mdrla/lb Pglycoproteins in murine RBC. Indeed, low levels of expression of Mdrla and Mdrlb were found in murine RBC (A. J. Smith, personal communication). A similar conclusion may be drawn for human $\mathrm{RBC}$ based on the observation that efflux of the fluorescent lipid analogues is dependent on GSSG, a compound not required for transport by Pglycoproteins.

The finding that MRP1 is responsible for outward transport of $\mathrm{C}_{6}$-NBDPS and $\mathrm{C}_{6}$-NBD-PC raises the question whether these modified lipids are merely considered as xenobiotic compounds that need to be rapidly expelled, or are reliable reporters of the endogenous phospholipids. The second possibility would implicate that drugs are expelled by MRP1 in symport with endogenous phospholipids including PS, which is then rapidly pumped back to the inner leaflet by the aminophospholipid translocase. Although we observed a more extreme accumulation of $\mathrm{C}_{6^{-}}$ NBD-PS in the inner leaflet of RBC from Mrpl knockout mice (cf. Fig. 2), the assessment of PS exposure by the prothrombinase assay did not lend support to the possibility that Mrpl affects endogenous PS distributions. The present findings suggest that caution should be exercised in extrapolating data obtained with lipid analogues used to study transbilayer migration of lipids, as they may not under all circumstances reflect transbilayer movement of endogenous lipids. In any event, aminophospholipid translocase activities measured with aminophospholipid probes are likely underestimated in cells containing an active MRP1. Conversely, experiments designed to measure MDR using NBD-lipid probes are subject to the influence of the activity of transporters for endogenous lipids that also recognize these probes. 


\section{Acknowledgement}

We would like to acknowledge Drs. G. van Meer (Academic Medical Center, Amsterdam) and A. van Helvoort (The Netherlands Cancer Institute, Amsterdam) for helpful discussion. We thank Drs. J. Wijnholds, A. H. Schinkel, J. Smit and P. Borst from the Netherlands Cancer Institute (Amsterdam) for making available the different knockout mice for this study. Finally, we thank Dr. A. van Helvoort for critically reading of the manuscript.

\section{REFERENCES}

Auland, M. E., Roufogalis, B. D., Devaux, P. F., and Zachowski, A. (1994) Reconstitution of ATP-dependent aminophospholipid translocation in proteoliposomes. Proc. Natl. Acad. Sci. USA 91, 10938-42

Bevers, E. M., Comfurius, P., van Rijn, J. L. M. L., Hemker, H. C., and Zwaal, R. F. A. (1982) Generation of prothrombin-converting activity and the exposure of phosphatidylserine at the outer surface of platelets. Eur. J. Biochem. 122, 429-36.

Bevers, E. M., Comfurius, P., and Zwaal, R. F. A. (1983) Changes in membrane phospholipid distribution during platelet activation. Biochim. Biophys. Acta 736, 5766.

Bevers, E. M., Wiedmer, T., Comfurius, P., Shattil, S. J., Weiss, H. J., Zwaal, R. F. A., and Sims, P. J. (1992) Defective $\mathrm{Ca}^{2+}$-induced microvesiculation and deficient expression of procoagulant activity in erythrocytes from a patient with a bleeding disorder: a study of the red blood cells of Scott syndrome. Blood 79, 380-8.

Bitbol, M., and Devaux, P. F. (1988) Measurement of outward translocation of phospholipids across human erythrocyte membrane. Proc. Natl. Acad. Sci. USA 85, 6783-7

Bosch, I., Dunussi Joannopoulos, K., Wu, R. L., Furlong, S. T., and Croop, J. (1997) Phosphatidylcholine and phosphatidylethanolamine behave as substrates of the human MDR1 P-glycoprotein. Biochemistry 36, 5685-94.

Connor, J., Gillum, K., and Schroit, A. J. (1990) Maintenance of lipid asymmetry in red blood cells and ghosts: effect of divalent cations and serum albumin on the transbilayer distribution of phosphatidylserine. Biochim. Biophys. Acta 1025, 82-86. 


\section{Chapter 5}

Connor, J., Pak, C. H., Zwaal, R. F. A., and Schroit, A. J. (1992) Bidirectional transbilayer movement of phospholipid analogs in human red blood cells. Evidence for an ATP-dependent and protein mediated process. J. Biol. Chem. 267, 19412-19417.

Connor, J., and Schroit, A. J. (1987) Determination of lipid asymmetry in human red cells by resonance energy transfer. Biochemistry 26, 5099-105.

Deeley, R. G., and Cole, S. P. (1997) Function, evolution and structure of multidrug resistance protein (MRP). Semin. Cancer Biol. 8, 193-204

Ishikawa, T. (1992) The ATP-dependent glutathione S-conjugate export pump. Trends Biochem. Sci. 17, 463-8.

Jedlitschky, G., Leier, I., Buchholz, U., Barnouin, K., Kurz, G., and Keppler, D. (1996) Transport of glutathione, glucuronate, and sulfate conjugates by the MRP gene-encoded conjugate export pump. Cancer Res. 56, 988-94.

Pulaski, L., Jedlitschky, G., Leier, I., Buchholz, U., and Keppler, D. (1996) Identification of the multidrug-resistance protein (MRP) as the glutathione-S-conjugate export pump of erythrocytes. Eur. J. Biochem. 241, 644-8.

Rosing, J., van Rijn, J. L. M. L., Bevers, E. M., van Dieijen, G., Comfurius, P., and Zwaal, R. F. A. (1985) The role of activated human platelets in prothrombin and factor $\mathrm{X}$ activation. Blood $65,319-32$.

Rosing, J., Tans, G., Govers-Riemslag, J. W., Zwaal, R. F. A., and Hemker, H. C. (1980) The role of phospholipids and factor Va in the prothrombinase complex. J. Biol. Chem. 255, 274-83.

Schinkel, A. H., Mayer, U., Wagenaar, E., Mol, C. A., van Deemter, L., Smit, J. J., van der Valk, M. A., Voordouw, A. C., Spits, H., van Tellingen, O., Zijlmans, J. M., Fibbe, W. E., and Borst, P. (1997) Normal viability and altered pharmacokinetics in mice lacking mdrl-type (drug-transporting) P-glycoproteins. Proc. Natl. Acad. Sci. USA 94, 4028-33.

Schroit, A. J., and Zwaal, R. F. A. (1991) Transbilayer movement of phospholipids in red cell and platelet membranes. Biochim. Biophys. Acta 1071, 313-29.

Seigneuret, M., and Devaux, P. F. (1984) ATP-dependent asymmetric distribution of spin-labeled phospholids in the erythrocyte membrane: relation to shape changes. Proc. Natl. Acad. Sci. USA 81, 3751-3755.

Shapiro, A. B., and Ling, V. (1997) Positively cooperative sites for drug transport by Pglycoprotein with distinct drug specificities. Eur. J. Biochem. 250, 130-7.

Smit, J. J., Schinkel, A. H., Oude Elferink, R. P., Groen, A. K., Wagenaar, E., van Deemter, L., Mol, C. A., Ottenhoff, R., van der lugt, N. M., and van Roon, M. A. 
(1993) Homozygous disruption of the murine mdr2 P-glycoprotein gene leads to a complete abscence of phospholipid from bile and to liver disease. Cell 75, 451-62.

Smit, J. J., Schinkel, A. H., Mol, C. A., Majoor, D., Mooi, W. J., Jongsma, A. P., Lincke, C. R., and Borst, P. (1994) Tissue distribution of the human MDR3 Pglycoprotein. Lab. Invest. 71, 638-49.

Tang, X., Halleck, M. S., Schlegel, R. A., and Williamson, P. (1996) A subfamily of Ptype ATPases with aminophospholipid transporting activity. Science 272, 1495-7.

van Helvoort, A., Giudici, M. L., Thielemans, M., and van Meer, G. (1997) Transport of sphingomyelin to the cell surface is inhibited by brefeldin A and in mitosis, where C6-NBD-sphingomyelin is translocated across the plasma membrane by a multidrug transporter activity. J. Cell Sci. 110, 75-83.

van Helvoort, A., Smith, A. J., Sprong, H., Fritzsche, I., Schinkel, A. H., Borst, P., and van Meer, G. (1996) MDR1 P-glycoprotein is a lipid translocase of broad specificity, while MDR3 P-glycoprotein specifically translocates phosphatidylcholine. Cell 87 , 507-517.

Wijnholds, J., Evers, R., van Leusden, M. R., Mol, C. A. A. M., Zaman, G. J. R., Mayer, U., Beynen, J. H., van der Valk, M., Krimpenfort, P., and Borst, P. (1997) Increased sensitivity to anticancer drugs and decreased inflammatory response in mice lacking the multidrug resistance-associated protein. Nat. Med. 3, 1275-1279.

Zaman, G. J. R., Lankelma, J., Tellingen, O., Beijnen, J., Dekker, H., Paulusma, C., Oude Elferink, R. P. J., Baas, F., and Borst, P. (1995) Role of glutathione in the export of compounds from cells by the multidrug-resistance-associated protein. Proc. Natl. Acad. Sci. 92, 7690-7694.

Zwaal, R. F. A., Comfurius, P., and Bevers, E. M. (1993) Mechanism and function of changes in membrane-phospholipid asymmetry in platelets and erythrocytes. Biochem. Soc. Trans. 21, 248-53.

Zwaal, R. F. A., and Schroit, A. J. (1997) Pathophysiologic implications of membrane phospholipid asymmetry in blood cells. Blood 89, 1121-32. 
Chapter 5 
Chapter 6

\section{Multidrug Resistance Protein 1 (MRP1) regulates lipid asymmetry in red blood cell membranes}

David W. C. Dekkers, Paul Comfurius, Rein G. J. van Gool, Edouard M.

Bevers and Robert F. A. Zwaal (2000) Biochem. J. 350, 531-535

Abstract: The role of Multidrug Resistance Protein 1 (MRP1) in the maintenance of transbilayer lipid asymmetry in the erythrocyte membrane was investigated. The transbilayer distribution of endogenous phospholipids and [(7-nitrobenz-2-oxa-1,3-diazol-4yl)amino]caproyl (NBD)-labeled lipid analogues in the absence or presence of inhibitors of MRP1 was compared. At equilibrium the transbilayer distribution of the NBD-analogues (in the absence of MRP1 inhibitors) was very similar to that of the endogenous lipids. Inhibition of MRP1 by verapamil or indomethacin resulted in a shift in the amount of probe that was internalized: approx. $50 \%$ NBDlabeled phosphatidylcholine $\left(\mathrm{C}_{6}\right.$-NBD-PC) and $9 \%$ NBDsphingomyelin $\left(\mathrm{C}_{6}\right.$-NBD-Spm) were no longer extractable by $\mathrm{BSA}$ in cells treated with inhibitor, in comparison with $25 \%$ and $3 \%$ for control cells, respectively. To verify whether inhibition of MRP1 also affected the distribution of the endogenous phospholipids, phospholipase $A_{2}$ and sphingomyelinase were used to assess the amount of each of the various lipid classes present in the membrane outer leaflet. No shift in phospholipid distribution was observed after $5 \mathrm{~h}$ of incubation with verapamil or indomethacin. However, after $\mathbf{4 8}$ $h$ of incubation with these inhibitors, significantly smaller amounts of PC and Spm were present in the outer membrane leaflet. No appreciable change was observed in the distribution of phosphatidylethanolamine (PE) or phosphatidylserine (PS). Decreased hydrolysis of $\mathrm{PC}$ and Spm was not due to endovesicle formation, as revealed by electron microscopy. This is the first report to show that MRP1 has a role in the maintenance of the outward orientation of endogenous choline-containing phospholipids in the erythrocyte membrane. 
Chapter 6 


\section{Introduction}

The phospholipids of the plasma membrane of mammalian cells are asymmetrically distributed over both leaflets of the bilayer. Phosphatidylcholine (PC) and sphingomyelin (Spm) are located predominantly in the outer leaflet, whereas the aminophospholipids phosphatidylethanolamine (PE) and phosphatidylserine (PS) are found mainly in the inner leaflet (reviewed in Zwaal and Schroit, 1997). An important contribution to the maintenance of lipid asymmetry comes from the activity of the aminophospholipid translocase, which specifically transports aminophospholipids from the outer to the inner leaflet at the expense of ATP (Beleznay et al., 1993; Seigneuret and Devaux, 1984). In addition to this inward transport, a non-specific outward movement (flop) has been reported to be present in erythrocyte membranes (Bitbol and Devaux, 1988; Conner et al., 1990; Connor et al., 1992). This outward movement, which was shown for both spin-labeled and NBD-labeled lipid probes, appears to be much slower than the inward transport of PS and PE by the aminophospholipid translocase. The putative so-called floppase, like the translocase, is inhibited at low temperature and by thiol reagents, and requires both ATP and GSSG for transport activity. Recent evidence has demonstrated that the floppase in erythrocytes is identical with MRP1 (Dekkers et al., 1998; Kamp and Haest, 1998), a member of the family of MRPs. MRP1 is an ATP dependent membrane transport protein that, like the family of multidrug resistance (MDR) proteins, is responsible for expelling toxic and xenobiotic compounds from the cell (Keppler et al., 1997). Raggers et al. (Raggers et al., 1999) demonstrated transport of sphingolipid analogues across the plasma membrane of LLC-PK1 kidney epithelial cells transfected with MRP1 cDNA. Like MRP1, MDR Pglycoproteins can also actively translocate different lipids across the membrane. Whereas transport by MDR3, which is most abundant in the bile-canalicular system, is restricted to PC (Smit et al., 1993; Smith et al., 1994), other MDR P-glycoproteins transport a variety of lipids across the membrane (van Helvoort et al., 1997; van Helvoort et al., 1996). Whereas most of these studies were restricted to transport of short-chain or fluorescently-labeled lipid analogues, two groups of workers (Bettaieb et al., 1996; Bezombes et al., 1998; van Helvoort et al., 1997; van Helvoort et al., 1996) have provided evidence that MDR P-glycoproteins fulfil a role in transport of endogenous choline-containing phospholipids across the membrane. The aim of the present study was to obtain evidence for a role of MRP1 in the transbilayer distribution of endogenous phospholipids. 


\section{Materials and Methods}

\section{Materials}

1-Oleoyl-2-[6(7-nitrobenz-2-oxa-1,3-diazol-4-yl)amino]caproyl-snsphingomyelin $\left(\mathrm{C}_{6}\right.$-NBD-Spm) and, 1-oleoyl-2-[6(7-nitrobenz-2-oxa-1,3diazol-4-yl) amino] caproyl-sn-glycero-3-phosphocholine( $\mathrm{C}_{6}$-NBD-PC), 1oleoyl-2-[6(7-nitrobenz-2-oxa-1,3-diazol -4-yl) amino] caproyl-snglycero-3-phosphoserine ( $\mathrm{C}_{6}$-NBD-PS), were obtained from Avanti Polar Lipids (Alabaster, AL). Verapamil, indomethacin, chlorpromazine and bovine serum albumin were purchased from Sigma (St. Louis, MO). Before the experiments, fresh stock solution of the inhibitors were prepared: $100 \mathrm{mM}$ verapamil in water; $1 \mathrm{M}$ indomethacin in ethanol and $100 \mathrm{mM}$ chlorpromazin in water. Phospholipase $\mathrm{A}_{2}$ (EC 3.1.1.4) from Naja naja and bee venom (Apis Mellifica) and sphingomyelinase (EC 3.1.4.12) from Stapylococcus Aureus were purified by the method of Zwaal et al. (Zwaal et al., 1975). All other reagents were of the highest grade commercially available.

\section{Isolation of erythrocytes}

Whole blood was obtained from healthy volunteers by venipuncture, with acid citrate dextrose $(\mathrm{ACD} ; 0.18 \mathrm{M}$ glucose, $0.08 \mathrm{M}$ trisodium citrate, $0.052 \mathrm{M}$ citric acid) as anti-coagulant in a final ratio of 1:5 (v/v). Erythrocytes were collected by centrifugation and washed with a Hepes buffer (136 mM NaCl, $2.7 \mathrm{mM} \mathrm{KCl,} 2 \mathrm{mM} \mathrm{MgCl} 2,10 \mathrm{mM}$ Hepes, $0.2 \mathrm{mM}$ EGTA, $10 \mathrm{mM}$ glucose, adjusted at $\mathrm{pH}$ 7.5). Cells were finally resuspended in the same buffer at a concentration of $5 \times 10^{8} \mathrm{RBC} / \mathrm{mL}$.

Inward movement of $C_{6}$-NBD-phospholipids.

Erythrocytes were incubated with $2 \mu \mathrm{M} \quad \mathrm{C}_{6}$-NBD-probe, which corresponded to approx. $1 \%$ of the endogenous lipids. At zero time the inhibitors were added from their respective stock solutions and the incubation is followed at a temperature of $37{ }^{\circ} \mathrm{C}$. At intervals $40 \mu \mathrm{L}$ aliquots from the cell suspension were removed and diluted in $160 \mu \mathrm{L}$ buffer with or without $1 \% \quad(w / v)$ BSA. After extraction at room temperature for $1 \mathrm{~min}$, cells were centrifuged at $12000 \mathrm{xg}$ and the pellets were solubilized in $2 \mathrm{~mL}$ of $1 \%(\mathrm{w} / \mathrm{v})$ Triton $\mathrm{X}-100$. The amount of internalized probe was determined by comparing the fluorescence 
intensity associated with the cells before and after extraction of the probe with BSA. The fluorescence intensities were measured at an excitation wavelength of $472 \mathrm{~nm}$ and emission wavelength of $534 \mathrm{~nm}$. The integrity of the lipid probes was verified with TLC. No degradation of the probes was observed during the course of the experiments.

\section{Treatment of erythrocytes with phospholipases and sphingomyelinase.}

Cells were incubated at $37^{\circ} \mathrm{C}$ for 5 and $48 \mathrm{~h}$ in the presence or absence of $100 \mu \mathrm{M}$ verapamil or $250 \mu \mathrm{M}$ indomethacin. During the $48 \mathrm{~h}$ incubation, cells were washed and the buffer and inhibitor were replaced every $8 \mathrm{~h}$. After incubation with inhibitor, erythrocytes were treated with phospholipases $\mathrm{A}_{2}$ and sphingomyelinase to hydrolyse lipids present in the outer leaflet as described previously (Verkleij et al., 1973). In brief, 5 $\mathrm{mL}$ of cell suspension was incubated with a mixture of 24 units of $N$. naja phospholipase $A_{2}$ and 40 units phospholipase $A_{2}$ from bee venom. After $30 \mathrm{~min}, 4$ units of sphingomyelinase was added. The cells were incubated for another $2 \mathrm{~h}$ at $37^{\circ} \mathrm{C}$ with occasional stirring to keep cells in suspension. During the incubation, the haemolysis was measured routinely and only when lysis remained below $5 \%$, were cells considered for further analysis. Hydrolysis was arrested by addition of 15 mM EDTA after which the cells were sedimented and analysed for phospholipid hydrolysis. Lipids were extracted and separated by two-dimensional TLC, followed by determination of phosphorus as described by Verkley et al. (Verkleij et al., 1973).

\section{Transmission electron microscopy}

After being washed, the cell suspension was centrifuged and the pellet was resuspended in $0.1 \mathrm{M}$ phosphate buffer containing $2.5 \%(\mathrm{v} / \mathrm{v})$ glutaraldehyde. After fixation, the cells were washed twice with $0.1 \mathrm{M}$ phosphate buffer and post-fixed for $1 \mathrm{~h}$ with $1 \%(\mathrm{w} / \mathrm{v}) \mathrm{OsO}_{4}$ in $0.1 \mathrm{M}$ phosphate buffer, dehydrated in a graded ethanol series and embedded in Epon 812. Ultrathin sections (approx. $70 \mathrm{~nm}$ ) were cut on a Reichert-Jung ultracut microtome and collected on 75-mesh Formvar-coated copper grids; the grids were contrasted with uranyl acetate in $50 \%(\mathrm{v} / \mathrm{v})$ ethanol for $10 \mathrm{~min}$, followed by staining for $5 \mathrm{~min}$ with lead citrate. The contrasted sections were dried in air and analysed in a Philips CM 10 microscope at $80 \mathrm{KeV}$. 


\section{Results}

Addition of $\mathrm{C}_{6}$-NBD-PC to washed human erythrocytes results in a slow inward transport of the probe, reaching equilibrium after approx. $6 \mathrm{~h}$ (Fig. $1 \mathrm{~A}$, lower curve). Inspection of the uptake curve shows that, at equilibrium, $25 \%$ of the probe is present in the inner leaflet and $75 \%$ in the outer leaflet, closely reflecting the distribution of endogenous PC in the erythrocyte membrane. Because NBD-lipid analogues have been demonstrated to be a substrate for outward transport by MRP1 (Dekkers et al., 1998; Kamp and Haest, 1998), the equilibrium distribution of $\mathrm{C}_{6}$ NBD-PC presumably results from spontaneous diffusion across the bilayer and extrusion by MRP1. Consequently, the inhibition of MRP1 was expected to result in a change in equilibrium distribution of the probe. Indeed, as shown in Fig. 1A, incubation with $100 \mu \mathrm{M}$ verapamil, well above the IC50 of 5-7 $\mu \mathrm{M}$ (Dekkers et al., 1998), led to an increased uptake of $\mathrm{C}_{6}$-NBD-PC, levelling off at equimolar distribution. Similar results were obtained when $250 \mu \mathrm{M}$ indomethacin $\left(\mathrm{IC}_{50}\right.$ of $\left.44-55 \mu \mathrm{M}\right)$ was used to inhibit MRP1.

The inward transport of $\mathrm{C}_{6}$-NBD-Spm in the absence and the presence of verapamil is depicted in Fig. 1B. After $24 \mathrm{~h}$, approx. 3\% $\mathrm{C}_{6}$-NBD-Spm was no longer extractable by BSA in control cells incubated in the absence of inhibitor. This value was lower than expected on the basis of the distribution of endogenous Spm, of which approx. $20 \%$ is found in the inner leaflet of the erythrocyte membrane (Verkleij et al., 1973). This might have been due to a low rate of transbilayer diffusion of this probe in comparison to $\mathrm{C}_{6}$-NBD-PC, so that equilibrium had not been fully attained even after incubation for $24 \mathrm{~h}$. Although less pronounced than found for $\mathrm{C}_{6}$-NBD-PC, an increased uptake of $\mathrm{C}_{6}$-NBD-Spm to almost $10 \%$ was observed in erythrocytes incubated with verapamil or indomethacin. It should be noted that translocase-mediated uptake of $\mathrm{C}_{6}$-NBD-PS was not inhibited by verapamil or indomethacin (results not shown). In fact, a consistent but small increase in the uptake of $\mathrm{C}_{6}$-NBD-PS was found in the presence of these inhibitors. This confirms previous findings obtained with erythrocytes from MRPl-knock-out mice (Dekkers et al., 1998).

To find out whether the inhibition of MRP1 also affected the distribution of endogenous phospholipids, we used phospholipase $A_{2}$ in combination with sphingomyelinase to assess the phospholipid composition in the outer leaflet of the membrane. When erythrocytes that had been incubated for 5 $\mathrm{h}$ with verapamil or indomethacin, were treated with phospholipases, no significant change in the pattern of hydrolysed lipids was observed in comparison to control erythrocytes (results not shown). 

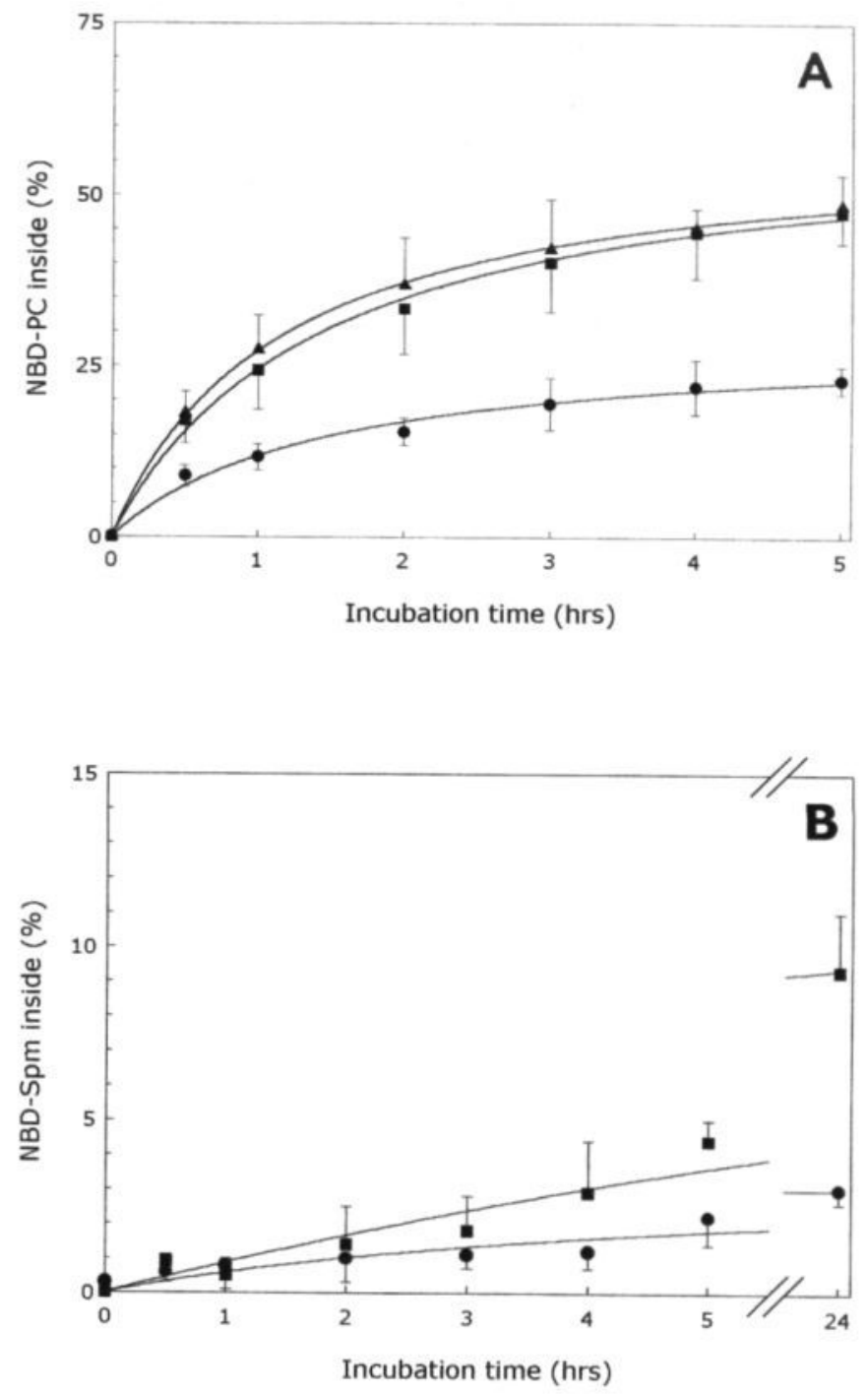

Fig. 1: Inward movement of fluorescent lipid analogues in human RBC.

A. Inward movement of $\mathrm{C}_{6}$-NBD-PC in the absence $(\bullet)$ and presence of $100 \mu \mathrm{M}$ verapamil ( $\mathbf{\square})$ or $250 \mu \mathrm{M}$ of indomethacin( $(\mathbf{\Delta})$. Mean values ( \pm S.D.) of 17 independent experiments with verapamil and 9 independent experiments with indomethacin are presented.

B. Inward movement of $\mathrm{C}_{6}$-NBD-Spm in the absence $(\bullet)$ and presence $(\boldsymbol{\square})$ of $100 \mu \mathrm{M}$ verapamil. Mean values $( \pm$ S.D.) of 4 independent experiments are presented. For reasons of clarity results for Spm uptake in the presence of indomethacin are not shown, because they are indistinguishable from the results in the presence of verapamil. 
Table 1: Phospholipid hydrolysis by the combined action of phospholipase $A_{2}$ and sphingomyelinase in erythrocytes incubated for $48 \mathrm{~h}$ in the absence or presence of MRP1 inhibitors verapamil or indomethacin.

$P$ values were obtained by comparison of the incubations with the use of paired Student's $t$ tests. Values are the means \pm S.E.M. for 12 experiments in which verapamil $(100 \mu \mathrm{M})$ was used and 5 experiments with indomethacin $(250 \mu \mathrm{M})$ as inhibitor for MRP1. The group of donors in the verapamil experiments was different from the donor group used in the indomethacin experiments, which is why the results of the two control groups are listed separately.

Phospholipid hydrolysis was calculated using PC+lysoPC as internal standard. Abbreviation: n.d., not detectable.

\begin{tabular}{|c|c|c|c|c|}
\hline \multirow[t]{3}{*}{ Lipid } & \multirow{2}{*}{\multicolumn{2}{|c|}{$\begin{array}{c}\text { Verapamil }(n=12) \\
\% \text { hydrolysis }( \pm \text { SEM })\end{array}$}} & \multirow{2}{*}{\multicolumn{2}{|c|}{$\begin{array}{l}\text { Indomethacin }(n=5) \\
\% \text { hydrolysis }( \pm \text { SEM })\end{array}$}} \\
\hline & & & & \\
\hline & Control & MRPI-inhibited & Control & MRP1-inhibited \\
\hline $\mathrm{PC}$ & $74 \pm 2$ & $67 \pm 1^{*}$ & $73 \pm 1$ & $65 \pm 2^{*}$ \\
\hline Spm & $82 \pm 1$ & $77 \pm 1^{*}$ & $78 \pm 2$ & $77 \pm 2$ \\
\hline PE & $25 \pm 1$ & $26 \pm 2$ & $22 \pm 2$ & $20 \pm 2$ \\
\hline PS & n.d. & n.d. & n.d. & n.d. \\
\hline
\end{tabular}

$*(\mathrm{p}<001)$

However, this could be explained by the slow transbilayer movement of endogenous phospholipids in the erythrocyte membrane, which for PC was estimated to have a half-time of between 3-26 hours, depending on the acyl chain composition (Middelkoop et al., 1986). We therefore prolonged the incubation period with inhibitors to $48 \mathrm{hrs}$ before analysing the lipids present in the outer leaflet. As shown in Tab. 1, the amount of PC that could be hydrolysed decreased from $74 \pm 2 \%$ in control cells to $67 \pm 1 \%$ in cells treated with verapamil, and from $73 \pm 1$ to $65 \pm 2 \%$ in cells incubated with indomethacin. For Spm the hydrolysis was $82 \pm 1 \%$ in control cells and $77 \pm 1 \%$ for verapamil-treated cells, whereas decreased Spm hydrolysis was less obvious in cells treated with indomethacin. No significant change in hydrolysis of PE was found. Hydrolysis of PS was not detectable in either control or inhibited cells.

These results seem to confirm earlier observations by Schrier et al. (Schrier et al., 1983), who also found a decreased hydrolysis of PC and Spm after treatment of erythrocytes with amphipathic compounds such as primaquine and chlorpromazine. However, they demonstrated that at high concentrations, these agents induce stomatocytosis and subsequent formation of endovesicles that could explain the decreased hydrolysis of PC and Spm. We therefore examined the morphology of the erythrocytes incubated with verapamil or indomethacin by electron microscopy. Fig. 2 illustrates that no endovesicles were formed after incubation for $24 \mathrm{~h}$ with $100 \mu \mathrm{M}$ verapamil or $250 \mu \mathrm{M}$ indomethacin, whereas occasional 
endovesicle formation was observed after incubation for $48 \mathrm{~h}$ (Fig. 2C-F). As a positive control, we used chlorpromazin at a concentration of 200 $\mu \mathrm{M}$, which causes massive production of endovesicle (Isomaa, 1987; Schrier et al., 1983) (Fig. 2B). In addition, in experiments to measure inward transport of NBD-lipid analogues under conditions inhibitory to MRP1, no appreciable endovesicle formation was found (Fig. 2G and H). This indicates that, in MRP1-inhibited cells, the decreased accessibility of PC and Spm to exogenously added phospholipases, and the increased amounts of fluorescent analogues of these lipids that were not extractable by BSA, were unrelated to the entrapment of lipid in endovesicle membranes.

\section{Discussion}

The use of fluorescently-labeled and spin-labeled lipid analogues has contributed significantly to a better understanding of the mechanisms that control transbilayer distribution and movement of membrane lipids. At equilibrium, the distribution of most of the NBD- or spin-labeled analogues of the major phospholipid classes closely reflects the distribution of the endogenous lipids. Both types of lipid probes have been instrumental in the discovery and further characterization of the aminophospholipid translocase, responsible for the fast and ATPdependent inward transport of aminophospholipids. In addition, these probes permitted the detection of a counter-transport, referred to as floppase activity, which is also ATP-dependent but seemed to be nonspecific with respect to the phospholipid polar headgroup (Bitbol and Devaux, 1988; Conner et al., 1990; Connor et al., 1992). Studies with MRP1 inhibitors (Kamp and Haest, 1998) and MRP1 knock-out mice (Dekkers et al., 1998) have demonstrated that the outward movement of NBD-labeled lipid analogues as observed in erythrocytes, is mediated by MRP1. Therefore, the equilibrium distribution of NBD-labeled lipids might result from spontaneous diffusion across the bilayer, a fast inward transport specific for aminophospholipids, and a much slower MRP1mediated outward transport which is non-specific. Blocking MRP1 causes a re-allocation of the lipid probes, which is most pronounced for $\mathrm{C}_{6}$-NBD$\mathrm{PC}$ because this probe becomes equally distributed over both membrane leaflets. However, $\mathrm{C}_{6}$-NBD-Spm does not seem to equilibrate at an equimolar distribution over both membrane leaflets. Although the apparently much lower rate of spontaneous diffusion of $\mathrm{C}_{6}$-NBD-Spm would require a longer time for equilibration, it is clear from the curve in Fig. 1B that an equal distribution over both leaflets is rather unlikely to be 
reached. This might suggest that, as well as MRP1, another transporter is operative for $\mathrm{C}_{6}$-NBD-Spm. Bettaieb et al. (Bettaieb et al., 1996) and Bezombes et al. (Bezombes et al., 1998) have suggested that a Pglycoprotein, not further defined, has a role in the preferential outward orientation of Spm in human leukemia KGla cells. Whether or not this protein is present in erythrocytes remains to be established. In addition $\mathrm{C}_{6^{-}}$ NBD-PS was found to be transported to the outer membrane leaflet by MRP1, as shown previously (Dekkers et al., 1998; Kamp and Haest, 1998). Because inward transport by the aminophospholipid translocase is much faster than the outward movement by MRP1, more than $80 \%$ of $\mathrm{C}_{6}$ NBD-PS is located in the inner leaflet at equilibrium. A minor but reproducible increased uptake of $\mathrm{C}_{6}$-NBD-PS was found in erythrocytes from MRP1 knock-out mice (Dekkers et al., 1998). $\mathrm{C}_{6}$-NBD-PE was not used in these studies, because it does not always reflect the distribution of the endogenous PE (Connor et al., 1992; Morrot et al., 1989). An important question raised by the present observations with lipid analogues is whether MRP1 is also involved in the outward transport of endogenous phospholipids. This issue has also been raised with regard to the function of the related family of MDR proteins. Van Helvoort and coworkers (van Helvoort et al., 1996) have shown that, in addition to NBD-lipid analogues, short-acyl-chain analogues of PC are also substrate for MDR1. With the exception of transport of natural PC by MDR3 in the bilecanalicular system (Smith et al., 1994) and the suggested role of Pglycoprotein in the distribution of endogenous Spm in leukemic cells (Bettaieb, 1996; Bezombes et al., 1998), no evidence for a function of MDR or MRP in the distribution of endogenous lipids has yet been presented. The present results demonstrate that prolonged inhibition of MRP1 in erythrocytes is associated with a shift in the distribution of endogenous PC and Spm. The distributions of PE and PS remained unchanged.

The absence of PS in the outer surface was also checked with the prothrombinase assay (Dekkers et al., 1998), an extremely sensitive method for detecting traces of PS in the membrane outer leaflet.

No change in prothrombinase activity of erythrocytes was found after $48 \mathrm{~h}$ incubation with verapamil or indomethacin. Schrier et al. (Schrier et al., 1983), using erythrocytes treated with primaquine, vinblastin or chlorpromazine also found decreased hydrolysis of PC and Spm by phospholipases without change in hydrolysis of PE and PS. They demonstrated that reorganization of membrane lipids was not due to a membrane-perturbing effect of these amphipatic compounds that would facilitate lipid migration across the bilayer. 

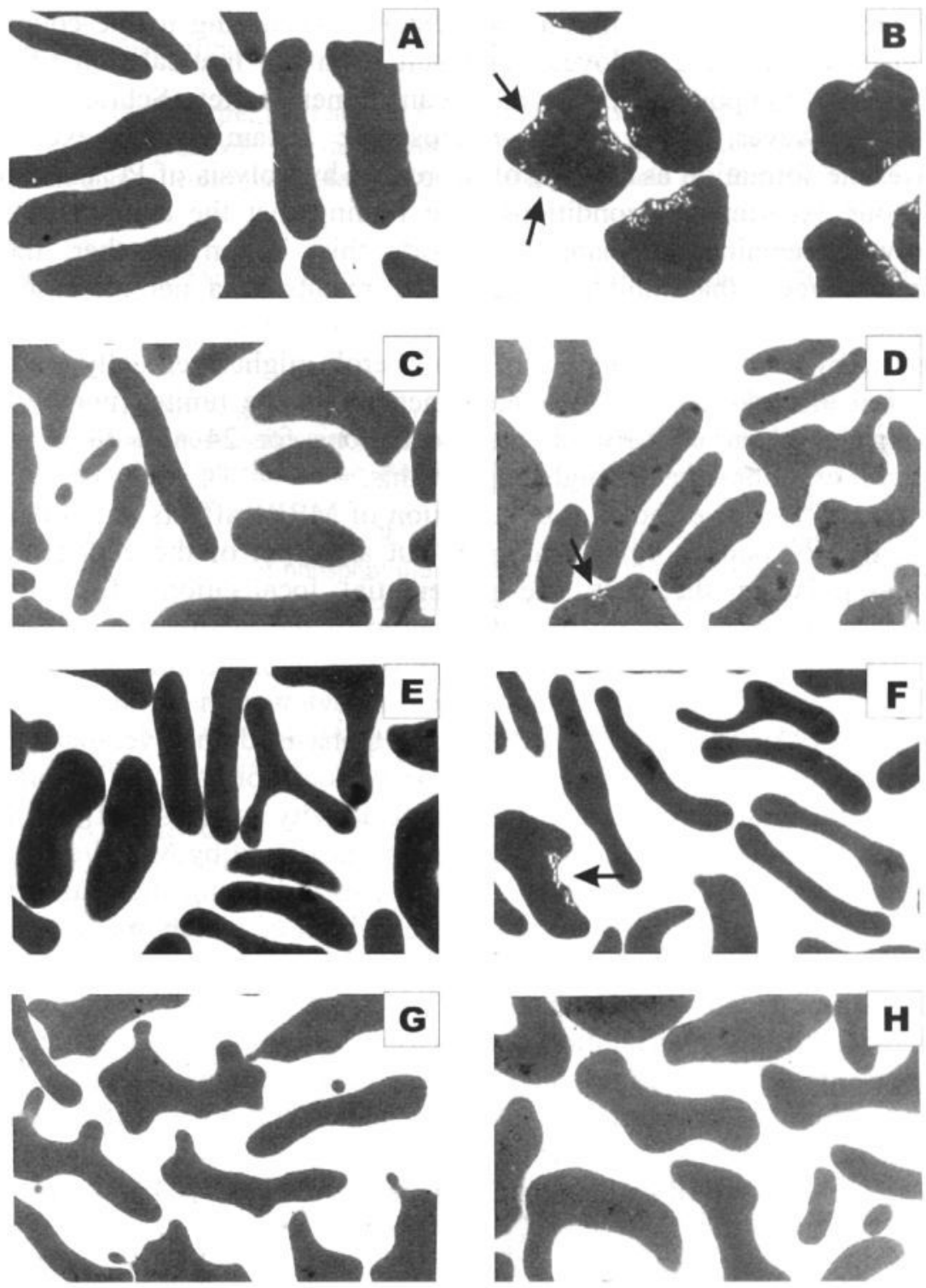

Fig.2: Electron micrographs of human erythrocytes. A, control cells; B, erythrocytes treated for $2 \mathrm{~h}$ with $200 \mu \mathrm{M}$ chloropromazin (positive control); C en D, erythrocytes treated with $100 \mu \mathrm{M}$ verapamil for $24 \mathrm{~h}(\mathrm{C})$ and $48 \mathrm{~h}$ (D); E and F, erythrocytes treated with $250 \mu \mathrm{M}$ indomethacin for $24 \mathrm{~h}(\mathrm{E})$ and $48 \mathrm{~h}(\mathrm{~F}) ; \mathrm{G}$ and $\mathrm{H}$, erythrocytes incubated with $\mathrm{C}_{6}$-NBD-PC for $5 \mathrm{~h}$ in the absence $(\mathrm{G})$ and presence $(\mathrm{H})$ of verapamil. Arrows indicate endovesicles. Magnification: approx. 2800-fold. 
In contrast, they showed that decreased hydrolysis of PC and Spm was due to entrapment of these lipids in endovesicles. According to the coupled bilayer-principle these endovesicles result from the intercalation of the amphipathic compounds in the membrane inner leaflet (Schrier et al., 1983). However, an electron-microscopic examination excludes endovesicle formation as a cause of decreased hydrolysis of PC and Spm under our experimental conditions. The finding that the amount of PE hydrolysed remained unchanged supports this. Taken together, these findings suggest that inhibition of MRP1 results in a net increase of phospholipid mass in the inner leaflet of the membrane that, unless corrected by outward movement of cholesterol, might eventually lead to formation of endovesicles. The small increase in the limited number of endovesicles observed between the incubations for 24 and $48 \mathrm{~h}$ with verapamil or indomethacin might support this.

In summary, we have shown that inhibition of MRP1 affects not only the distribution of phospholipid analogues but also that of the endogenous phospholipids. In the past, the preferential localisation of cholinecontaining phospholipids in the outer leaflet of the membrane has often been explained to balance the inward movement of PS and PE by the activity of the aminophosholipid translocase (reviewed in Williamson and Schlegel, 1994). However, it should be emphasized that verapamil or indomethacin, even after incubation for $48 \mathrm{~h}$, does not have an inhibitory effect on the aminophospholipid translocase activity as measured with $\mathrm{C}_{6}$ NBD-PS. In addition, the outward movement mediated by MRP1 after 48 $\mathrm{h}$ in the absence of inhibitors is not affected, indicating that sufficient amounts of ATP and GSSG are still present, both of which are cofactors for MRP1 activity (Dekkers et al., 1998). Thus, by inhibiting MRP1 while leaving aminophospholipid translocase intact, the outward orientation of choline-containing phospholipids decreases without compensation by aminophospholipids. We therefore conclude that MRP1 has an active role in the preferential orientation of PC and Spm in the outer leaflet of the erythrocyte membrane, and that this orientation does not merely result from active transport of aminophospholipids to the inner leaflet.

\section{REFERENCES}

Beleznay, Z., Zachowski, A., Devaux, P. F., Navazo, M. P., and Ott, P. (1993) ATP dependent aminophospholipid translocation in erythrocyte vesicles: stoichiometry of transport. Biochemistry $32,3146-52$. 
Bettaieb, A. Record, M., Come, M. G., Bras, A. C., Chap, H., Laurent, G., and Jaffrezou, J. P. (1996) Opposite effects of tumor necrosis factor alpha on the sphingomyelin-ceramide pathway in two myeloid leukemia cell lines: role of traverse sphingomyelin distribution in the plasma membrane. Blood 88, 1465-72.

Bezombes, C., Maestre, N., Laurent, G., Levade, T., Bettaieb, A., and Jaffrezou, J. P. (1998) Restoration of TNF-alpha-induced ceramide generation and apoptosis in resistant human leukemia KGla cells by the P-glycoprotein blocker PSC833. Faseb. J. 12,101-9.

Bitbol, M., and Devaux, P. F. (1988) Measurement of outward translocation of phospholipids across human erythrocyte membrane. Proc. Natl. Acad. Sci. USA 85, 6783-7

Conner, J., Gillum, K., and schroit, A. J. (1990) Maintenance of lipid asymmetry in red blood cells and ghosts: effect of divalent cations and serum albumin on the transbilayer distribution of phosphatidylserine. Biochim. Biophys. Acta 1025, 82-86.

Connor, J., Pak, C. H., Zwaal, R. F. A., and Schroit, A. J. (1992) Bidirectional transbilayer movement of phospholipid analogs in human red blood cells. Evidence for an ATP-dependent and protein mediated process. J. Biol. Chem. 267, 19412-19417.

Dekkers, D. W. C., Comfurius, P., Schroit, A. J., Bevers, E. M., and Zwaal, R. F. A. (1998) Transbilayer movement of NBD-labeled phospholipids in red blood cell membranes: Outward-directed transport by the multidrug resistance protein 1 (MRP1). Biochemistry 37 (42), 14833-14837.

Isomaa, B., Hagerstrand, H., and Paatero, G. (1987) Shape transformations induced by amphiphiles in erythrocytes. Biochim. Biophys. Acta 899, 93-103.

Kamp, D., and Haest, C. W. M. (1998) Evidence for a role of the multidrug resistance protein (MRP) in the outward translocation of NBD-phospholipids in the erythrocyte membrane. Biochim. Biophys. Acta 1372, 91-101.

Keppler, D., Leier, I., and Jedlitschky, G. (1997) Transport of glutathione conjugates and glucuronides by the multidrug resistance proteins MRP1 and MRP2. Biol. Chem. $378,787-791$.

Middelkoop, E., Lubin, B. H., Op den Kamp, J. A. F., and Roelofsen, B. (1986) Flipflop rates of individual molecular species of phosphatidylcholine in the human red cell membrane. Biochim. Biophys.Acta 855, 421-424.

Morrot, G., Herve, P., Zachowski, A., Fellmann, P., and Devaux, P. F. (1989) Aminophospholipid translocase of human erythrocytes: phospholipid substrate specificity and effect of cholesterol. Biochemistry $28,3456-3462$.

Raggers, R. J., van Helvoort, A., Evers, R., and van Meer, G. (1999) The human multidrug resistance protein MRP1 translocates sphingolipid analogs across the plasma membrane. J. Cell Sci. 112, 415-422. 
Schrier, S. L., Chiu, D. T-Y., Yee, M., Sizer, K., and Lubin, B. (1983) Alteration of membrane phospholipid bilayer organization in human erythrocytes during drug induced endocytosis. J. Clin. Invest. 72, 1698-1705.

Seigneuret, M., and Devaux, P. F. (1984) ATP-dependent asymmetric distribution of spin-labeled phospholids in the erythrocyte membrane: relation to shape changes. Proc. Natl. Acad. Sci. USA 81, 3751-3755.

Smit, J. J., Schinkel, A. H., Oude Elferink, R. P., Groen, A. K., Wagenaar, E., van Deemter, L., Mol, C. A., Ottenhoff, R., van der lugt, N. M., and van Roon, M. A. (1993) Homozygous disruption of the murine mdr2 P-glycoprotein gene leads to a complete abscence of phospholipid from bile and to liver disease. Cell 75, 451-62.

Smith, A. J., Timmermans-Hereijgers, J. L. P. M., Roelofsen, B., Wirtz, K. W. A., van Blitterswijk, W. J., Smit, J. J. M., Schinkel, A. H., and Borst, P. (1994) The human MDR3 P-glycoprotein promotes translocation of phosphatidylcholine through the plasma membrane of fibroblasts from transgenic mice. FEBS Letters 354, 263-266.

Van Helvoort, A., Giudici, M. L., Thielemans, M., and van Meer, G. (1997) Transport of sphingomyelin to the cell surface is inhibited by brefeldin A and in mitosis, where C6-NBD-sphingomyelin is translocated across the plasma membrane by a multidrug transporter activity. J. Cell Sci. 110, 75-83.

van Helvoort, A., Smith, A. J., Sprong, H., Fritzsche, I., Schinkel, A. H., Borst, P., and van Meer, G. (1996) MDR1 P-glycoprotein is a lipid translocase of broad specificity, while MDR3 P-glycoprotein specifically translocates phosphatidylcholine. Cell 87 , 507-517.

Verkleij, A. J., Zwaal, R. F. A., Roelofsen, B., Comfurius, P., Kastelijn, D., and van Deenen, L. L. M. (1973) The asymmetric distribution of phospholipids in the human red cell membrane. A combined study using phospholipases and freeze-etch electron microscopy. Biochim. Biophys. Acta 323, 178-193.

Williamson, P., and Schlegel, R. A. (1994) Back and forth: the regulation and function of transbilayer phospholipid movement in eukaryotic cells (Review). Mol. Membr. Biol. 11, 199-216.

Zwaal, R. F. A., and Schroit, A. J. (1997) Pathophysiologic implications of membrane phospholipid asymmetry in blood cells. Blood $89,1121-32$.

Zwaal, R. F. A., Roelofsen, B., Comfurius, P., and van Deenen, L. L. M. (1975) Organization of phospholipids in human red cell membranes as detected by the action of various purified phospholipases. Biochim. Biophys. Acta 406, 83-96. 
MRPI regulates lipid asymmetry 
Chapter 6 
Chapter 7

Discussion 
Chapter 7 
The results presented in this thesis reveal new information about the regulation of transbilayer movement of lipids. Although the regulation of transbilayer movement of lipids is still not fully understood, the involvement of lipid transporters is beyond dispute. An aminophospholipid translocase is responsible for the inward movement of the aminophospholipids and is counter-balanced by an outward directed transport of all lipids facilitated by the floppase (MRP1). Both processes require ATP-hydrolysis for activity. MRP1 is able to transport NBD-lipid analogues but also endogenous lipids as described in chapter 5 and 6 . Although the activity of MRP1 in red blood cells is much lower than the activity of the aminophospholipid translocase, both proteins seem to be necessary for the maintenance of lipid asymmetry. Mechanisms of maintenance or collapse of lipid asymmetry are interesting to investigate due to their importance in physiological and pathological processes. The change in membrane lipid distribution is most clearly manifested by the exposure of phosphatidylserine in the outer leaflet. The exposure of PS on platelets is of physiological importance as it serves as binding sites for blood coagulation complexes, necessary for an acute response to injury. Furthermore, PS exposure in various cell types could have a function as recognition site for macrophages. This mechanism of scavenging PS exposing cells is important to remove redundant cells during tissue development, but is also required for clearance of thrombogenic cells from the blood circulation. Disturbances in one of the mechanisms responsible for regulation of the transbilayer distribution may result in clinical manifestations. Increased surface exposure of PS could result from alterations in the aminophospholipid translocase activity. In sickle cells, under deoxygenating conditions, an increased surface exposure of aminophospholipids was shown which was accompanied by a decrease in translocase activity (Blumenfeld et al., 1991). A decreased, though rather small, aminophospholipid translocase activity is also observed in red blood cells from patients' with ß-thalassemia (Srinivasan and Basu, 1996).

A rare disorder, in which the patients' platelets and also red blood cells are defective in $\mathrm{Ca}^{2+}$-induced lipid scrambling is known as Scott syndrome. The diminished exposure of PS at the outer leaflet results in an impaired tenase- and prothrombinase activity, leading to a moderately severe bleeding disorder. Recently, a reversed phenomenon was found, referred to as Stormorken syndrome, resulting in a hyper coagulant state (Stormorken et al., 1995). Increasing evidence becomes available for a role of $\mathrm{ABC}$ transporters in lipid transport and related pathological processes. Uni-directional transport of PC is catalyzed by a member of the Pglycoprotein family, in the canalicular domain of murine hepatocyte plasma membranes, to provide PC for bile production (Smit et al., 1993). 
ABCA1 (ABC1) is involved in Tangier disease. Under normal conditions, HDL carries cholesterol extruded from peripheral tissue. Although Tangier disease is associated with low levels of $\mathrm{HDL}$, in vitro, studies indicated that a defective efflux of cholesterol from cultured fibroblasts of patients' with Tangier disease is not due to low HDL but is related to a defective $\mathrm{ABCl}$ protein (reviewed in Schmitz, 2000). ABCG1 (ABC8) regulates cholesterol and lipid movement in macrophages, especially to overcome macrophage lipid overloading ("foam-cell" formation in atherosclerosis). Inhibition of $\mathrm{ABC} 8$ leads to a reduced efflux of cholesterol and cholinephospholipids (Klucken et al., 2000). Based on the findings presented in this thesis and data available from other studies, I would like to use this discussion to speculate on possible models to explain loss of lipid asymmetry.

The simplest way to explain collapse of membrane lipid asymmetry is a mechanism in which inhibition of the aminophospholipid translocase and the floppase (MRP1) leads to a spontaneous randomization of all lipids caused by transmembrane diffusion (Fig. 1A). Spontaneous transmembrane diffusion, however, is very slow and varies between 3 and $26 \mathrm{~h}$ for phosphatidylcholine (Middelkoop et al., 1986). Furthermore, Bevers et al. (Bevers et al., 1992) showed that prolonged ATP depletion in red blood cells resulting in inhibition of both transporters, does not lead to appreciable loss of lipid asymmetry over days. Calcium-dependent activation of a scrambling mechanism seems to be necessary to lead to a rapid collapse of lipid asymmetry.

A pore-forming model as proposed in Fig. 1B, would be consistent with the observed bi-directional and non-selective properties of the scramblase. Such a pore could either consist of several protein subunits, or may be formed by a single protein. As shown in Fig 1B, the polar headgroup migrates through a hydrophilic core while the acyl chains remain in the hydrophobic part of the membrane. The formation of a pore is consistent with the data presented in chapter 3 , where we observed that an increase in size of the headgroup is associated with a decrease of scrambling activity. Not only the size of the headgroup but also the backbone of the lipid species determines the kinetics of transport. Spm and PC, which differ in their backbone moiety but contain the same choline headgroup, have completely different rates of $\mathrm{Ca}^{2+}$-induced scrambling in red blood cells. 
$1 \mathrm{~A}$

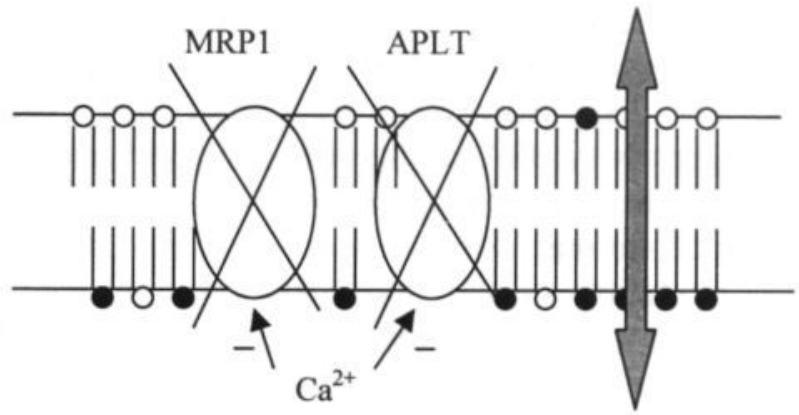

$1 \mathrm{~B}$

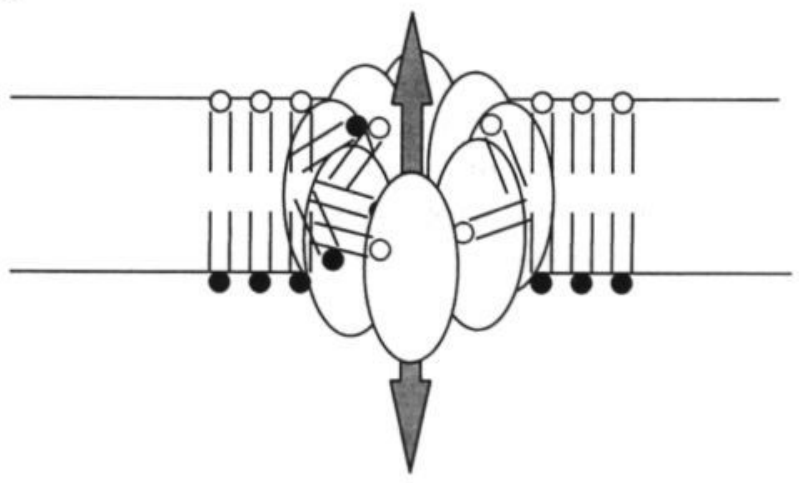

$1 \mathrm{C}$

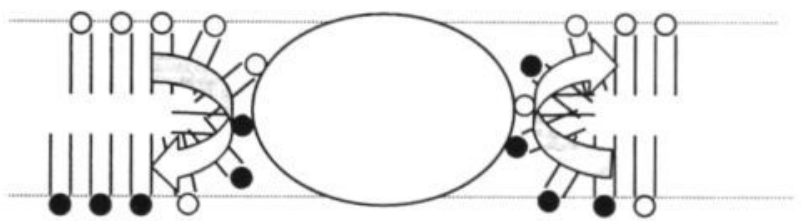

Fig. 1: Proposed models for $\mathrm{Ca}^{2+}$-induced lipid movement. 1A: prime model 1B: Pore-forming model 1C: Hydrophobic-mismatch model. Black circles represent aminophospholipids and white circles the cholinephospholipids.

Similarly, the rate of scrambling of GalCer was much less than that of PGal, despite its somewhat smaller headgroup (galactose in stead of phospho-galactose). These findings could indicate a diminished recognition for the scramblase of lipids with a ceramide backbone. 
Alternatively, the preferential location of sphingosine-based lipids in rafts may also explain the decreased scrambling activity (Brown et al., 2000). One might expect that association of these lipids within rafts would affect their ability to be extracted with BSA. However, extraction of cells loaded with Spm and GalCer analogues with BSA results in a complete removal of the probe from the outer leaflet. Also, it is not known whether rafts are maintained under scrambling conditions.

The assembly, or active formation of the pore, could be related to phosphorylation events. Several groups (Dachary-Prigent et al., 1997; Dekkers et al., 1998; Pasquet et al., 1998) showed that a diminished scrambling activity was related to a decrease in phosphorylated tyrosine residues of various proteins. White erythrocyte ghosts are still able to scramble their lipids (Bevers et al., 1992; Connor and Schroit, 1990; Williamson et al., 1985) indicating that hydrolysable ATP is not required. However, as shown in chapter 4 , a diminished tyrosine phosphorylation pattern is found when $\mathrm{Ca}^{2+}$-induced lipid scrambling is inhibited or defective as in case of a patient with Scott syndrome. Although we concluded in chapter 4 that the diminished tyrosine phosphorylation pattern is an epiphenomenon, possibly associated with deficient lipid scrambling but not causal to this defect, we can not exclude that regulation of lipid scrambling is controlled by phosphorylation events. First, in chapter 4 , only the tyrosine-phosphorylation pattern was investigated. If the scramblase is constitutively tyrosine phosphorylated, it would be possible that the level of this phosphorylated protein is too low to be detected on Western blots even in non-activated cells. Furthermore, phosphorylation of threonine of serine-residues, which we did not investigate, could be the regulatory step. Zhou et al. (Zhou et al., 1997), who first cloned a putative scramblase, a $37 \mathrm{kDa}$ protein, showed that a potential protein kinase $\mathrm{C}$ phosphorylation site at $\mathrm{Thr}^{159}$ was present, indeed suggesting that other phosphorylation events could be responsible for lipid scrambling.

The finding that prolonged starvation of red blood cells is accompanied with a decreased scrambling activity could result from dephosphorylation of protein(s) and subsequent inability to form a pore. Observations in platelets by Williamson et al. (Williamson et al., 1995) revealed that in time the activity of the scrambling process is abolished when these cells are activated with calcium/ionophore. Since treatment with calcium/ionophore is accompanied by a rapid consumption of ATP, it can be speculated that also under these circumstances dephosphorylation occurs, resulting in disassembly of the pore. In contrast, in calcium/ionophore treated red blood cells, scramblase activity is not lost in time (unpublished observation). This may be explained by a higher 
phosphatase activity in platelets in comparison to red blood cells. Recently, Frasch et al. (Frasch et al., 2000) showed that direct phosphorylation by protein kinase $\mathrm{C} \delta$, of the phospholipid scramblase cloned by Zhou et al. (Zhou et al., 1997), results in an increased scramblase activity in activated Chinese hamster ovary cells.

While the diameter of the pore will obviously set limits to the size of the polar headgroup of the lipid that undergoes scrambling, other factors may also determine the kinetics of scrambling. Interaction of lipids with other membrane protein- or lipid components or with cytoskeletal structures may restrict their lateral migration to the pore sites.

Bevers et al. (Bevers et al., 1992) showed that positive charged TMA-DPH is transported only under scrambling conditions, suggesting that the scramblase is not selective to anionic and neutral polar headgroup lipids. Therefore charge of the lipid headgroup probably plays a minor role in transbilayer movement of lipids.

With respect to the glyco-phospholipids, hydration could be responsible for the decreased scrambling activity observed for these lipids. If lipids have to be dehydrated prior to movement through a non-aqueous pore, movement will be decreased with increasing size of the carbohydrate residues.

A third model for a scramblase mechanism is based on a hydrophobic mismatch principle (Reviewed in Killian, 1998) as shown in Fig. 1C. A $\mathrm{Ca}^{2+}$-induced conformational change of a particular transmembrane protein may cause short circuiting the outer and the inner leaflet of the bilayer. This reduces the transversal rearrangement of the lipids to a process of lateral diffusion. However, lateral diffusion is very rapid, $10^{7} \mathrm{~s}^{-1}$ (Devaux, 1991) which makes it unlikely as a rate limiting step. The rate of scrambling in a 'mismatch model' as proposed in Fig. 1C is most probably restricted by size and/or dehydration energy of the polar headgroup or interaction with other membrane components, analogous to the restrictions described for the (aqueous) pore model.

Devaux (Devaux, 1991) proposed a model (origination of lipid asymmetry) in which the activity of the aminophospholipid translocase is the driving force for the redistribution of the other lipids (PC, Spm) to the outer leaflet. The accumulation of the aminophospholipids on the inside creates "sites" on the outside, which become occupied by the other lipids (PC, Spm) just by simple diffusion. An unbalanced number of sites between inner and outer leaflet result in bending of the bilayer. For the collapse of lipid asymmetry a similar idea can be used. The activation of a calcium 
dependent "reverse" aminophospholipid translocase could explain the collapse of lipid asymmetry (Bassé et al., 1993; Gaffet et al., 1995). Gaffet et al. (Gaffet et al., 1995) showed that when platelets are activated with calicium/ionophore, PS and PE are rapidly redistributed whereas PC migrated considerably less. However, these observations are not in concordance with the observations made by Bevers et al. (Bevers et al., 1992) who showed that the scrambling kinetics of PC in platelets resembles that of PS and that movement of both lipids is impaired in Scott cells. Hamon and coworkers (Hamon et al., 2000) postulated an ABCtransporter $(\mathrm{ABC1})$, which was activated by a rise of intracellular calcium. Experiments with knock-out mice showed calcium/ionophore-induced scrambling of PS only, whereas the distribution of PC remained indistinguishable from that of control cells. Since, this protein is ATPdependent the findings of Hamon et al. (Hamon et al., 2000) are not compatible with the observation that white erythrocyte ghosts are able to scramble their membrane phospholipids in the presence of calcium but absence of ATP (Bevers et al., 1992; Connor and Schroit, 1990).

Concerning the endogenous lipids it is remarkable that upon treatment with calcium/ionophore the endogenous PC in red blood cells seems not redistributed on a large scale at least when measured with phospholipases (Chandra et al., 1987). Furthermore preparation of red blood cell ghosts in the presence of calcium results in an increased degradation of the aminophospholipids up to $50 \%$ whereas PC degradation showed no significant difference with respect to red blood cell ghosts in the absence of calcium (Williamson et al., 1985). In contrast as discussed in chapter 3, a significant scrambling of $\mathrm{C}_{6}$-NBD-PC is found when red blood cells are treated with calcium/ionophore. This discrepancy between endogenous PC and the parent fluorescent probe may be due to: i) Endogenous PC does not move whereas the $\mathrm{C}_{6}$-NBD-PC does. ii) Endogenous PC moves much slower than $\mathrm{C}_{6}$-NBD-PC. This is already shown in chapter 6 where inhibition of MRP1 leads to a redistribution of $\mathrm{C}_{6}$-NBD-PC in 3-4 hours, whereas an incubation of more than 24 hours is necessary to observe movement of the endogenous PC. iii) The rate of inward movement of endogenous PC equals the rate of outward movement. The experiment in which $\mathrm{C}_{6}$-NBD-PC movement is measured, however, starts with the condition where $100 \%$ of the NBD-probe is either on the inside or on the outside. The experiment performed with phospholipases to examine the endogenous PC redistribution starts with a situation in which $75 \%$ of $\mathrm{PC}$ is present in the outer leaflet whereas the rest is present in the inner leaflet. Comparison between the rates of $\mathrm{C}_{6}-\mathrm{NBD}-\mathrm{PC}$ and endogenous $\mathrm{PC}$ remains elusive due to the difference in the detection method and starting situations. 
Comparison of transbilayer movement between different probes and endogenous lipids but also the movement in different cell types should be interpreted with care. Although the rate of lipid scrambling differs between platelets and red blood cells, evidence has been presented that the same scramblase could be responsible for the phenomenon of $\mathrm{Ca}^{2+}$-induced lipid scrambling (Bevers et al., 1992). The similarity between the scrambling process, which is activated during apoptosis and the scrambling process switched on during cellular activation, has been questioned. Williamson et al. (Williamson et al., 2001) attempted to discriminate between these two processes. They showed that B-cells of a patient with Scott syndrome, which were found to be defective in lipid scrambling when challenged with calcium/ionophore, did show increased transbilayer movement of both $\mathrm{C}_{6}$-NBD-PC and $\mathrm{C}_{6}$-NBD-PS as well as endogenous PS when driven in apoptosis. While it cannot be excluded that more than one scramblase is present in these cells, these results could also suggest different pathways of activating the same scramblase.

The models described above could be involved in the collapse of lipid asymmetry. However, it remains speculative due to a large number of variables, which are encountered. Is the process driven by just one protein or are there more transporters involved? What is the influence of membrane constituents, intracellular membranes, rafts or interaction with cytoskeleton proteins? What is the influence of the energy-status of cells? Understanding of the mechanism involved in generating and regulating membrane lipid sidedness could lead to important and new insights in pathophysiological processes in which aberrant behavior of cell membranes is an underlying phenomenon.

\section{REFERENCES}

Bassé, F., Gaffet, P., Rendu, F., and Bienvenue, A. (1993). Translocation of spinlabeled phospholipids through plasma membrane during thrombin- and ionophore A23187-induced platelet activation. Biochemistry 32, 2337-44.

Bevers, E. M., Wiedmer, T., Comfurius, P., Shattil, S. J., Weiss, H. J., Zwaal, R. F. A., and Sims, P. J. (1992). Defective $\mathrm{Ca}^{2+}$-induced microvesiculation and deficient expression of procoagulant activity in erythrocytes from a patient with a bleeding disorder: a study of the red blood cells of Scott syndrome. Blood 79, 380-8.

Blumenfeld, N., Zachowski, A., Galacteros, F., Beuzard, Y., and Devaux, P. F. (1991). Transmembrane mobility of phospholipids in sickle erythrocytes: effect of deoxygenation on diffusion and asymmetry. Blood 77, 849-54. 
Brown, D. A., and London, E. (2000). Structure and function of Sphingolipid- and Cholesterol-rich membrane rafts. J. Biol. Chem. 275, 17221-17224.

Chandra, R., Joshi, P. C., Bajpai, V. K., and Gupta, C. M. (1987). Membrane phospholipid organization in calcium-loaded human erythrocytes. Biochim. Biophys. Acta 902, 253-262.

Connor, J., and Schroit, A. J. (1990). Aminophospholipid translocation in erythrocytes: evidence for the involvement of a specific transporter and an endofacial protein. Biochemistry 29, 37-43.

Dachary-Prigent, J., Pasquet, J. M., Fressinaud, E., Toti, F., Freyssinet, J. M., and Nurden, A. T. (1997). Aminophospholipid exposure, microvesiculation and abnormal protein tyrosine phosphorylation in the platelets of a patient with Scott syndrome: a study using physiologic agonists and local anaesthetics. Br. J. Haematol. 99, 959-67

Dekkers, D. W. C., Comfurius, P., Vuist, W. M., Billheimer, J. T., Dicker, I., Weiss, H. J., Zwaal, R. F. A., and Bevers, E. M. (1998). Impaired $\mathrm{Ca}^{2+}$-induced tyrosine phosphorylation and defective lipid scrambling in erythrocytes from a patient with Scott syndrome: a study using an inhibitor for scramblase that mimics the defect in Scott syndrome. Blood 91, 2133-8

Devaux, P. F. (1991). Static and dynamic lipid asymmetry in cell membranes. Biochemistry 30,1163-1173.

Frasch, S. C., Henson, P. M., Kailey, J. M., Richter,D. A., Janes, M. S., Fado, V. A., and Braton, D. L. (2000). Regulation of phospholipid scramblase activity during apoptosis and cell activation by protein kinase C $\delta$. J. Biol. Chem. 275, 23065-23073.

Gaffet, P., Bettache, N., and Bienvenue, A. (1995). Transverse redistribution of phospholipids during human platelet activation: evidence for a vectorial outflux specific to aminophospholipids. Biochemistry 34, 6762-9.

Hamon, Y., Broccardo, C., Chambenoit, O., Luciani, M. F., Toti, F., Chaslin, S., Freyssinet, J. M., Devaux, P. F., McNeish, J., Marguet, D., and Chimini, G. (2000). $\mathrm{ABCl}$ promotes engulfment of apoptotic cells and transbilayer redistribution of phosphatidylserine. Nat. Cell Biol. 2, 399-406.

Killian, J. A. (1998). Hydrophobic mismatch between proteins and lipids in membranes. Biochim. Biophys. Acta 1376, 401-416.

Klucken, J., Buchler, C., Orso, E., Kaminski, W. E., Porsch Ozcurumez, M., Liebisch, G., Kapinsky, M., Diederich, W., Drobnik, W., Dean, M., Allikmets, R., and Schmitz, G. (2000). ABCG1 (ABC8), the human homolog of the Drosophila white gene, is a regulator of macrophage cholesterol and phospholipid transport. Proc. Natl. Acad. Sci. USA 97, 817-22 
Middelkoop, E., Lubin, B. H., Op den Kamp, J. A. F., and Roelofsen, B. (1986). Flipflop rates of individual molecular species of phosphatidylcholine in the human red cel membrane. Biochim. Biophys. Acta 855, 421-424.

Pasquet, J-M., Dachary-Prigent, J., and Nurden, A. T. (1998). Microvesicle release is associated with extensive protein tyrosine dephosphorylation in platelets stimulated by A23187 or a mixture of thrombin and collagen. Biochem. J. 333, 591-599.

Schmitz, G., Kaminski, W. E., and Orso, E. (2000). ABC transporters in cellular lipid trafficking. Curr. Opin. Lipid. 11, 493-501.

Smit, J. J., Schinkel, A. H., Oude Elferink, R. P., Groen, A. K., Wagenaar, E., van Deemter, L., Mol, C. A., Ottenhoff, R., van der Lugt, N. M., and van Roon, M. A., (1993). Homozygous disruption of the murine mdr2 P-glycoprotein gene leads to a complete absence of phospholipid from bile and to liver disease. Cell 75, 451-62.

Srinivasan, P. T., and Basu, J. (1996). Altered membrane phospholipid organization and erythrophagocytosis in E beta-thalassemia. Biochim. Biophys. Acta 1285, 65-70.

Stormorken, H., Holmsen, H., Sund, R., Sakariassen, K. S., Hovig, T., Jellum, E., and Solum, O. (1995). Studies on the haemostatic defect in a complicated syndrome. An inverse Scott syndrome platelet membrane abnormality. Thromb. Haemost. 74, 124451

Williamson, P., Algarin, L., Bateman, J., Choe,H-R. and Schlegel, R. A. (1985). Phospholipid asymmetry in human erythrocyt ghosts. J. Cell. Phys. 123, 209-214.

Williamson, P., Christie, A., Kohlin, T., Schlegel, R. A., Comfurius, P., Harmsma, M., Zwaal, R. F. A., and Bevers, E. M. (2001) Phospholipid Scramblase Activation Pathways in Lymphocytes. Biochemistry 40, 8065-72

Williamson, P., Bevers, E. M., Smeets, E. F., Comfurius, P., Schlegel, R. A., and Zwaal, R. F. A. (1995). Continuous analysis of the mechanism of activated transbilayer lipid movement in platelets. Biochemistry $34,10448-55$

Zhou, Q. S., Zhao, J., Stout, J. G., Luhm, R. A., Wiedmer, T., Sims, P. J. (1997). Molecular cloning of the human plasma membrane phospholipid scramblase - a protein mediating transbilayer movement of the plasma membrane phospholipids. J. Biol. Chem. 272, 18240-18244. 
Chapter 7

116 


\section{Nederlandse samenvatting}

Alle levende cellen zijn omgeven door een celmembraan. Dit membraan bestaat voornamelijk uit lipiden en eiwitten. Lipiden zijn moleculen die een hydrofobe (water afstotende) staart en een hydrofiele (water aantrekkende) kop bevatten. Door dit karakter zullen lipiden in een waterig milieu zich rangschikken met de kop naar de water fase en de vetzuurstaarten naar elkaar gericht zodanig dat deze apolaire staarten niet blootgesteld worden aan de waterige omgeving. Dit levert een dubbellaag (bilaag) op zoals weer gegeven in Fig. 1. In deze bilaag bevinden zich de eiwitten welke geheel zijn ingebed in de bilaag dan wel gebonden zijn op het grensvlak van de bilaag.

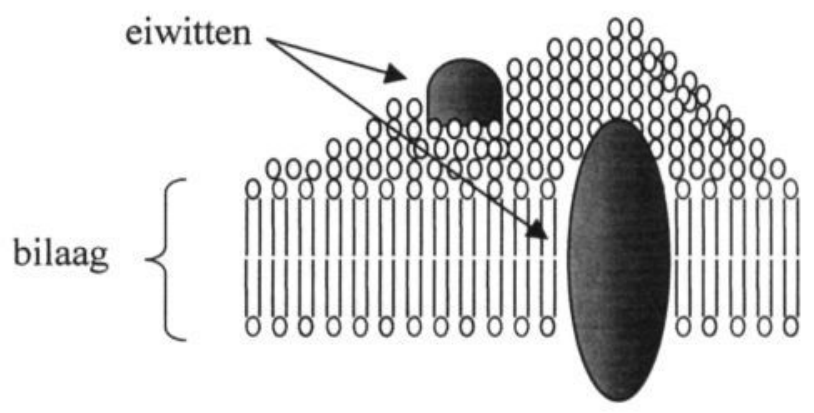

Fig. 1 Schematische weergave van de bilaag van een celmembraan.

De fosfolipiden van de plasmamembraan van cellen zijn asymmetrisch verdeeld. De choline-houdende fosfolipiden, fosfatidylcholine (PC) en sphingomyeline (Spm) zijn voornamelijk gesitueerd in de buitenste monolaag van het membraan terwijl de aminofosfolipiden fosfatidylethanolamine (PE) en fosfatidylserine (PS) zich ophouden in binnenste monolaag. Deze asymmetrische verdeling wordt zeer nauwkeurig gereguleerd omdat veranderingen aan het membraan oppervlak gevolgen hebben voor fysiologische processen die zich afspelen aan het oppervlak van dit membraan. De transbilaag beweging van lipiden over het membraan wordt gefaciliteerd door tenminste een drietal eiwitten: 1. de aminofosfolipiden translocase, verantwoordelijk voor het naar binnen transporteren van de aminofosfolipiden, 2. de 'floppase', verantwoordelijk voor het uitwaardse transport van alle fosfolipiden, en 3 . 
de zogenaamde 'scramblase', een eiwit dat de beweging eveneens van alle lipiden in beide richtingen over het membraan versneld ('scramblase' is afgeleid van het engelse 'to scramble' dat 'roeren' of 'mengen' betekent). Terwijl de aminofosfolipiden translocase en de floppase van belang zijn voor het instandhouden van een asymmetrische verdeling van de lipiden over het membraan, leidt activatie van de scramblase tot het opheffen van deze asymmetrisch verdeling.

De studies die beschreven staan in dit proefschrift beogen meer inzicht te verschaffen in de mechanismen die verantwoordelijk zijn voor zowel de instandhouding als het verlies van membraan lipiden asymmetrie.

Hoofdstuk 1 en 2 geven een overzicht van de huidige kennis over het instandhouden en het opheffen van de fosfolipiden asymmetrie in de plasmamembraan. Met name de rol van de verschillende lipiden transporters wordt onder de loep genomen. Het opheffen van de lipiden asymmetrie heeft als belangrijkste consequentie het exposeren van PS in de buitenste monolaag van de membraan. De aanwezigheid van PS op het buitenoppervlak van de celmembraan is belangrijk voor een efficiente bloedstolling, maar dient daarnaast als herkenningsmolecuul voor macrofagen bij het verwijderen van dode of oude cellen.

Het activeren van de scramblase door verhoging van de intracellulaire calcium concentratie leidt tot het homogeniseren (scramblen) van alle lipiden over beide membraanhelften. In de studies beschreven in hoofdstuk 3 wordt getracht ondersteuning te vinden voor een porie-model als mechanisme voor een versnelde beweging van de lipiden. Hierbij wordt voorgesteld dat het fosfolipid met de polaire kop door een polair kanaal over het membraan beweegt, terwijl de vetzuurstaarten in de hydrofobe matrix blijven. Door verandering van de kopgroep van de lipiden konden we -in overeenstemming met dit model- laten zien dat de snelheid en mate van transbilaag beweging door de scramblase afhankelijk is van onder meer de grootte van de polaire kop van de lipiden. Tevens bleek de aanwezigheid van een amino-groep belangrijk voor de kinetiek van de transbilaag beweging van lipiden: verandering van de kopgroep van PE door methylering resulteerde in een sterke verandering van de transporteigenschappen van het betreffende lipid.

Het Scott syndroom is een ziekte die veroorzaakt wordt door een defecte scramblase activiteit waardoor onvoldoende PS wordt geexposeerd tijdens activatie van bloedplaatjes. Het belangrijkste gevolg van deze verminderde PS expositie is een vertraagde bloedstolling. De defecte scramblase activiteit in Scott syndroom is niet beperkt tot bloedplaatjes, maar is ook 
aanwezig in de rode en witte bloedcellen van deze patienten. De waarneming dat Scott cellen -in tegenstelling tot controle cellen- na behandeling met calcium/ionofoor een sterk verminderd tyrosine fosforyleringspatroon vertonen, leidde ons ertoe te onderzoeken of er een directe relatie bestaat tussen dit tyrosine-fosforyleringsdefect en de gestoorde lipiden scrambling. Fosforylering van eiwitten wordt bewerkstelligd door kinases, enzymen die fosfaatgroep(en) koppelen aan bepaalde aminozuurresiduen van eiwitten, bijv. tyrosine-, threonine-, of serine-residuen. Door fosforylering treden er veranderingen op in het eiwit waardoor het eiwit actief kan worden. Defosforylering, gekatalyseerd door in de cel aanwezige fosfatasen, kunnen deze activatie weer ongedaan maken. Hoewel een tyrosine-fosforyleringsdefect bij Scott werd waargenomen, heeft het onderzoek als beschreven in hoofdstuk 4 laten zien dat een causaal verband tussen de twee defecten onwaarschijnlijk is.

De floppase werd in 1990 voor het eerst gepostuleerd door Connor and Schroit. Zij lieten zien dat er een uitwaardse beweging was van zowel choline- als aminofosfolipiden. Deze beweging bleek ATP afhankelijk en te remmen door temperatuurverlaging.

In hoofdstuk 5 en 6 worden de experimenten besproken die hebben geleid tot het identificeren van dit eiwit. Hiervoor werd onder meer gebruik gemaakt van erythrocyten 'ghosts' verkregen door osmotische lysis van rode bloedcellen, gevolgd door resealing van de membraan. Experimenten met deze erythrocyten "ghosts" leidden ons naar een component in het cytoplasma welke, naast ATP, nodig bleek te zijn voor de activiteit van de floppase. Deze component bleek geoxideerd glutathion (GSSG) te zijn. Mede op basis van deze waarnemingen werd MRP1, een van de eiwitten uit de familie van multidrug resistance proteins, onderzocht als kandidaat voor de floppase. Het gebruik van specifieke remmers van MRP1 resulteerde in een vrijwel volledige blokkade van de uitwaardse beweging, overigens zonder beinvloeding van de aminofosfolipiden translocase activiteit. Omdat dit indirect bewijs was dat inderdaad MRP1 verantwoordelijk is voor de waargenomen floppase activiteit werden er proeven uitgevoerd met rode bloedcellen van muizen, deficient in een of meerdere multidrug resistance proteins. Hiervoor werden zogenaamde 'knock-out' muizen gebruikt, waarbij het gen voor het betreffende eiwit is uitgeschakeld. MRP1-deficiente rode bloedcellen toonden een volledige afwezigheid van het uitwaardse transport, terwijl rode bloedcellen van muizen deficient voor MDR1 en 2 geen verandering ten op zichte van de controle cellen lieten zien. Dit leidde tot de conclusie dat -althans in rode bloedcellen- MRP1 verantwoordelijk is voor de floppase activiteit. 
Omdat het bestuderen van transbilaag bewegingen in bovengenoemde experimenten verricht werd met behulp van lipiden probes, rees de vraag of MRP1 in staat is ook de endogene lipiden te transporteren. Een manier om de beweging van endogene lipiden te bestuderen is gebruik te maken van fosfolipases. Tot op zekere hoogte kunnen deze enzymen de buitenste lipidenlaag afbreken zonder verlies van membraanintegriteit. Door de afbraak van lipiden in cellen waarin MRP1 geremd is te vergelijken met de afbraak in controle cellen zonder deze remmer, kan informatie worden verkregen over een eventuele herverdeling van de endogene lipiden en daarmee de rol van MRP1. Remming van MRP1 bleek inderdaad een verschuiving te veroorzaken in de verdeling van PC en Sph over het membraan. Echter, de verdeling van de aminofosfolipiden werd niet beinvloed. De meest waarschijnlijke verklaring hiervoor is dat de aminofosfolipiden translocase activiteit niet werd beinvloed door de gebruikte remmers. Geconcludeerd wordt dat MRP1 zeer waarschijnlijk verantwoordelijk is voor het uitwaardse transport van endogene lipiden over het membraan van de rode bloedcel.

Daarmee wordt de eerdere opvatting, als zou de aanwezigheid van cholinehoudende fosfolipiden in de buitenste helft van de membraan het gevolg zijn van een compensatie voor het aminofosfolipiden transport naar binnen, minder waarschijnlijk. De samenwerking van de aminofosfolipiden translocase en MRP1 resulteert in een asymmetrische verdeling van de lipiden van de celmembraan zoals men die in de rode bloedcel aan treft. Opheffen van de lipiden asymmetrie is niet louter het uitschakelen van deze twee eiwitten, maar vereist een mechanisme dat, afhankelijk van de intracellulaire calcium-ionen concentratie, de scramblase aanzet en de lipiden randomiseert. Overigens sluiten de hier gepresenteerde studies geenszins uit dat er nog andere eiwitten een rol spelen in de regulatie van transbilaag lipiden verdeling. 


\section{Nawoord/Acknowledgements}

Aan alles komt een eind. Zo ook aan vijf jaar Maastricht. Na een hele leuke en mooie tijd sluit ik iets af wat voor mij heel veel betekent. Natuurlijk heb ik dit niet alleen........... Iemand die vaak een proefschift gelezen heeft kan deze zin feilloos afmaken. Daarom wil ik het op een heel andere manier doen namelijk met een anekdote.

Er was eens een jongen die ontzettend graag profvoetballer wilde worden. Zijn vader was briljant en zijn oom kon ook een aardig potje voetballen. Mensen zeiden dat hij de beste voetballer van de club zou worden. $\mathrm{Nu}$ jaren later word dit nog steeds beweerd. Helaas was de knaap jong en onervaren en moest hij opboxen tegen de idealen van de ouderen. Zijn vader die hem steunde in alles, vertelde hem te genieten van het voetbal. Tevens zei hij dat er maar weinig jongens het tot profvoetballer schoppen. Zijn oom viel hem aan op alleen de slechte prestaties, met de hoop dat hij daarvan zou leren. Zijn zelfvertrouwen klapte ineen en de lol en het plezier in het spel verdween. Zes jaar later begreep hij zijn vader pas. Nu 20 jaar later geniet hij nog steeds van het voetbal. Van deze harde leerschool leerde hij veel. Van de ene leerde hij, spirit, doorzettingsvermogen en hardheid. Van de ander waarderen, accepteren en moraliseren. Beide hadden het beste met hem voor en beiden hebben een grootte invloed gehad op de knaap die hij nu is.

Mensen bedanken is niet moeilijk. Maar de vraag waar de gradatie ligt van de inspanning die hij/zij doet ten opzichte van het dankbaar zijn is een hele andere kwestie. En dus iedereen die zich aangesproken voelt voor de daden en inspanningen voor mijn persoon, hartstikke bedankt!

Natuurlijk zijn er uitzonderingen, en zijn er personen die op een bepaald moment in je leven een extra woordje dienen te krijgen.

Leon, onze treinreizen en discussies, maar vooral het vrij maken van je tijd als ik weer eens bekneld raakte in een tekenprogramma (dit laatste geldt ook voor Henri en Berry), maakte je een zeer gewaardeerde collega. Antonio, voor het ontwerpen van de cover.

Edouard, Paul en Rob, drie bazen, een weelde voor een AIO. Van onze discussies heb ik veel geleerd, alhoewel ik over bepaalde dingen anders dacht dan jullie (mischien wat te moeilijk en te ambitieus). Toch zou het zonder jullie niet gelukt zijn. Bedankt!

Paranimf Han, voor je vriendschap en omdat je mijn paranimf wilt zijn.

Joyce, een vriendin met wie ik "samengewoond", gedronken, gehuild en gelachen heb. Iemand die ik zal missen als ieders leven ons verder brengt in een andere baan of andere stad. Bedankt voor de geweldige tijd en je vriendschap.

Esther, ik hoop dat de hectische tijd nu wat minder wordt. Zonder jouw zou het een hel geweest zijn.

Mijn vader heb ik al vernoemd, maar naast hem mag mijn moeder natuurlijk niet ontbreken. Een eenheid die mij gemaakt, gevormd en gesteund heeft door heel mijn leven.

Ik zie uit naar het vervolg. 


\section{Publications}

David W.C. Dekkers, Paul Comfurius, Wim M.J. Vuist, Jeffrey T. Billheimer, Ira Dicker, Harvey J. Weiss, Robert F. A. Zwaal and Edouard M. Bevers (1998) Impaired $\mathrm{Ca}^{2+}$-induced tyrosine phosphorylation and defective lipid scrambling in erythrocytes from a patient with Scott Syndrome. A study using an inhibitor for scramblase that mimics the defect in Scott syndrome. Blood 91, 1-7

David W.C. Dekkers, Paul Comfurius, Alan J. Schroit, Edouard M. Bevers and Robert F.A. Zwaal (1998) Transbilayer movement of NBD-labeled phospholipids in red blood cell membranes: Outward directed transport by the Multidrug Resistance Protein 1 (MRP1). Biochemistry 37 1483314837

Edouard M. Bevers, Paul Comfurius, David W.C. Dekkers, Marjan Harmsma and Robert F.A. Zwaal (1998) Regulatory mechanisms of transmembrane phospholipid distributions and pathophysiological implications of transbilayer lipid scrambling. Lupus 7 suppl 2: S126-131

Edouard M. Bevers, Paul Comfurius, David W.C. Dekkers, Marjan Harmsma and Robert F.A. Zwaal (1998) Transmembrane phospholipid distributions in blood cells: control mechanisms and pathophysiological significance. Biological chemistry 379, 973-986

Edouard M. Bevers, Paul Comfurius, David W.C. Dekkers and Robert F.A. Zwaal (1999) Lipid translocation across the plasma membrane of mammalian cells. Biochimica et Biophysica Acta 1439317-330.

David W.C. Dekkers, Paul Comfurius, Rein G.J. van Gool, Edouard M. Bevers and Robert F.A. Zwaal (2000) Multidrug Resistance Protein 1 (MRP1) regulates lipid asymmetry in red blood cell membranes. Biochemical Journal 350, 531-535

David W. C. Dekkers, Paul Comfurius, Edouard M. Bevers and Robert F. A. Zwaal (2001) Comparison between $\mathrm{Ca}^{2+}$-induced scrambling of various NBD-labelled lipid analogues in red blood cells. Biochemical Journal (Submitted) 


\section{Curriculum vitae}

De schrijver van dit proefschrift werd geboren op 1 september 1968 te Veldhoven. Na het doorlopen van de MAVO en HAVO te Veldhoven werd vanaf september 1988 de opleiding Hoger Laboratorium Onderwijs (HLO) gevolgd te Eindhoven. In de afrondende fase werd onderzoek verricht naar een zuiveringsmethode voor filterzand gebruikt in waterzuiveringsinstallaties. In Januari 1992 werd het diploma behaald. In april 1992 werd de dienstplicht vervuld. In september 1993 werd de studie scheikunde gestart aan de Universiteit Utrecht, met als specialisatie Biochemie (Prof. Dr. B. de Kruijff). Het diploma werd behaald in augustus 1996. In oktober van datzelfde jaar kon worden gestart met het in dit proefschrift beschreven onderzoek aan de universiteit van Maastricht, onder supervisie van Prof. Dr. R.F.A. Zwaal en Dr. E.M. Bevers. 

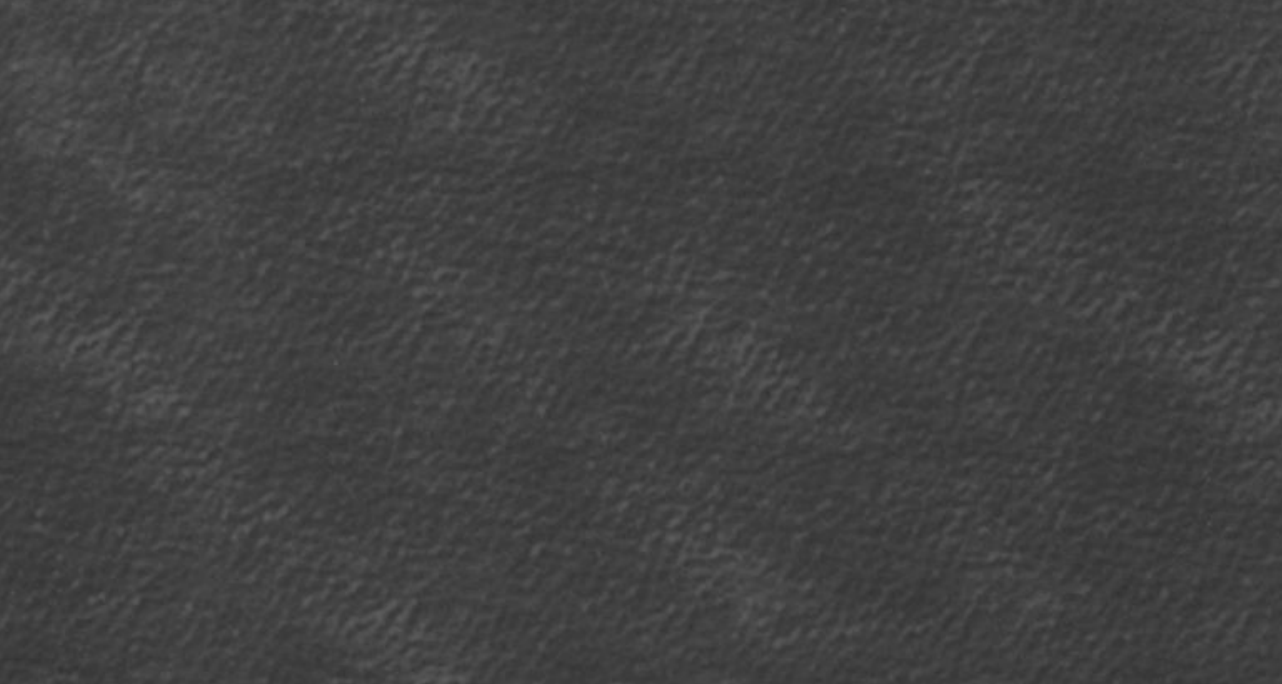

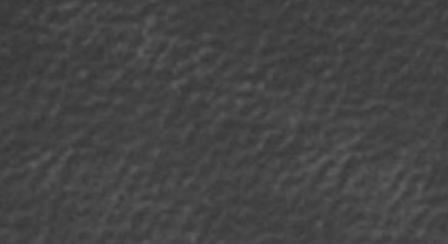

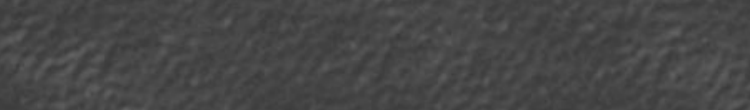

2001

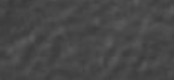
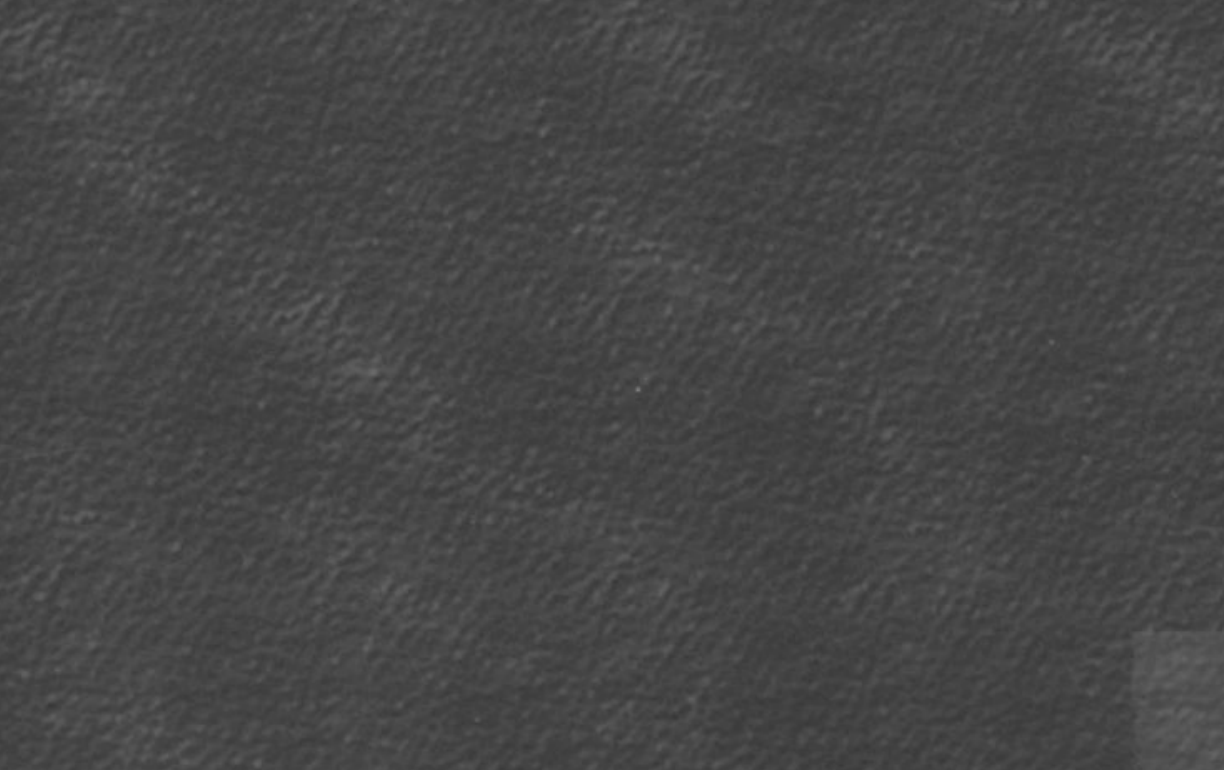

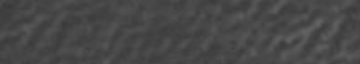
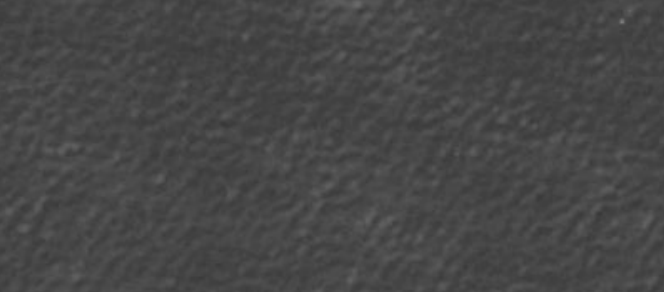